\title{
Urban poverty and health in developing countries: Household and neighborhood effects [Arabic]
}

Mark R. Montgomery

Population Council

Paul C. Hewett

Population Council

Follow this and additional works at: https://knowledgecommons.popcouncil.org/departments_sbsr-pgy

Part of the Demography, Population, and Ecology Commons, Family, Life Course, and Society Commons, International Public Health Commons, and the Maternal and Child Health Commons How does access to this work benefit you? Let us know!

\section{Recommended Citation}

Montgomery, Mark R. and Paul C. Hewett. 2004. "Urban poverty and health in developing countries: Household and neighborhood effects," Policy Research Division Working Paper no. 184 [Arabic]. New York: Population Council. Version of record: https://doi.org/10.1353/dem.2005.0020 


$$
\text { قرق بحوث السياسات عمل }
$$

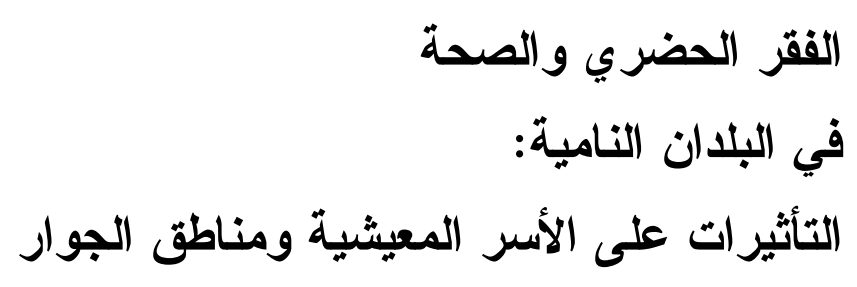

مارك ر. مونتجومري Mark R. Montgomery بول سي. هيويت" Paul C. Hewett

2004 رقم 184 


\section{الفقر الحضري والصحة في البلدان النامية: \\ التأثيرات على الأسر المعيشية ومناطق الجوار}

مارك ر. مونتجومري Mark R. Montgomery

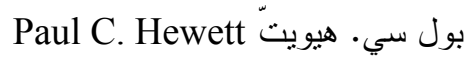

مارك ر. مونتجومري Mark R. Montgomery هو أستاذ اقتصاد بجامعة ولاية نيويورك في سنوني بروك

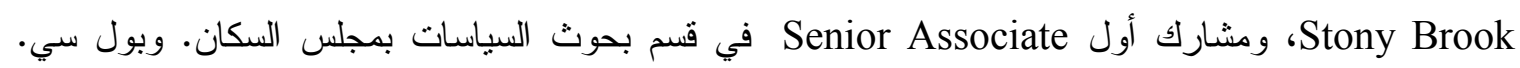
هيويت" Paul C. Hewett هو زميل في قسم بحوث السياسات بمجلس السكان. قامت مؤسسة ويليام وفلور التبان the Andrew W. ومؤسسة أندرو و. ميلّون Mellon Foundation بتمويل هذه الورقة.

لا يجوز إعادة إنتاج هذه المادة العلمية دون الموافقة الخطية للمؤلفَين. للحصول على قائمة بورقات العمل الصادرة

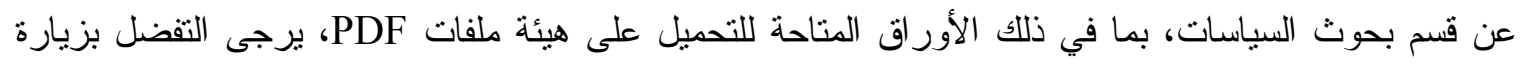

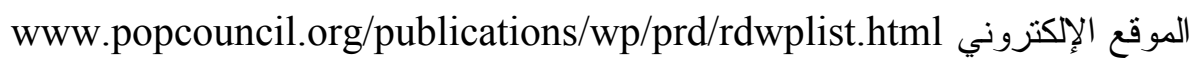

(C) 2004 حقوق الطبع محفوظة لمجلس السكان 
في الولايات المتحدة وغير ها من البلدان ذات الاخول المرتفعة، حيث يعيش أغلب الناس في المدن، هناك اهتمام مكثق على مستوى الباحثين و البر امج بنأثثر ات مستويات المعيثة بالأسر المعيشية ومناطق الجوار ار على الصحة. غير أنه لم تتظر سوى دراسات قليلة للغاية حول مدن البلدان النامية في هذه القضايا. تبحث هذه الورقة فيما إذا كانت صحة النساء و الأطفال الصغار في هذه المدن نتأثر بكل من مستويات المعيشة بالأسر المعيشية ومناطق

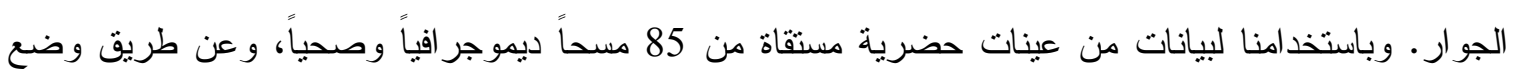

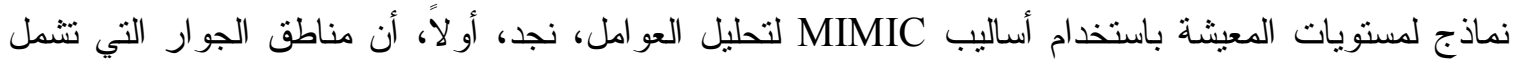

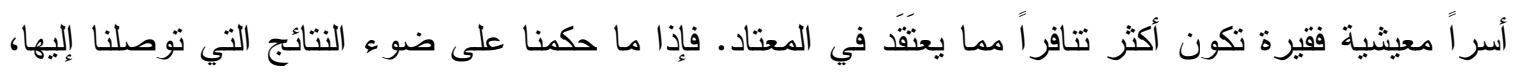

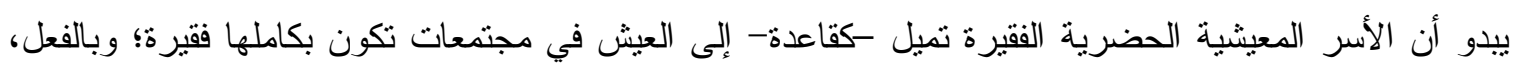
فإن حو الي و احد من كل عشرة جير ان للأسر المعيثية الفقيرة يكون ثرياً إلى حد ما، وينتمي إلى الثريحة الأعلى لئى

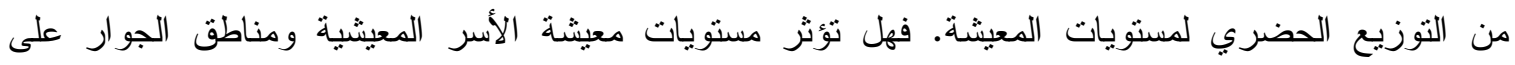
الصحةٌ وبتطبيقنا لنماذج متعددة المتغيرات multivariate مع ضبط غيرهير ها من المتغيرات الاقتصادية الاجتماعية، فإننا نكتشف أن لمستويات المعيشة داخل الأسر المعيشية تأثثر بالغ على ثلاثة معايير للصحة: الحاجة لمنع الحمل بطريقة حديثة، وهي حاجة لم يتم الوفاء بها؛ وتو اجد مقدم خدمة مدرب خلال عملية الولادة؛ وطول الأطفال بالنسبة لأعمار هم. ويكون لمستويات المعيشة داخل مناطق الجو ار تأثثر إضافي هام على الصحة في كثير

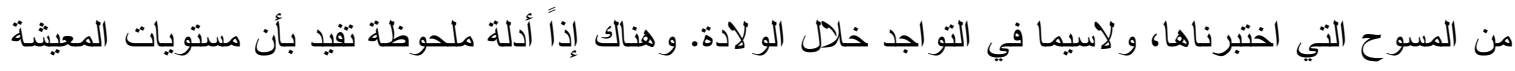
في كل من الأسر المعيثية ومناطق الجوار من شأنها إحداث فارق شديد الأهمية بالنسبة للصحة. 
في الستقبل المنظور، سيتركز النمو السكاني العالمي في الأساس في مدن البلدان النامية وبلداتها. ووفقاً للأمم المتحدة (2000)، فإنه بحلول عام 2030، سوف يتخطى التعداد السكاني العالمي إجمالي اليوم بفارق 2.06 بليون

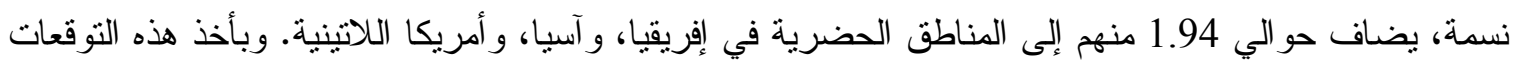
بعين الاعتبار ، لابد للباحثين المعنيين بالفقر و الفرص أن يصيغو ا مخاوفهم بثكل متز ايد داخل سياقات حضرية.

ماذا يمكن أن تتطوي عليه الحياة في المدن بالنسبة لمستويات الصحة الإنجابية وأوجه عدم المساو اة على المستوى

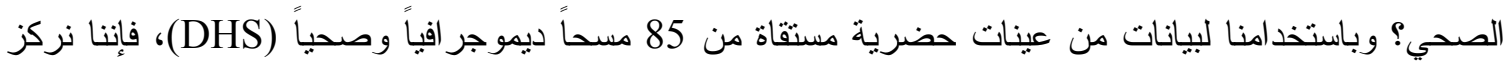

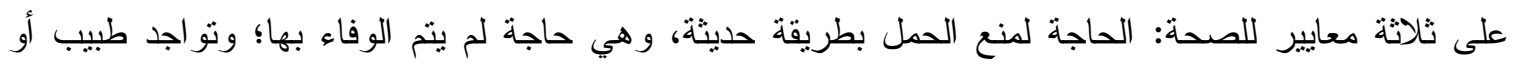

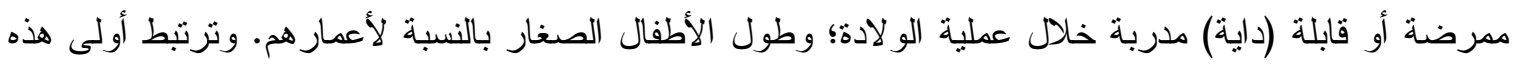

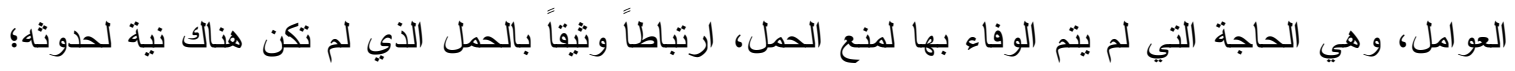
وحضور الولادة هو وسيلة لحماية الأمهات والأطفال في وقت الولادة؛ وطول الأطفال بالنسبة لأعمار هم هو

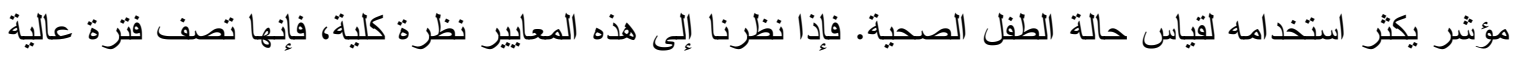

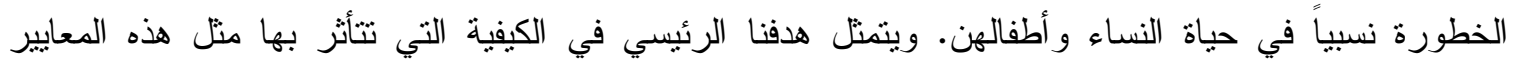

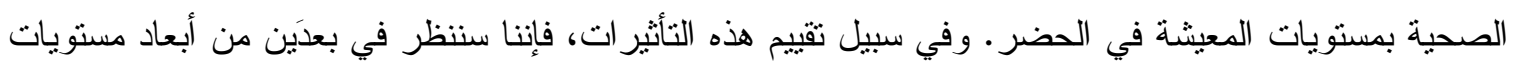

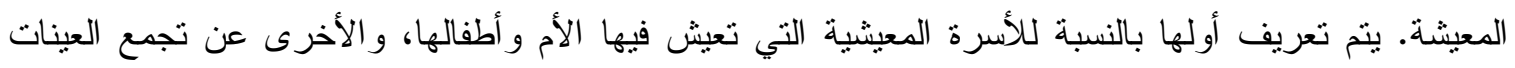

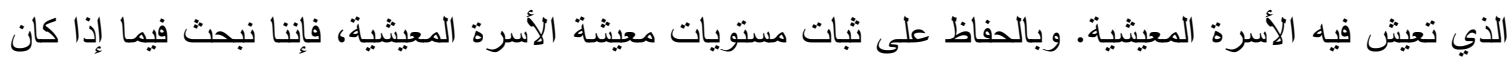
الفقر و الغنى في منطقة الجوار المحيطة يؤثران على الصحة.

لماذا يوجد هناك اهتمام بـ "تأثيرات منطقة الجوار" neighborhood effects هذه عادة ما كان يتم تأطير المناقثنات التي تنور حول الفقر الحضري في العالم النامي من حيث ظروف معبثة سكان الأحياء العشوائية

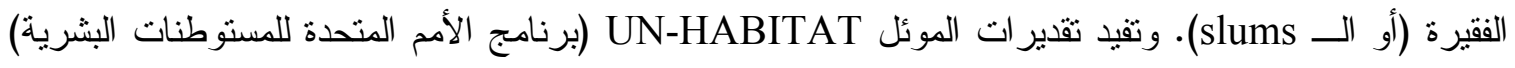

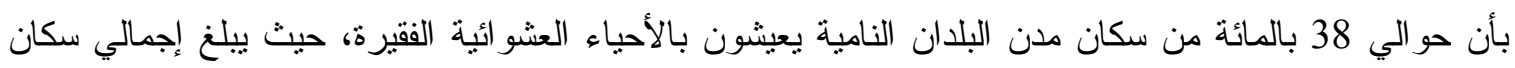

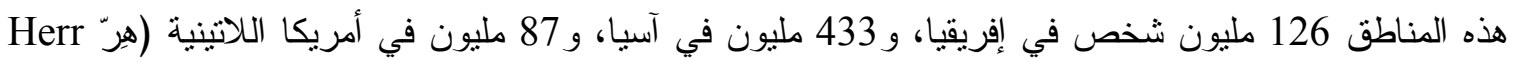

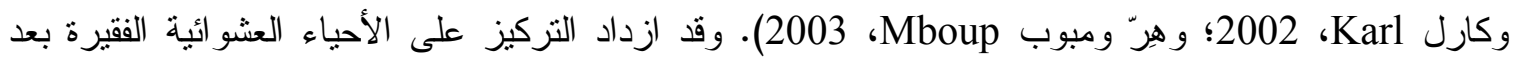

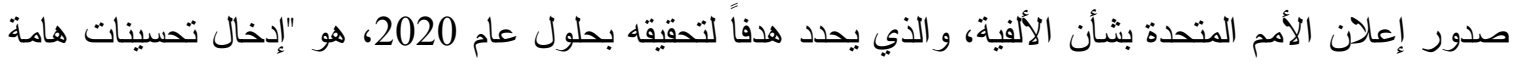

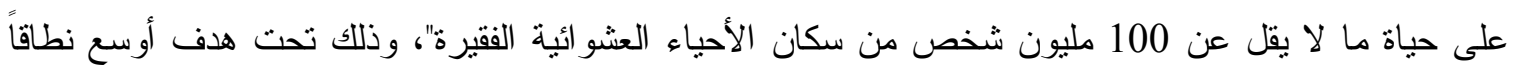

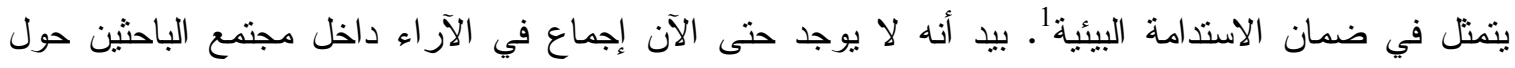

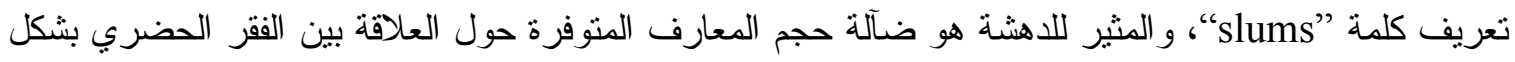

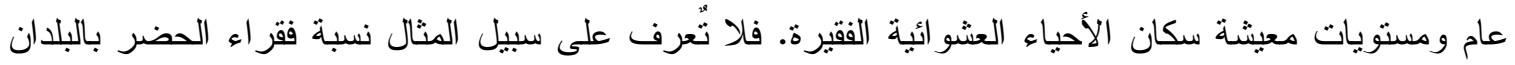

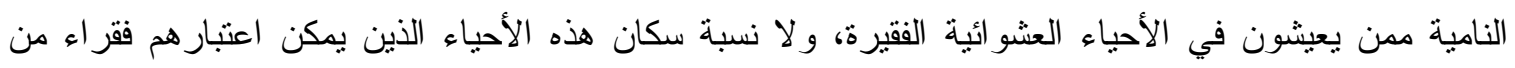

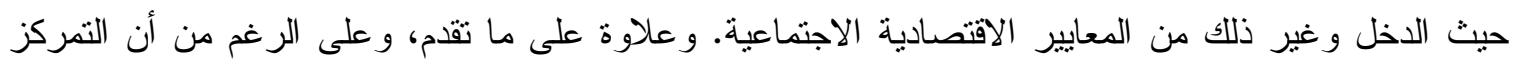

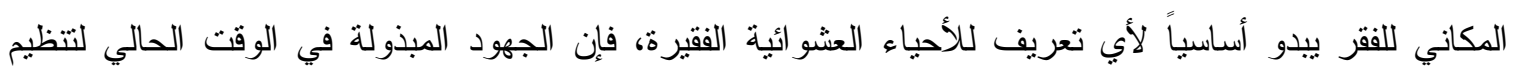


التعريفات الخاصة بمططلح الأحياء العشوائية الققيرة أو الـ slums (باستخدام مؤشرات الوصول لماء الثرب

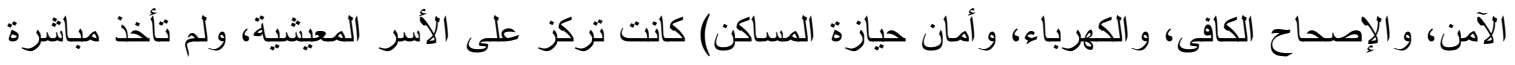
في الحسبان تركيزات الفقر أو الغنى بمناطق الجوار التي تحيط بالأسر المعيشية.

وبسبب الإهمال النسبي للمر اجع الخاصة بالفقر الحضري في البلدان الفقبرة لتأثيرات مناطق الجوار، فإنها تتاقض

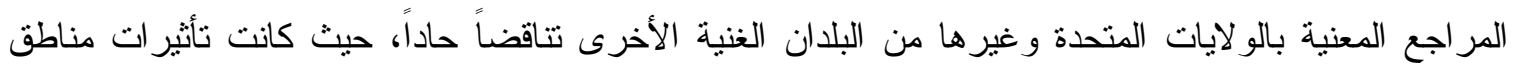

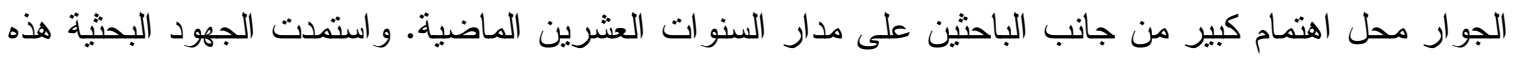

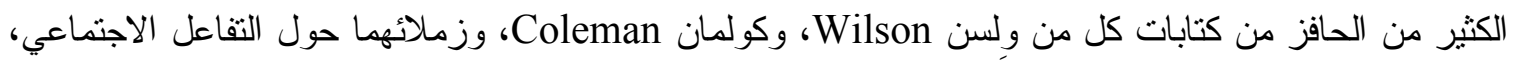

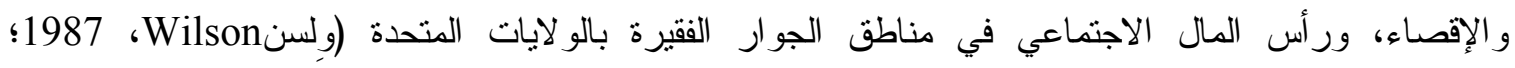

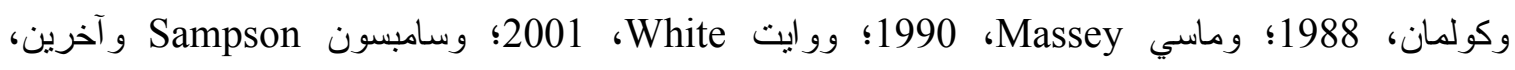

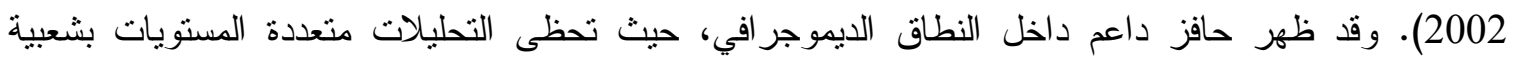

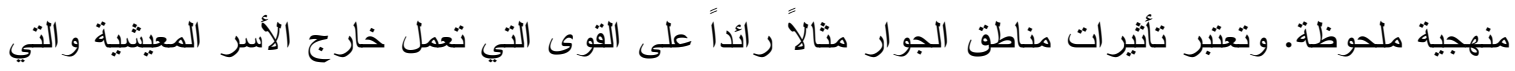

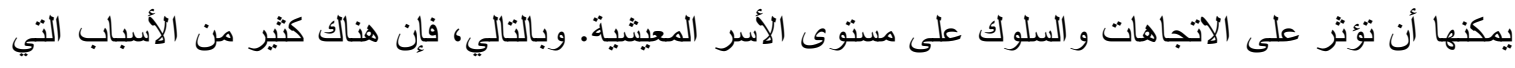

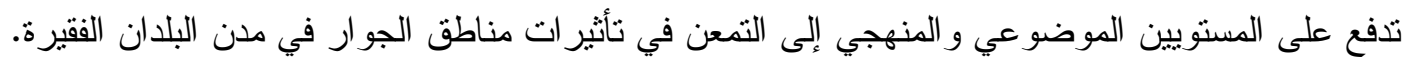

ما الذي يسبب إذاً هذا الإهمال؟ من بين العوائق الرئيسية التي واجهها هذا البحث كان قلة البيانات الخاصة

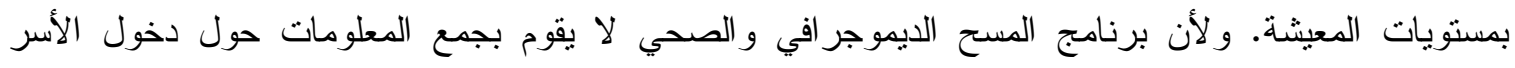

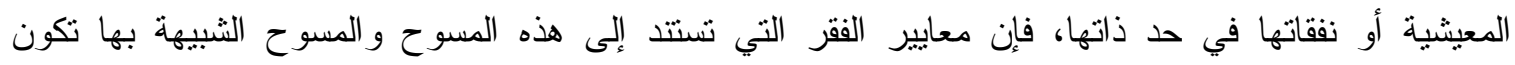
مقصورة على ما يمكن صياغته من مجموعة صغيرة من متغير ات الوكالة، بما في ذللك ملكية السلع الاستهلاكية المعرة، إلى جانب نقييمات يعوز ها الإتقان حول جودة الإسكان. وقد ظهرت مر اجع حية خلال السنوات القئ القليلة

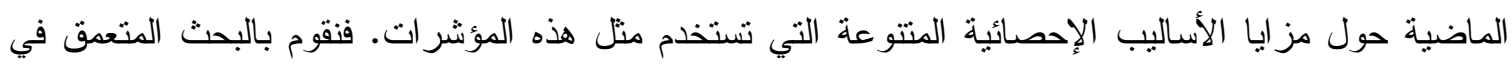

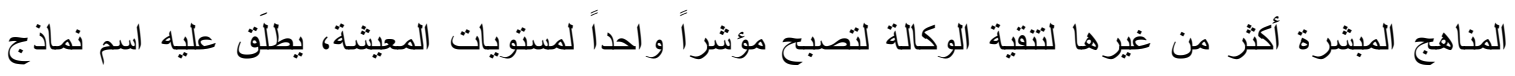

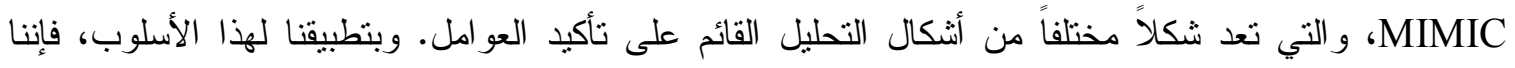

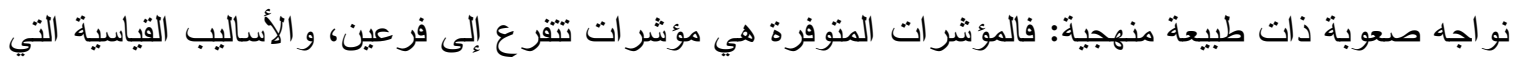
تقوم على تحليل العو امل لا تكون ملائمة في مثل هذه الحالات. وقد قمنا بوضع أنماط خاصة بنا بنا للتقدير للتصدي لهذه المشكلة. يتم تتظيم هذه الورقة كما يلي: في البداية، نقوم برسم موجز لنظرية تأثيرات مناطق الجوار على الصحة، مستتدين

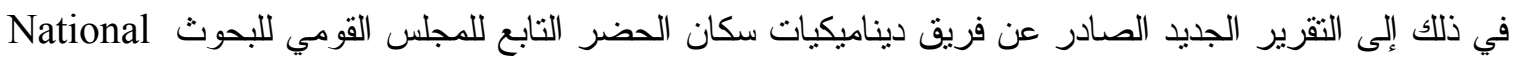
Research Council's Panel on Urban Population Dynamics فيعطي فكرة عامة عن النماذج و القضايا الإحصائية التي لابد من مواجهتها لنتكيل سبل يمكن الدفاع عنها لقياس

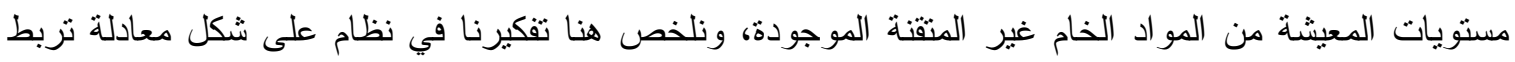
بين مستوى المعيشة في الحضر من ناحية والصحة من ناحية أخرى. ويصف القسم الثالث بيانات المسح 
الديموجر افي و الصحي، فيقدم إحصائيات وصفية حول التدابير الصحية، والمجموعة الأساسية من المتغيرات التقسيرية المستخدمة في النماذج، ومؤشرات مستويات معيشة الأسر المعيثية. ثم نقوم بمقارنة مستويات المعيشة ومقاييس الفقر للأسر المعيشية بالمقاييس الموجزة التي ينت حسابها على مستوى تجمع أخذ العينات، بهدف فهم مدى قرب الصلة بين مستويات معيثة الأسر المعيثية ومناطق الجوار. بعد هذا، يقوم القسم التالي بتقديم نتائج متعددة المتغير ات عن المقاييس الصحية الثلاثة، حيث لا تقوم النماذج سوى على العوامل الخاصة بمستويات معيشة الأسر المعيشية المبينة أولاً، ومن بعدها نماذج لعوامل تتعلق بكل من الأسر المعيشية ومناطق الجوار. وتتنهي الورقة بأفكار حول جدول أعمال للمزيد من العمل.

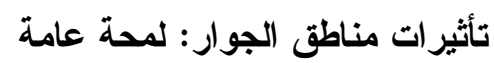
قد يساعد الثكل 1 على وضع القضايا في أطر محددة. ففي الأحياء العشوائية الفقيرة بنيروبي، نجد أن معدلات

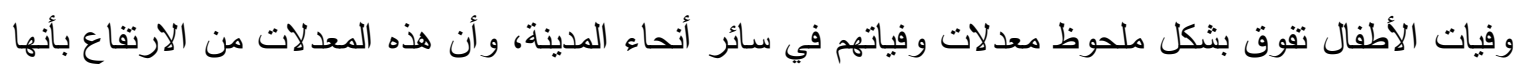
تتخطى حتى معدلات الوفيات في الريف.

شكل 1: مقارنة بين نسب التو اجد خلال الولادات ومعدلات وفيات الأطفال (5q0) في عينة الأحياء العشوائية الفقيرة بنيروبي بالنسبة لكامل نيروبي، و المدن الأخرى في كينيا، و المناطق الريفية، وكينيا بأكملها. المصدر: المركز الإفريقي لبحوث السكان و الصحة (2002).

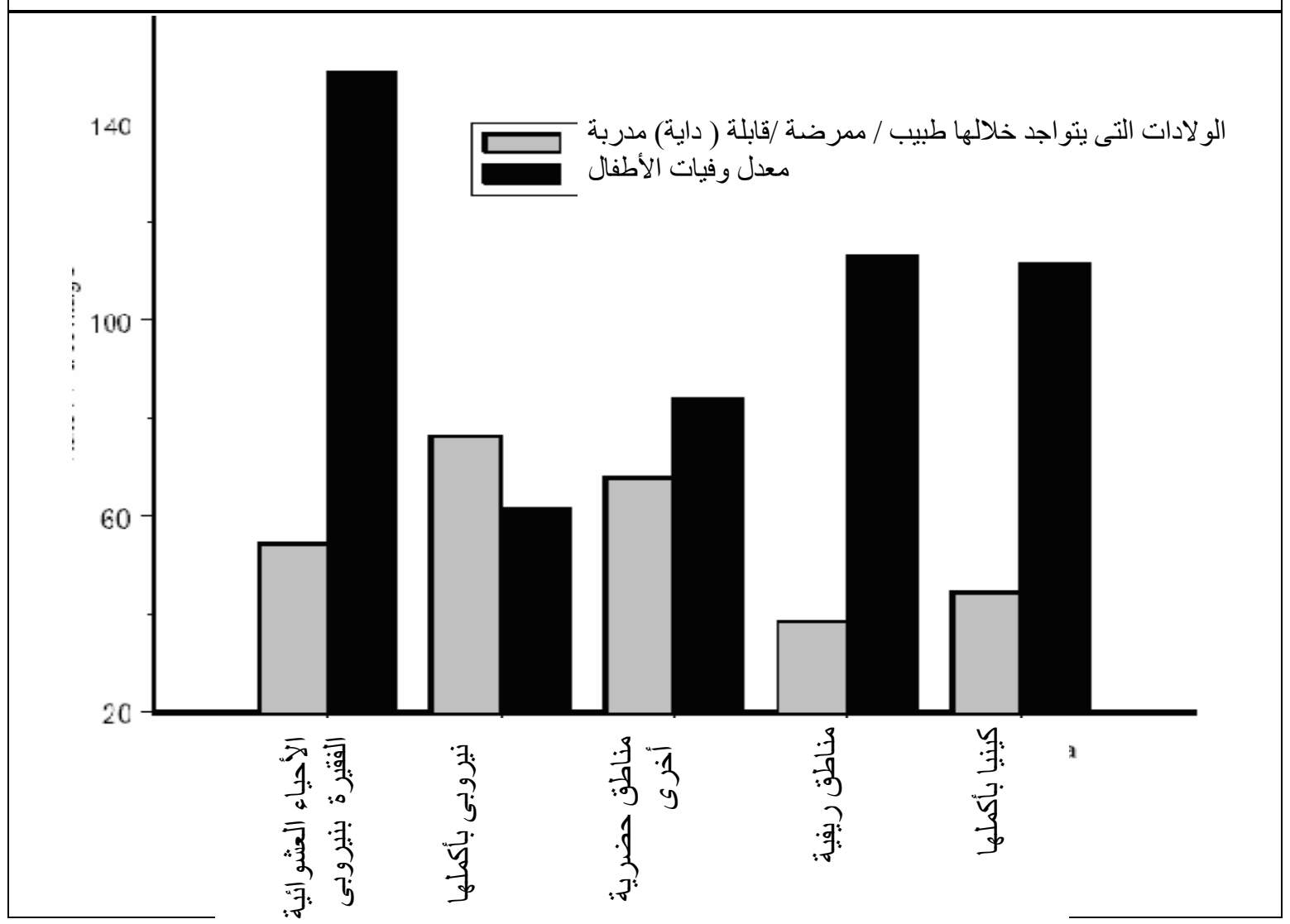


فإذا كان لسكان الحضر ميزة على مستوى الصحة، كما يفترَض في غالبية الأحيان، فإنه يبدو أنه يتم تقاسم هذه

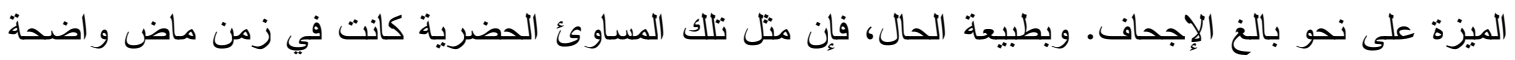
في الغرب: ففي القرن التاسع عشر، لم يكن من غير الثائع أن تكون معدلات الوفيات في الأحياء العشوائية الفقيرة في الحضر أعلى بكثير منها في الريف. وفي ذلك العصر، كان من المفهوم تماماً أن التمركز المكاني لسكان الحضر يعرضهم لمخاطر أكبر من حيث الإصابة بالأمراض المعدية. و الملاحظ في عالمنا اليوم أن الاختلافات بين الحضر و الريف تكون أكثر تجلياً، لأن الكثير من المدن، حتى الكائن منها في بلدان فقيرة، نجح في توفير أساسيات البنية التحنية الصحية اللازمة لاحر الأمر اض المعدية، كما أنه يتم بشكل عام توفير خدمات لات لات صحية علاجية أفضل لسكان المدن. وبالفعل، وكما بيّن فريق ديناميكيات سكان الحضر (2003)، مستعيناً ببيانات

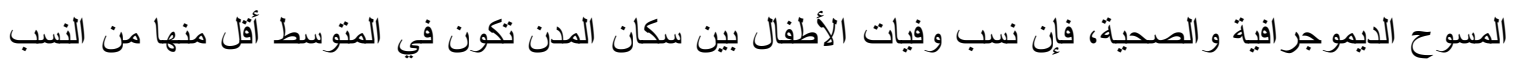
الني وجدَت في الريف. غير أنه إذا نظرنا إلى مستوى أعمق من المتوسطات الحضرية، فإنه نتكثف لنا اختلافات بالغة في مجال الصحة- فعادة ما يو اجه الفقر اء من سكان المدن مخاطر صحية تقترب في سوءها من المظاهر

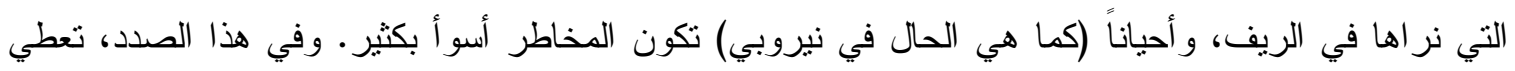
الأعمدة المبينة في شكل (1) و المتعلقة بالتو اجد خلال الو لادات فكرة عما يمكن مشاهدته بشكل عام في البلدان

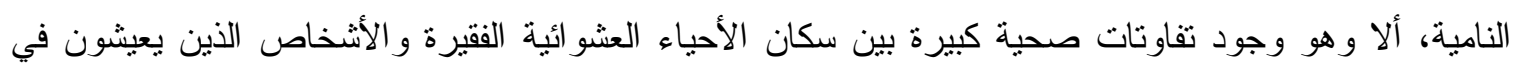
أماكن أخرى من المدينة، إلا أن سكان الأحياء العشو ائية الفقيرة يكونون أكثر حصانة إلى حد ما من الماء المخاطر من ساكني الريف.

يتمحور اهتمامنا في هذه الورقة حول سكان الحضر دون سواهم. وبتحديدنا للانتباه في الأجز اء الخاصة بالثكل (1) التي تتثير إلى حضر كينيا، فإننا نلاحظ وجود اختلافات ضخمة على مستوى الصحة داخل الكتلة الحضرية للسكان. وجدير بالملاحظة أن أوجه عدم المساواة هذه داخل المنطقة الحضرية الواحدة لا تتلقى سوى قليل من الانتباه من جانب الباحثين، إلا أنها ستأخذ بالطبع وزناً أكبر في جميع الحسابات الخاصة بالفقر حيث تستمر البلدان

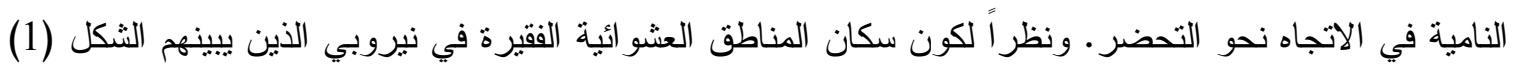
يمثلون أسو أ الثرائح صحة في حضر كينيا، فإن هناك القتر اح باحتمال فرض التركز ات المكانية للفقر الموجودة في تللك الأحياء لعقوبات صحية تفوق ما يمكن أن يحمله الفقر داخل الأسر المعيشية وحده. غير أن الثكل لا يميز

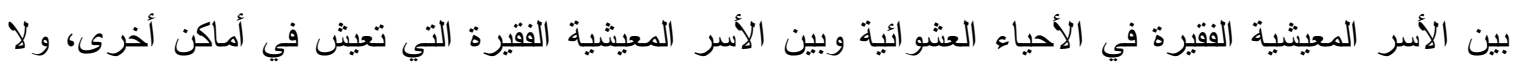

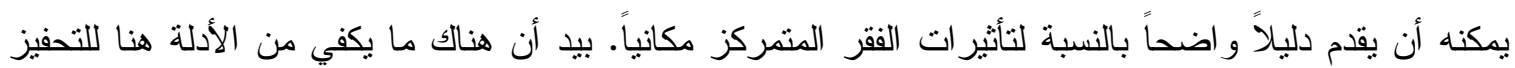
على القيام بمزيد من البحث المتعمق.

\section{رسم عام لإطار النظريات}

لا يمكننا أن نفي حق الطرق العديدة التي يمكن بها لمناطق الجوار وما يتصل بها من تأثنير ات سياقية أن تؤثز على الصحة. وفي الكتاب الجديد الذي صدر عن فريق ديناميكيات سكان الحضر (2003)، يقدم الفريق عرضاً شاملاً لهذه النظريات، مع إعطاء الاهتمام لما لها من تداعيات على الفقر على مستوى منطقة الجو ار (أو مستويات 
المعيشة) و السلوك الديموجر افي الفردي في مدن البلدان النامية. وفي سبيل التلخيص الموجز لوجهة نظر هذا الفريق، وهي وجهة نظر مطولة ومعقدة، بعتمد جزء كبير اً منها على أمتلة تجريبية مستقاة من تجربة الو لايات المتحدة- يتوقع المرء أن تكون لمناطق الجو ار أهمية لعدة أسباب. فمن حيث الأمر اض المعدية، ثبت منذ أمد بعيد أن القرب المكاني لسكان الحضر المتتوعين من شأنه خلق مظاهر خارجية صحية health externalities سلبية. ويقدم كل من تيماوس Timæus ولاش Lush (1995) مناقشة مستقيضة حول هذه المظاهر الخارجية. وكما رأينا في حالة نيروبي، فإنه من الممكن للمظاهر الخارجية المرتبطة بالتلوث البيئي و الأمر اض المعدية أن تسبب مخاطر صحية تعزى إلى العيش في الأحياء العشو ائية الفقيرة، تتافس المخاطر الموجودة في المناطق الريفية أو لون تفوقها، على الرغم من وصول سكان الحضر الأسهل بشكل عام إلى وسائل النقل والخدمات الصحية الحديثة في

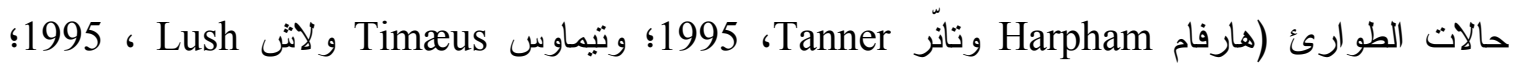
، African Population and Health Research Center والمركز الإفريقي لبحوث السكان والصحة ولهنئ

و هناك عوامل أخرى يقل الاعتر اف بها، إلا أنه ربما تكون لها نفس الأهمية، ألا وهي المظاهر الخارجية الاجتماعية social externalities التي تظهر في الحياة الحضرية. ترتبط النساء الأفر اد و الأسر المعيشية بغيرها في مناطق جو ارها من خلال رو ابط تحققها الثبكات الاجتماعية، ويمكن من خلال مثل هذه الدو ائر الاجتماعية أن تتدفق المعلومات حول كيفية إدر الك المخاطر الصحية والاستجابة لها، والأماكن التي تتو افر فيها الخدمات الملائمة. وبالطبع، فإن رو ابط الثبكات الاجتماعية عادةً ما تتخطى منطقة الجوار المحلية. إلا أنه دار جدل يفيد

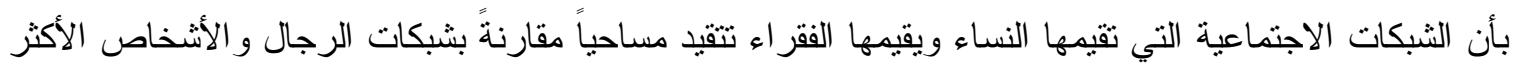
ثر اءً. كما أن التكاليف النسبية للسفر قد تكون أكبر بالنسبة للفقراء، وبالتالي، فإن النساء اللاتي لديهن أطفال و أعباء منزلية قد تجدن أن الروتين اليومي لحياتهن يتحدد في المقام الأول داخل مناطق جوارهن الهحلية (ماك كالّوخ McCulloch، 2003، وفريق ديناميكيات سكان الحضر، 2003). و وعلى الرغم من عدم علمنا بوجود أية بحوث حديثة حول الثبكات الاجتماعية وانتثار المعلومات الصحية داخل مدن البلدان النامية، فإن العمل الذي قام به كل من بيرمان و آخرين Behrman (2001)، وكاستر لاين Casterline و آخرين (2001) يوثث ما للشبكة من تأثثرات على استخدام وسائل منع الحمل داخل الأماكن الريفية وشبه الحضرية الإفريقية.2.

عادة ما تستتد النظريات الخاصة بالجماعات المرجعية المحلية و المقارنات الاجتماعية (إذا لم يتم اختبار ها بشكل

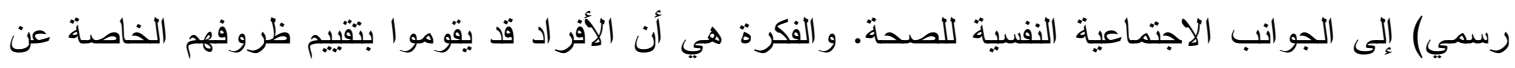
طريق مقارنتها بما يمكن ملاحظته من ظروف الآخرين (فان دن إيدن van den Eeden، وهونتر Hüttner،

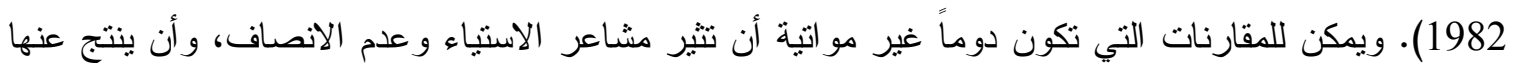
توترات ومخاوف تقوض من الصحة العقلية. وهناك سبب للاعتقاد بإمكان تأثثر منل هذه الآليات على الصحة

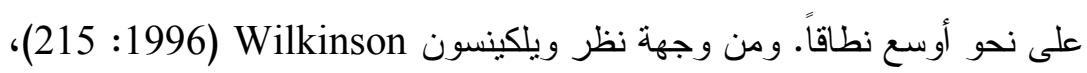


ما يهم هو المشاعر الاجتماعية، وليس التعرض لبيئة يفترض أنها تحمل مو اد سامة. فالبيئة

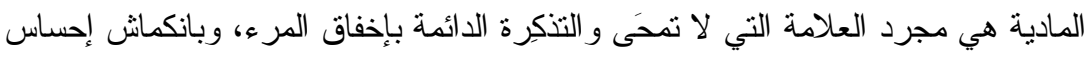
المرء بأي حس بملكية مكان داخل مجتمع، وبالإقصاء وتر اجع القيمة الاجتماعية كإنسان.

وتكرار تعرض الفقراء لأوجه عدم الانصاف الاجنماعي هذه قد يبدد من إحساسهم بالثقة على المسنوى الاجتماعي، ويضعف من حس الكفاءة الثخصية لديهم و اللازمة لتأكيد مطالبتهم بالموارد الصحية و الانخر اط بغير ذلك من الأشكال في سلوك بنّاء من السعي ور اءهُ الصحة.

ولم يتم بعد، و إلى حد بعيد، اختبار دور المكانة الاقتصادية الاجتماعية النسبية، كما يتم قياسها عن طريق الدخل الفردي بالنسبة لتوزيع دخل المجتمع المحيط أو الجماعة الاجتماعية الأوسع، ولاسيما بالنسبة للوحدات المكانية كمناطق الجوار الصغيرة (وِن Wen وآخرون، 2003). وفي بحوث الولايات المتحدة، ظهرت بعض لوض الأدلة -

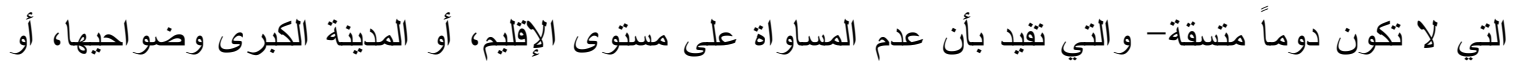

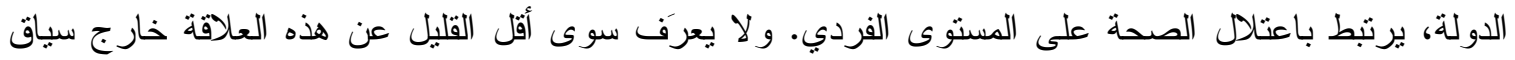
الو لايات المتحدة. وتتضمن الآليات الاجتماعية الأخرى ذات التأثثرات المشابهة ما يتصل منها بالفصل السكني

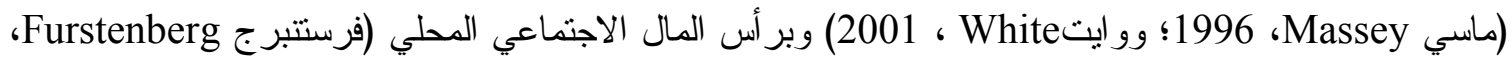
1993؛ و آبر Aber وآخرين، 1997؛ وفرستتبرج وهيو Hughes، Astone و آخرين، وأستون

ركزت الكثير من هذه المر اجع على التمركز المكاني للفقر، غير أن تأثثرات الثراء المتمركز مكانباً تستحق هي

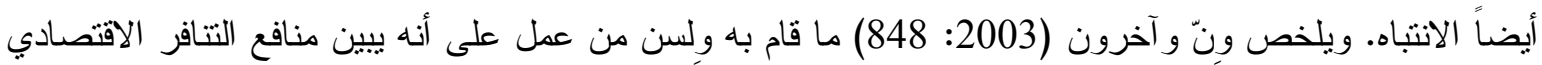

في نموذج [ولِن [Wilson]، نوجد نز ابط موجب بين انتشار الأشخاص من ذوي الاخول المتوسطة/

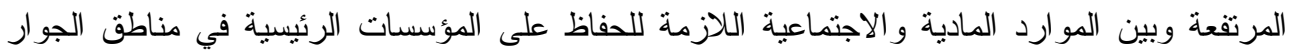

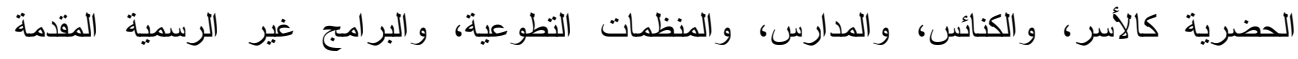

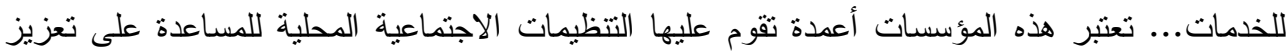
حس التضامن داخل مناطق الجوار وحثد السيطرة الاجتماعية غير الرسمية.

وفي در اسة أجر اها وِنّ Wen و آخرون (2003: 856)، تبين أن ثر اء منطقة الجوار له نأثثراً إيجابياً هاماً على

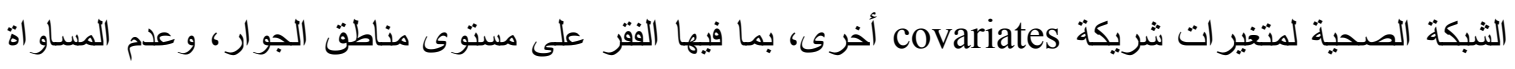
في الدخل، و إجمالي التحصيل الدراسي، وتخلف مستويات الصحة في مناطق الجوار • بيد أن بيبلي Pebley

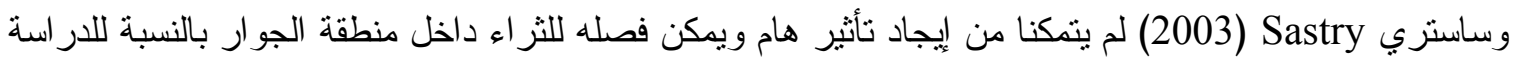
التي أجرياها في لوس أنجلوس حول الدرجات التي يحققها الأطفال في الاختبار ات، بالنظر إلى أوجه الرقابة على 
المستوى الوسيط لدخل الأسر في مناطق الجوار، وهو تأثير إيجابي هام على هذه الأرقام. بالإضافة إلى هذه

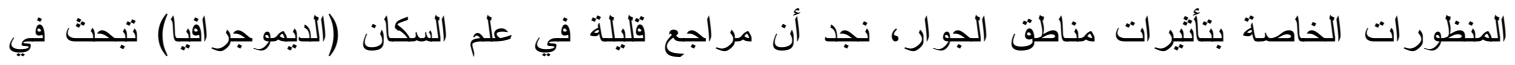

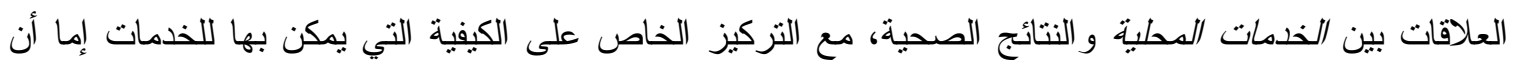

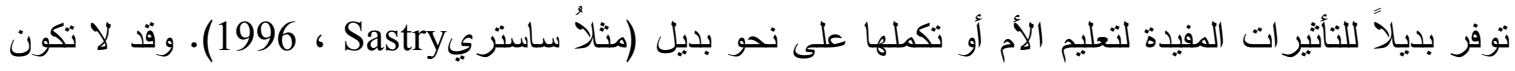

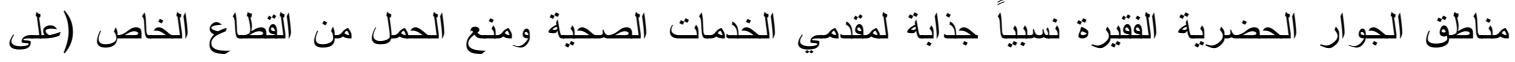

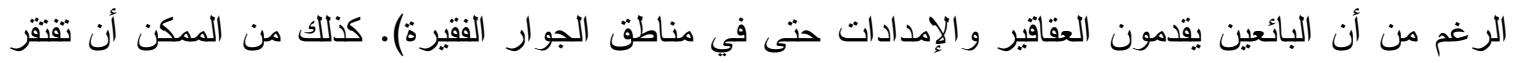

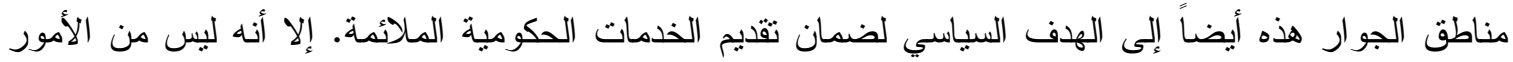

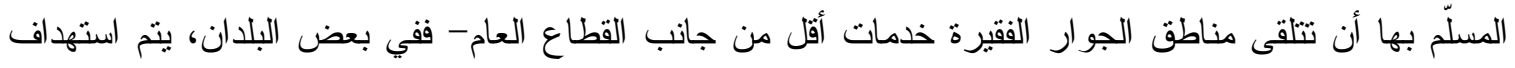

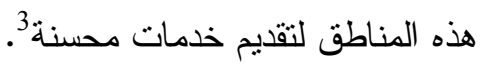

\section{ما مدى قوة الأدلة؛}

ان الدراسات الامبريقية التي تناولت تأثيرات مناطق الجوار في مدن البلدان النامية هى أبعد ما يكون عن

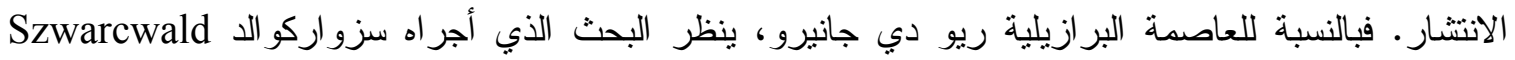

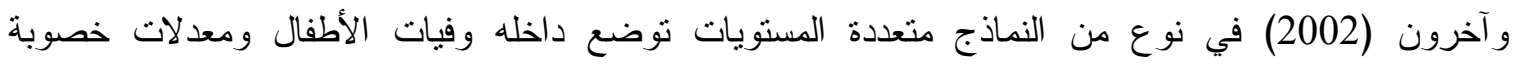
المر اهقين على مستوى الإحصاء السكاني بحيث بعتمد على نسبة الفقر وتوزيع معدلات الفقر في المناطق

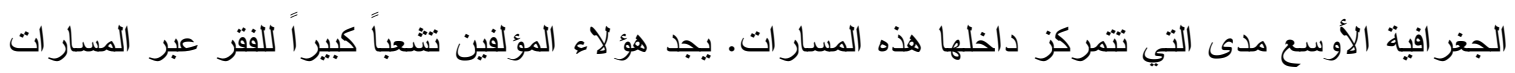

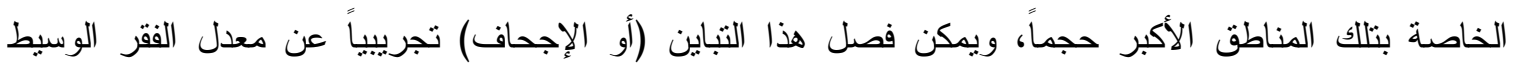

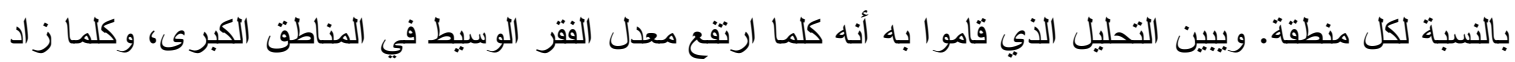

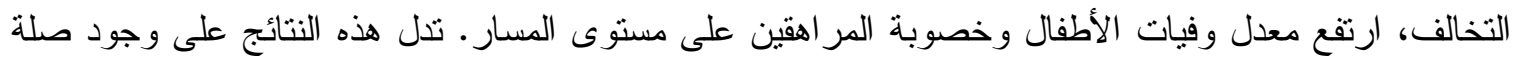
بين الإجحاف الاقتصادي الاجتماعي المحلي والصحة، وإن لم يكن مقنعاً بنفس قدر التقييمات الخاصة بالنماذئ

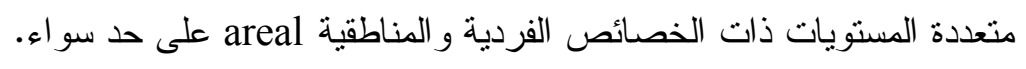

وكما لاحظ عدد من الباحثين (مثل تيماوس Timæus ولاش Lush ، Szwarcwald آل 1995؛ وسزواركو الد و آخرون، 2002؛ وآبرج ينجوي Aُberg Yngwe وآخرون، 2003؛ ودر اكّر Drukker و آخرون، 2003؛

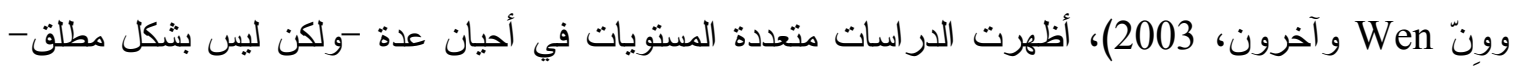

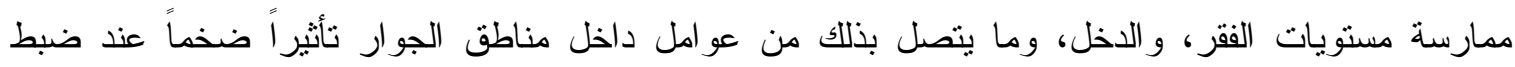
المتغيرات الثريكة على المستوى الفردي. ومن المككن للتسامت على نفس الخط المجمعة الفردية والمكانية أن يجعل التمييز بين الثأثيرات الفردية وتأثثرات مناطق الجوار أمراً أكثر صعوبة. ويحذر جينثر Ginther وآخرون (2000)، ممن يستخدمون بيانات طولية بها قائمة غنية من المتغيرات الفردية،

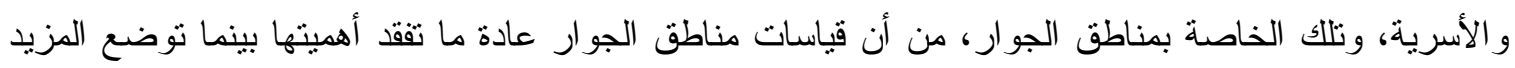
من المتغيرات الثريكة على مستوى الأسرة والمستوى الفردي في الحسبان. وتتدر الدراسات الطولية الخاصة بمثل هذه العلاقات، بينما تكون دراسات التذخل التي جرت على نحو عثو ائي حتى أكثر ندرة. 
ما هي منطقة الجوار الحضرية للوحدات الجغرافية التي تتو افر حولها بيانات مجمعة سفي الولايات المتحدة، تكون هذه عبارة عن مجالات

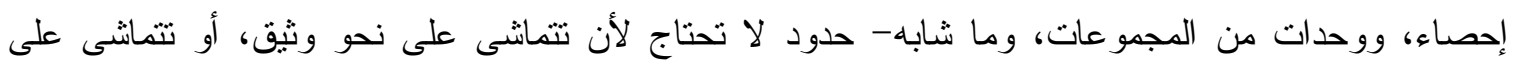
الإطلاق- مع الحدود الاجتماعية لمناطق الجوار كما تحددها أنماط التفاعل الاجتماعي، والانتشار، ودانئ والمقارنة. وبالإضافة لما سبق، وكما لوحظ سابقاً، فقد يكون للشبكات الاجتماعية تأثثرات هامة على السلوك الفردي الإدي و الأسري، ولا تقتصر الاتصالات الخاصة بهذه الثبكات بالضرورة على مساحة مناطق الجوار المحلية.

وفي قطعة ترجع إلى سنوات مضت، و إن كنا لا نزال نتذكرها ولا تزال نستفزنا، يركز كل من ولّمان Wellman مناطق الجو ار وذلك الذي يحدث داخل الثبكات الاجتماعية الفردية. فتشمل الثبكات الاجتماعية من وجهة نظر هما

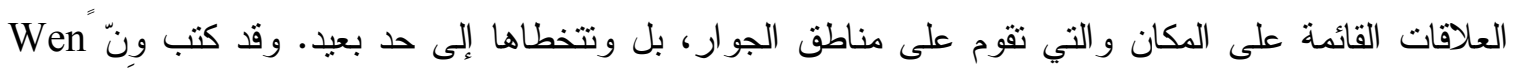
وآخرون (2003: 845) حول نأثير ات الصحة و الجماعات المرجعية، حيث أقر : "لا يتضح أبي من المستويات

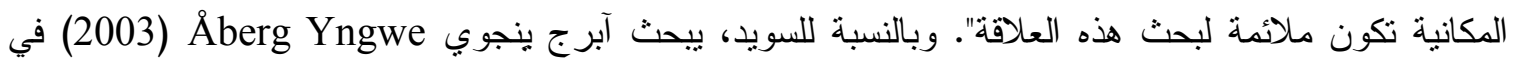

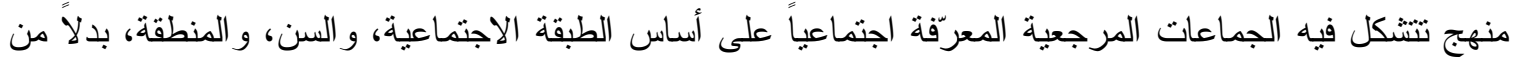
أن تتحدد على أساس الجغر افيا المحلية.

حتى المنهج المكاني يكون إثكالياً. فيشدد كولتون Coulton و آخرون (1997) وساستري Sastry و آخرون (2002) على التعقيدات التي ينطوي عليها نرسيم الحدود الجغرافية لمناطق الجوار الحضرية. فطلب كولتون

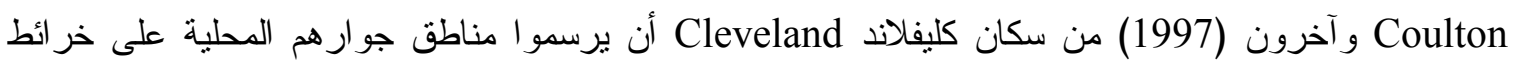
ووجدوا أن الحدود المتصورة عادة ما كانت تختلف بشكل ضخم عن حدود الوحدات القائمة على الإحصاء. وكان هناك تباين ضخم بين السكان في المدى المكاني لمناطق جوارهم المتصورة. و على الرغم من هذا التباين، فإنه

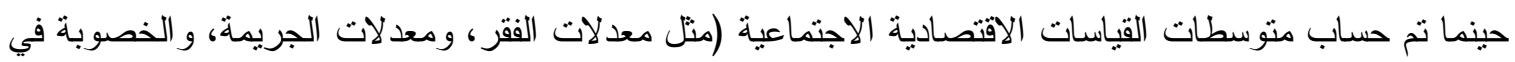
غير سياق الزواج) عن مناطق الجوار المتصورة، ثم مقارنتها بأرقام عن مسارات التعداد، ثبت أن نركيب

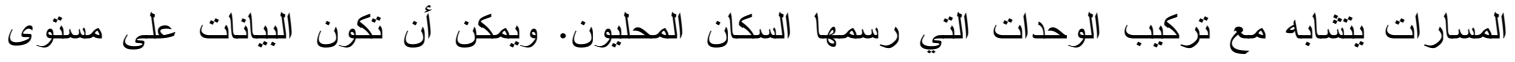
المنطقة، بالنسبة لكليفلاند Cleveland على الأقل، بمثابة توكيلات مفيدة. ولا نعرف بوجود أي بحث آخر تعرض لهذه النقطة الحيوية.

في هذه الورقة، كما هي الحال بالنسبة لكثير من المراجع التي تتاولت تأثثرات مناطق الجوار، تفرَض علينا تعريفات مناطق الجو ار بفعل طبيعة البيانات المنوفرة. تقوم المسوح الديموجر افية و الصحية بجمع البيانات داخل

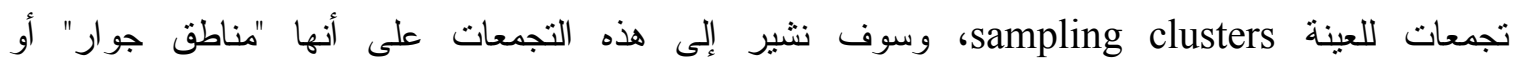
neighborhoods. ويكون الباب، بالطبع، مفتوحاً لتحديد النطاق الذي تمنل به تجمعات عينات المسوح 


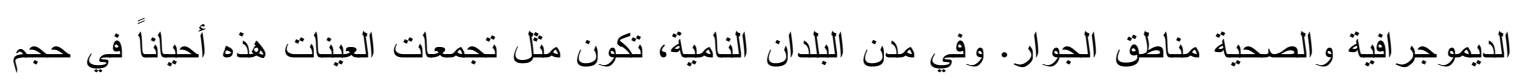

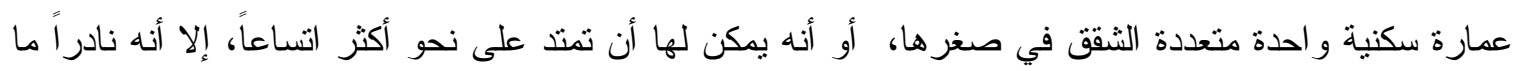

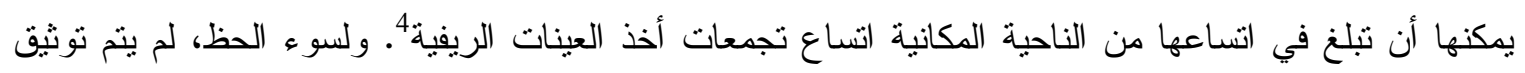

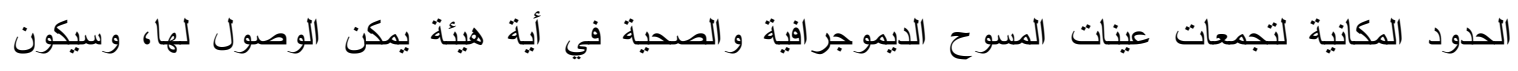

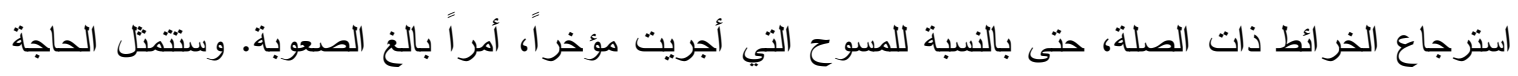
لبذل المزيد من الجهد الجهيد لتحديد طبيعة التفاعلات الاجتماعية التي تحدث داخل هذه الحدود المكانية وخارجها.

لذا، فإن النحديد الدقيق للمسارات التي تؤثر بها مناطق الجوار على الصحة يكون، ولأسباب كثيرة، خارج نطاق

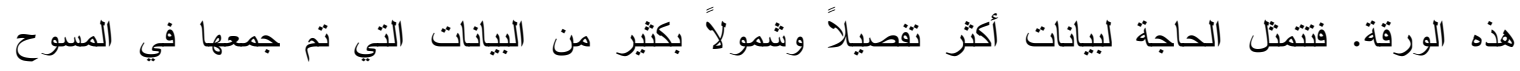

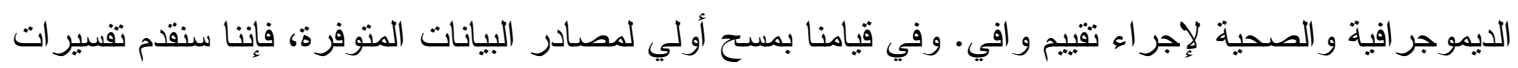

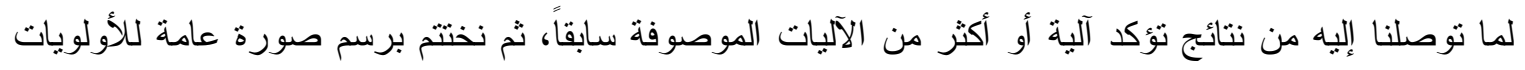
الخاصة بالبحوث في المسنقبل.

\section{لمحة إحصائية عامة}

تتخذ الدخصصات التي سيتم البحث فيها هيئة نظم معادلات يكون فيها المتغير الصحي، الذي يشار له بـ Y،

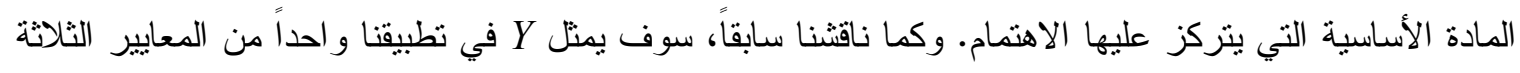

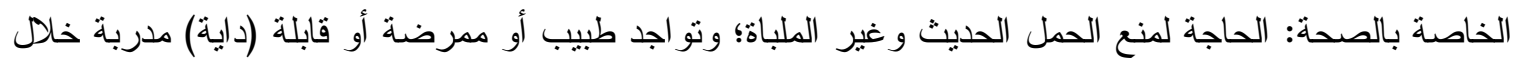

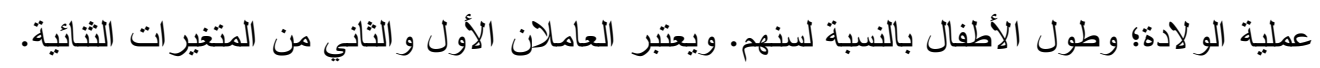

وفيما يختص بالنماذج الخاصة بالحاجة غير الملباة والتو اجد خلال الولادات، فإننا نكتب المعادلة الهيكلية الأساسية على هيئة متغير كامن كالآتي:

$$
Y^{*}=W^{\prime} \theta+f \delta+\varepsilon
$$

حيث يساوي المتغير الملاحَظ غير المستقل

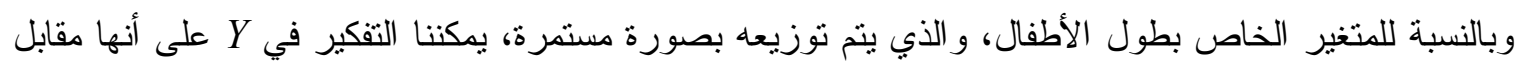


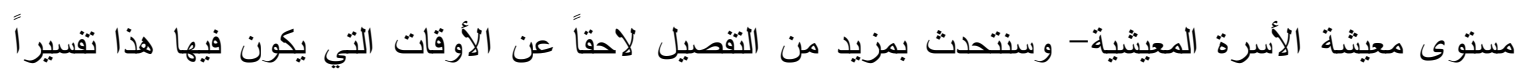
يؤخذ به. و هناك عامل آخر غير صالح للملاحظة، هو ع، يقوم مقام شرط التشويش بالنسبة لهذه المعادلة الهيكلية. 
ونضع نموذجاً للعامل f، مثل

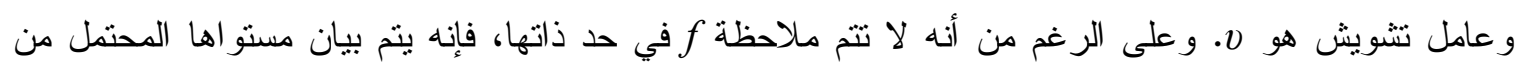
خلال القيم التي أخذت عن طريق

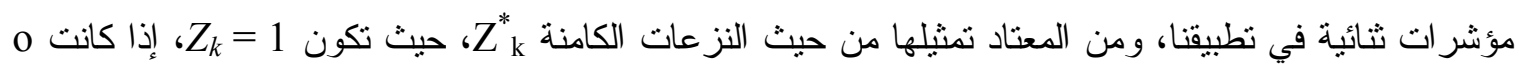

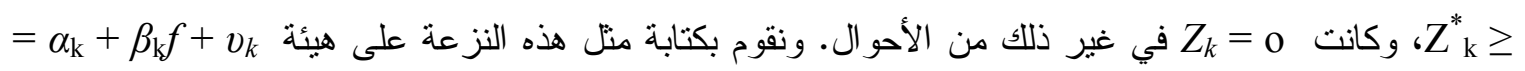
Z Z

$$
\begin{array}{r}
\mathrm{Z}_{1}^{*}=\alpha_{1}+X^{\prime} \gamma+v+v_{1} \\
\mathrm{Z}_{2}^{*}=\alpha_{2}+\beta_{2} \cdot X^{\prime} \gamma+\beta_{2} v+v_{2}
\end{array}
$$

$$
\mathrm{Z}_{\mathrm{k}}^{*}=\alpha_{\mathrm{k}}+\beta_{\mathrm{K}} \cdot X^{\prime} \gamma+\beta_{\mathrm{K}} v+v_{K}
$$

في هذه المجموعة من المعادلات، تبين البار امترات

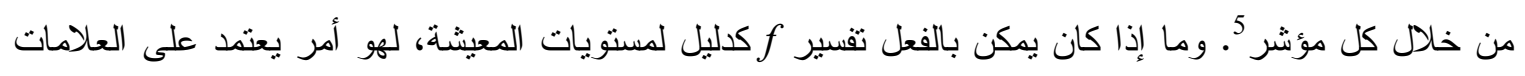
التي تعرضها هذه البار امترات.

وبالتالي، فإن نظام المعادلات بأكمله يشمل المعادلة الصحية (1) و المعادلات (2) بالنسبة لمؤشرات مستويات

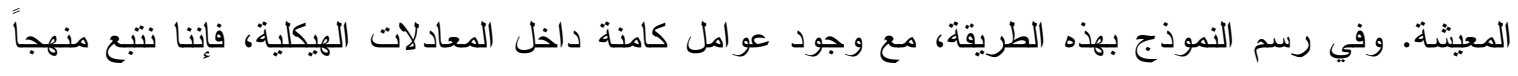

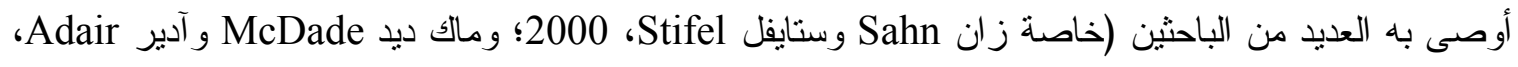

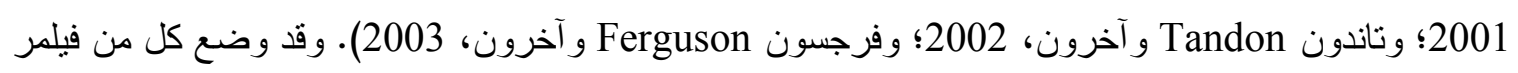
Filmer

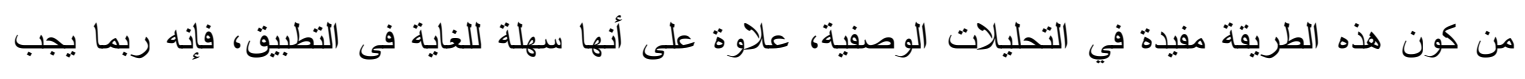

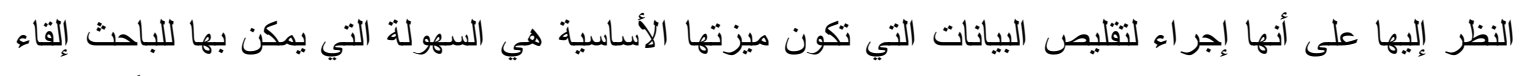

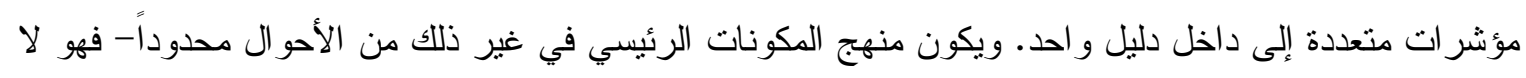

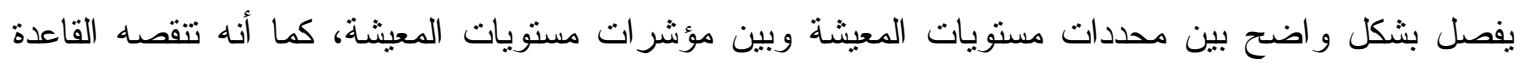

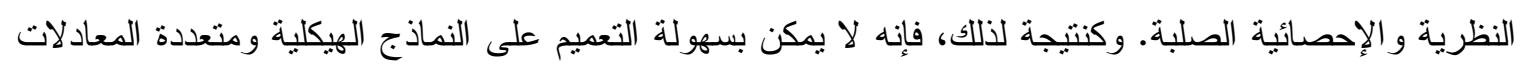

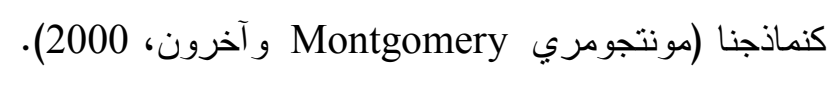

وفي هذه الورقة، سنتبع منهجاً ينكون من خطوتين التقدير النظام بالكامل. فإذا ما افترضنا أنه سيتم توزيع عناصر

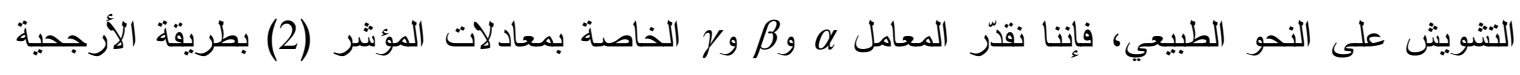
القصوى method of maximum likelihood، كما هو موصوف في الملحق ب، باستخدام النظم التي كتبنا 
عنها تحقيقاً لهذا الغرض 6. ويستقى تقدير

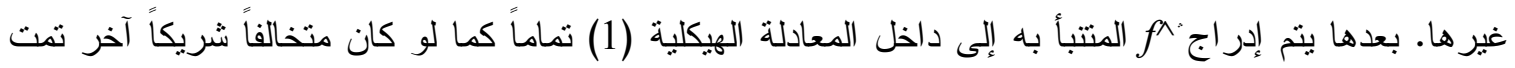

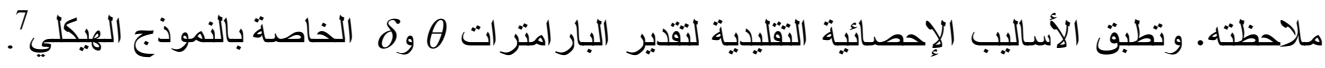

ومن المهم الاعتر اف بنقة أساسية: إننا نفترض أن مصطلحات التشويش علاقة اعتماد متبادل. و القلق الرئيسي هو أن عامل التشويش ع الخاص بمعادلة الصحة قد تربطه علاقة متبادلة بـ v أو بأحد عو امل التشويش kv. ويمكن لعلاقة منبادلة تتضمن ع أن تتشأ إذا كانت النزعة لملكية إحدى السلع

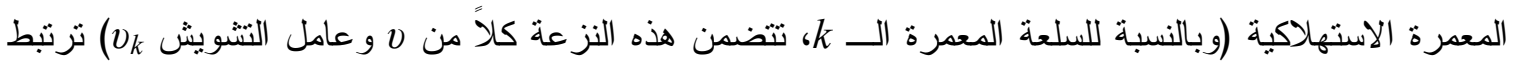
إلى حد ما بعامل النشويش ع الذي تشنمل عليه المعادلة الصحية الرئيسية. وعندما يتم تقدير معادلات المؤشر (2) بصورة منفصلة، كما هي الحال في المنهج الذي نتبعه، فإن عامل التقدير ^ر يتسق في هذه الحالة بالنسبة لـ لـ،

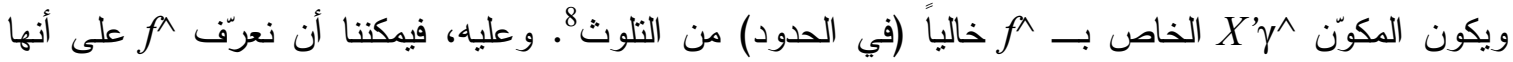
تساوي ^

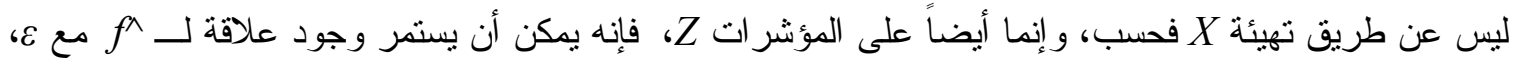
حتى داخل الحد. فإذا كان هنالك ما يدعو للقلق بسبب منل هذا التحيز، فإنه لابد من تعديل الإجر اء الذي كان ينتج عنه في السابق ^f. إلا أنه بسبب عدم تو افر أي سبب قاهر لدينا يدعونا للتشكك في العلاقة المتبادلة، فإننا لم نقم

\section{نمذجة عامل مستويات المعيشة}

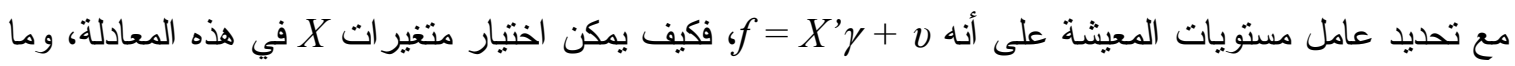
هي العلاقة التي يجب أن تكون بينها وبين متغير ات W - إذا كانت هناك علاقة على الإطلاق - التي تدخل المعادلة الصحية الرئيسية؟ كيف يمكن التفرقة بين متغيرات X، التي تم وضعها كمددات لمستويات المعيشة، وبين المتغير ات $\left\{Z_{k}\right\}$ التي تكون بمثابة مؤشر ات لمستويات المعيشة؟

كما لاحظ مونتجومري Montgomery و آخرون (2000)، فإنه لا يوجد سوى إجماع بسيط داخل المر اجع حول

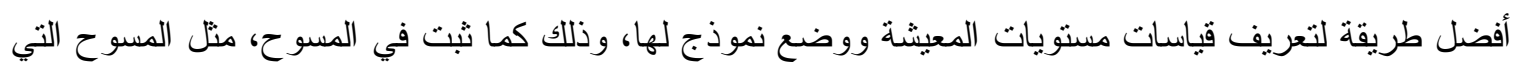
أرسلها برنامج المسح الديموجر افي و الصحي، و الني تفقتر إلى بيانات حول الاستهلاك، و الإنفاق، و الدخول. ومع قلة البيانات التي يعول عليها بالنسبة للاستهلاك، فإننا نرى أنه من المالائم تعريف مجموعة المؤشرات الخاصة بمستويات المعيشة \} $\left\{Z_{k}{ }^{2}\right.$ من حيث السلع المعرة الاستهلاكية و أغر اض السكن ذات الجودة التي يتم جمع بيانات حولها. وباستخدام هذه المؤشرات، فإننا نضع ما أسماه كل من ماكديد وآدير McDade and Adair (2001)

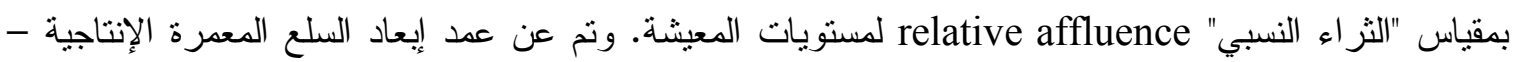

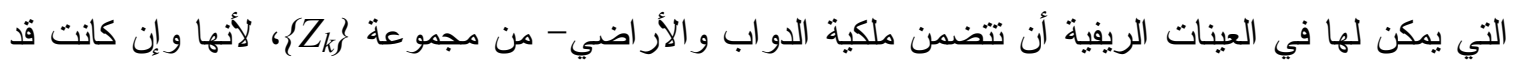
تساعد على تحديد الاستهالك النهائي، فإنها لا تعتبر في حد ذاتها مقاييس لذلك الاستهلاك. فهي تعد وسيلة لتحقيق 
غاية، أو بعبارة أخرى، يمكن القول بأنه ينظرَ إلى السلع المعرة الإنتاجية بشكل أفضل على أنها دذخلات في الوظائف الإنتاجية الخاصة بالأسر المعيشية، بدلاً من كونها مقاييس للاستهلاك مسنقاة من إنتاج الأسر المعيشية.

وتبعاً لهذا المنطق، فإذا توفرت متغير ات السلع المعمرة الإنتاجية للعينات الحضرية التي نهتم بها، فإنه لابد لنا من

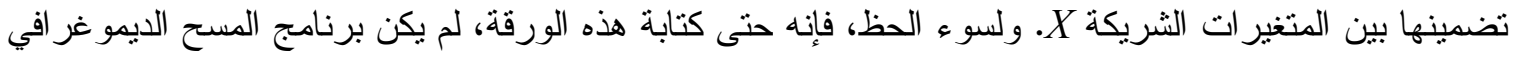

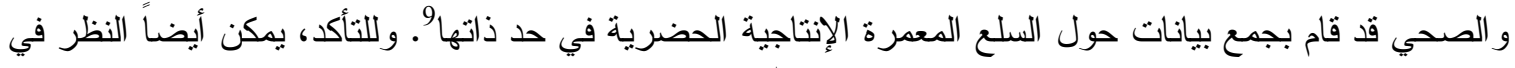

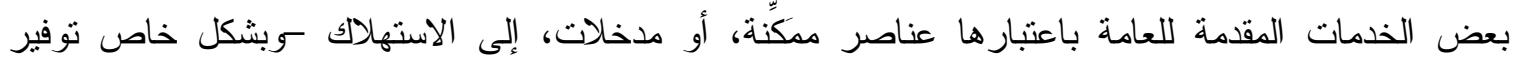

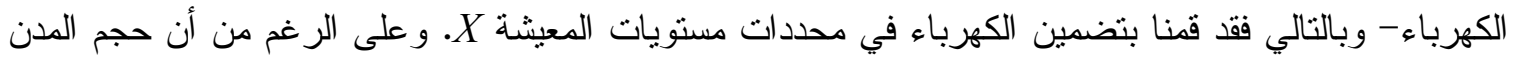

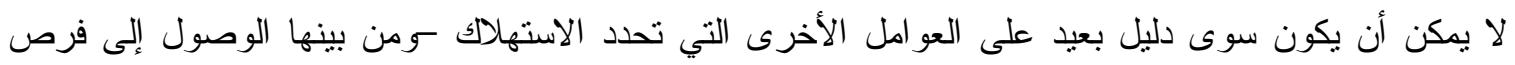

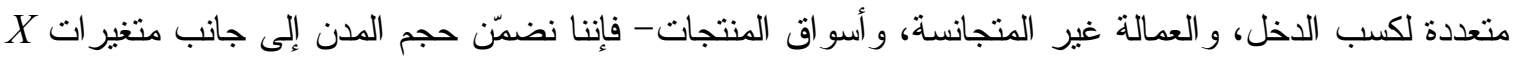

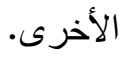

وربما لا يكون من غير الملائم مقارنة تعليم الكبار بإحدى السلع المعمرة الإنتاجية، حيث أن التعليم هو أحد

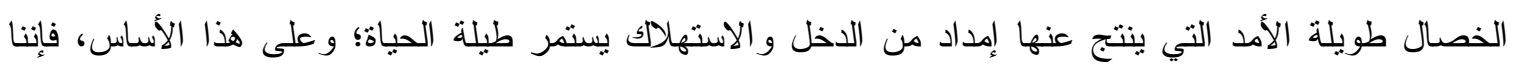
نقوم بتضمين التعليم الذي حصل عليه رب الأسرة المعيشية (وسنه) في تخصيصنا للمحددات X. و وعندما نقوم بذللك، فإننا ندرك "الأدوار المزدوجة" التي يلعبها النعليم في السلوك الديموغر افي (مونتجومري

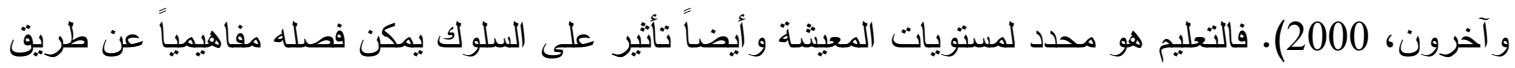
الصلات التي تربط بينه وبين الثقة الاجتماعية، والقدرة على معالجة المعلومات، واتساع الثبكات الاجتماعية

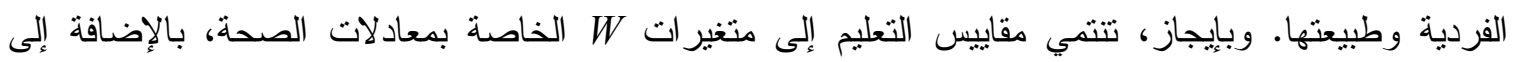

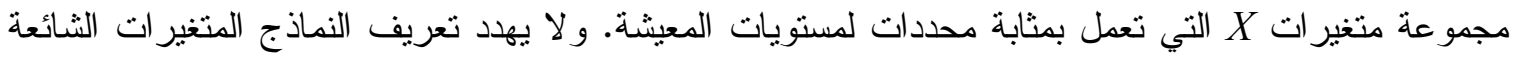

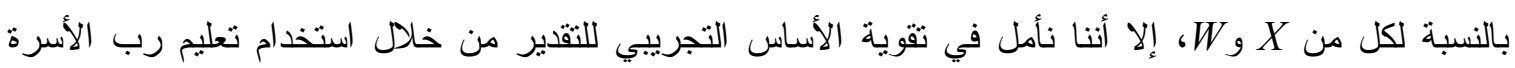

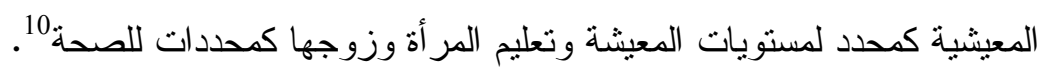

\section{مستويات المعيشة على مستوى منطقة الجوار}

من الواضح وجود كثير من القضايا التي يجب مو اجهتها لتحديد نماذج مستويات المعيثة على المستوى الفردي

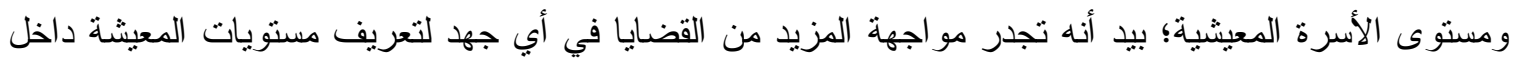

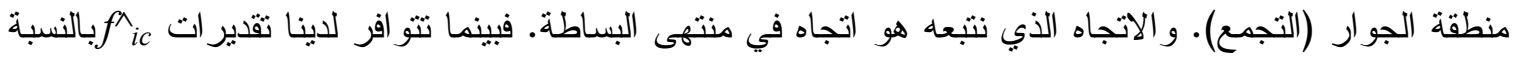
للأسرة المعيشية i داخل التجمع c، فإننا نقوم ببناء قياس على مستوى التجمعات عن الأسرة المعيشية i من خلال

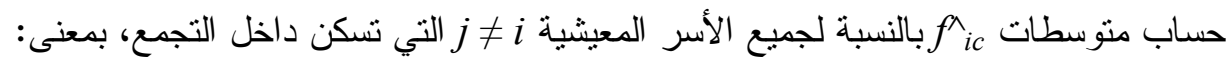

$$
f^{\wedge}{ }^{c}=1 / n \sum_{j \neq I} f_{j c}
$$


حيث يكون $n_{c}$ هو عدد الأسر المعيشية في التجمع ناقص واحداً. وفي عملنا الوصفي، نقوم كذلك بوضع مقاييس

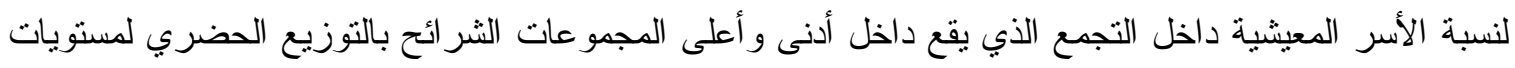
المعيشة.

فنقوم بالبحث في منهجين بديلين يمكن تبريرهما بشكل أفضل من ناحية الاقتصاد القياسي econometric ـ في و احد من المنهجين، يتم إخخال العامل f الخاص بمستويات المعيشة على مستوى التجمعات، إلى جانب العامل f الخاص بمستوى الأسر المعيشية، ويتم وضع نماذج له من حيث المتغير ات على مستوى التجمعات. ويمكن تتفيذ هذا المنحى ثنائي العامل إلى حد كبير بنفس الطريقة كما المنحى ذي العامل الواحد، على الرغم من أن التقدير

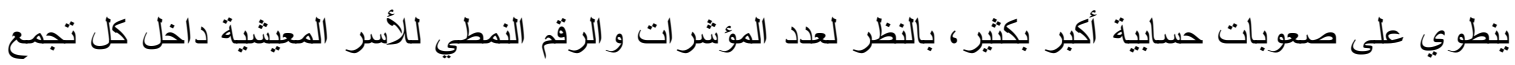
كما يتبين في بيانات المسح الديموغر افي و الصحي التي نستخدمها. وهنالك بديل، لم يتم تبريره بنفس القدر من

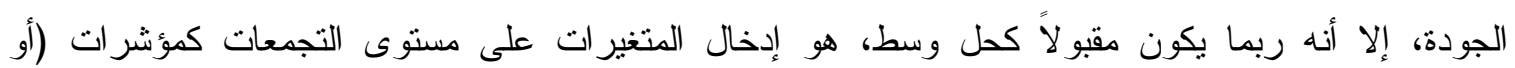
محددات) لعامل و احد من عو امل مستويات المعيشة على مستوى الأسرة المعيشية.

\section{محددات البيانات و النماذج}

تأتي البيانات التي يتم الاعتماد عليها في هذا التحليل من 85 مسحاً جرت في المراحل 2-4 من برنامج المسح

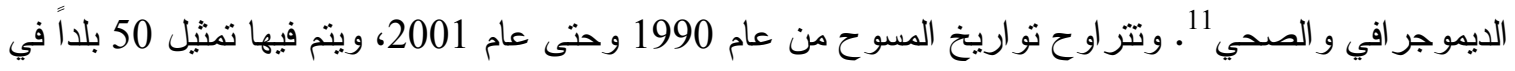
ست مناطق نامية. راجع الجدول أ-1 في الملحق أ للاطلاع على قائمة بهذه البلدان و السنوات التي جرت فئمات فيها المسوح.

\section{مقاييس صحية}

يتم عرض ملخصات إقليمية لتوزيعات المتغيرات الصحية -الحاجة غير الملباة بالنسبة لدنع الحمل الحديث؛

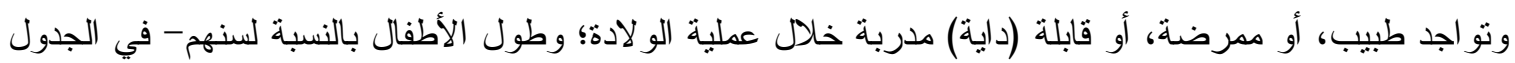
1. ونستخدم هنا وفي أجز اء أخرى من الورقة مثل هذه الملخصات و المتوسطات الإقليمية لوضع النتائج داخل سياق. وهنا تجدر الإثارة إلى أن المسوح الديموجر افية و الصحية لا تمثل تمثيلاً دقيقاً أية منطقة نامية، حيث أنه لم تشارك جميع بلدان أية إقليم، أو حتى جميع البلدان الكبرى فيه، في برنامج المسح الديموجر افي و الصحي. وعلاوة على ما تقدم، فان عدة بلدان أرسلت عدة مسوح ديموجر افية وصحية.

ويبين العمود الأول من الجدول (1) النسب المئوية للنساء اللاتي لايهن حاجة غير ملباة لمنع الحمل. ويمكن القول بوجود حاجة غير ملباة عندما تعرب امر أة ما لا تستخدم وسائل منع الحمل في الوقت الحالي عن رغبتها في منع إنجاب المزيد من الأطفال أو تأجيل هذا الإنجاب (وسِتوف Westoff وبيلي Pebley، 1981؛ ووستوف Westoff وبانكولي Bankole، 1995؛ وكاستر لاين Casterline وسيندنج هinding؛ 2000). ومن بين النساء اللاتي تفدن بأنهن ثرغبن في وقف إنجاب الأطفال بشكل عام أو بتأجيل مرة الإنجاب القادمة سباستثناء النساء غير 
المعرضات لخطر الإنجاب (كالنساء الحوامل، أو اللاتي نعانين من انقطاع الطمث، أو اللاتي هن لسن في

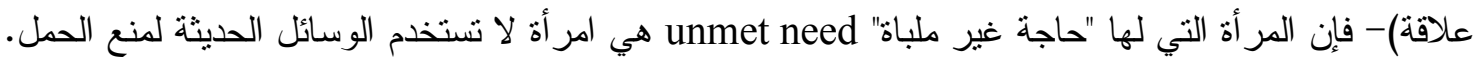

و المقياس الصحي الثاني الذي يبينه الجدول (1) مأخوذ من نواريخ الأمومة السابقة في المسوح الديموجر افية

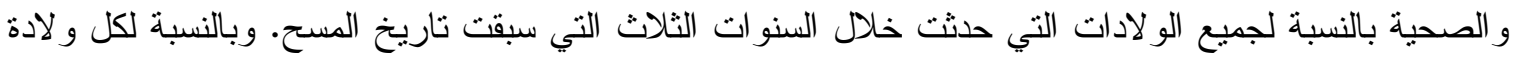

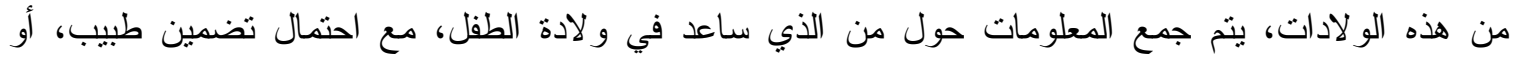
ممرضة، أو قابلة (داية) مدربة ، أو قابلة أخرى، أو مولدّة نقليدية أخرى، أو أح أحد الأقارب.

جدول(1) القيم الوسيطة للحاجة الحضرية غير الملباة، ونو اجد طبيب أو ممرضة أو قابلة مدربة خلال عملية الولادة،

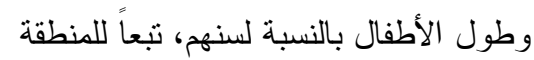

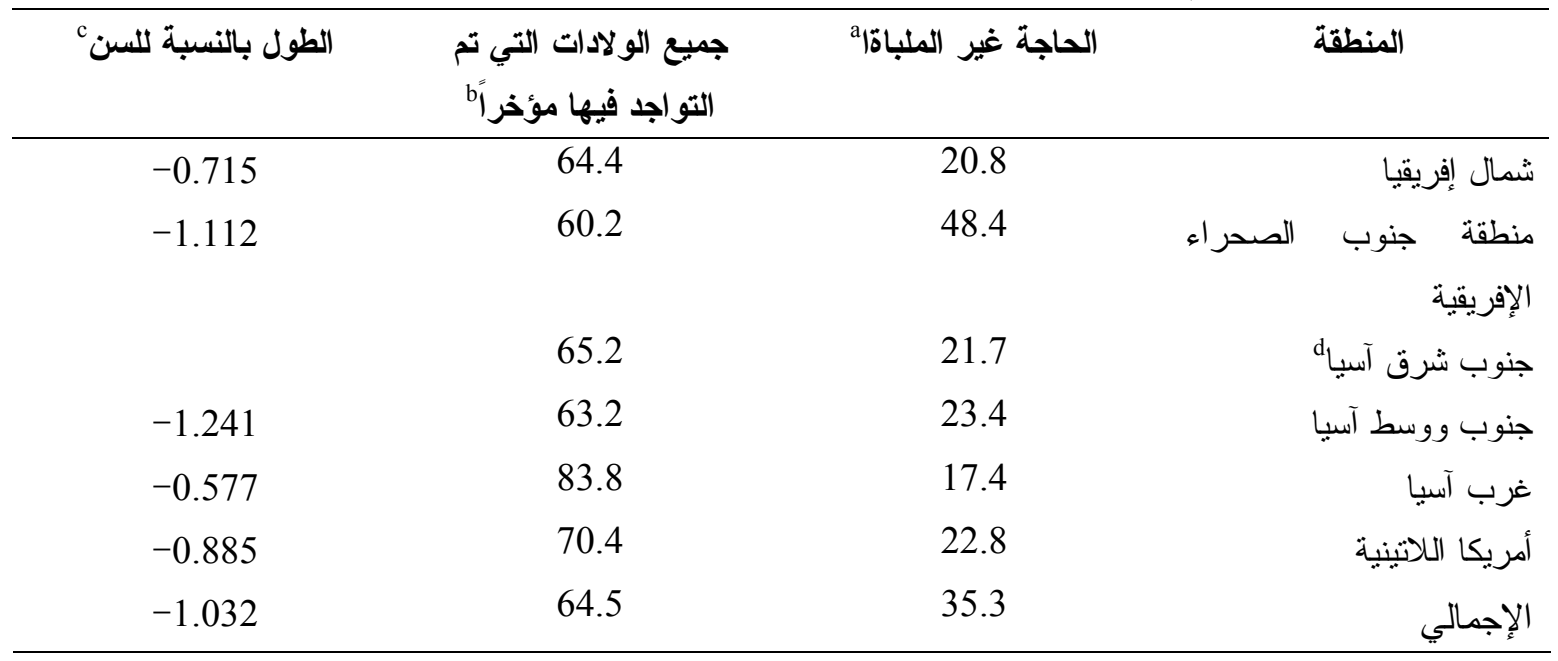

"يتم التعبير عنها عن طريق النسب المئوية للسيدات المعرضات لخطر أن نكون لديهن حاجة غير ملباة.

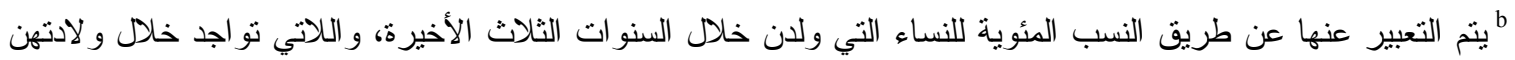
طبيب، أو ممرضة، أو قابلة مدربة. c يتم التعبير عنها من خلال الانحر افات المعيارية المستقاة من إحدى النسب المرجعية الدولية الوسيطة، حيث يكون 1.0-

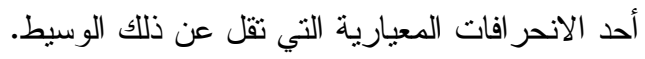

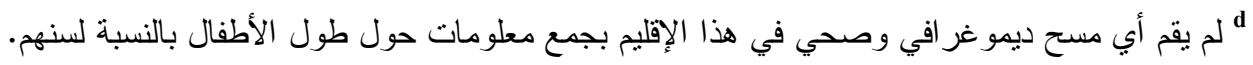

وسوف يركز هذا التحليل على النساء اللاتي حضر ولاداتهن خلال السنوات الثلاث الأخيرة طبيب، أو ممرضة،

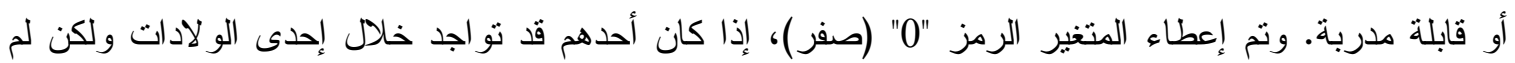

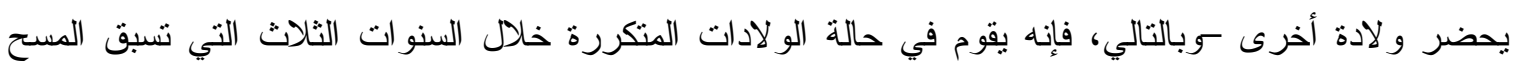
بقياس الحضور المنسق. 
يقوم برنامج المسح الديموجر افي و الصحي بجمع المعلومات حول طول ووزن كل طفل ولِد خلال السنو ات الثلاث

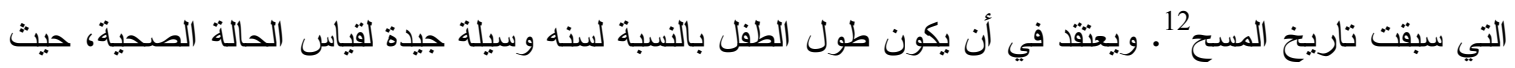

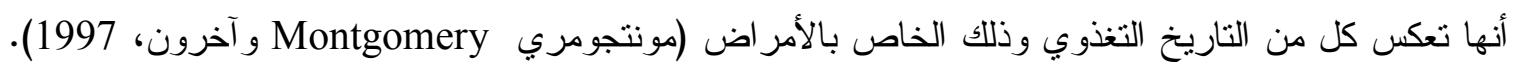

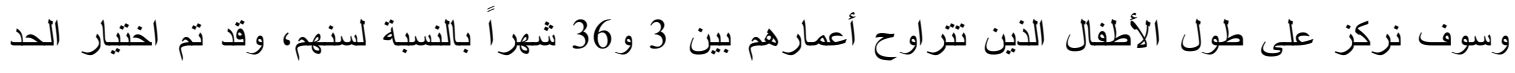

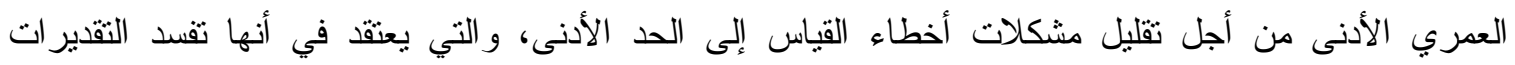

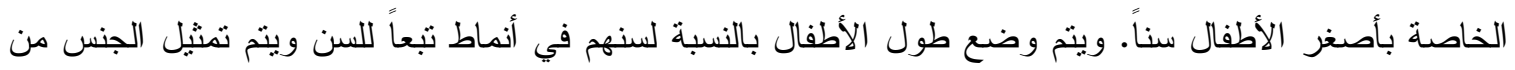

$$
\text { حيث الانحر افات المعيارية للنسب المرجعية الدولية الوسيطة. }
$$

\section{متغيرات تفسيرية}

تم تضمين مجموعة صغيرة من المتغيرات المستقاة من المسوح الديموجرافية والصحية بحيث يتم على أساسها نحقيق الرقابة الاقتصادية الاجتماعية. ويتم عرض إحصائيات وصفية لهذه المتغيرات في الملحق أ؛ ونقوم هنا

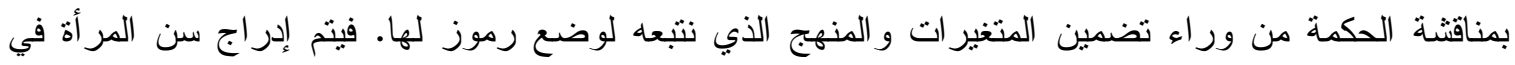
المجموعات النقليدية التي تغطي كل منها خمس سنوات. ويتم بيان السياق الحضري من خلاه المتغير ات الوهية حول السكن في عاصمة البلاد أو مدينة كبرى أخرى (عرّقتها المسوح الديموجر افية و الصحية

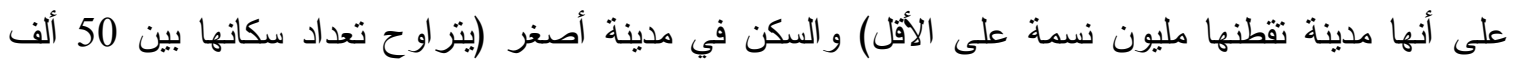

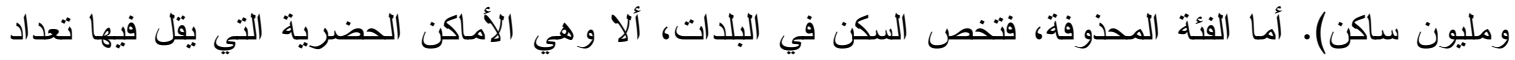

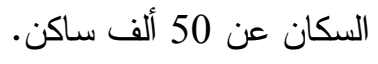

جدول (2) ترميز التحصيل الدر اسي للتحليلات متعددة المتغير ات

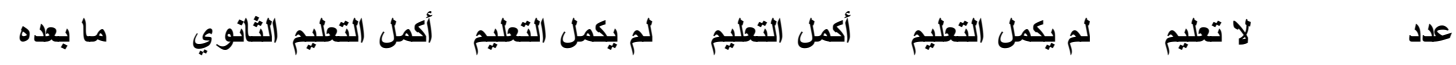

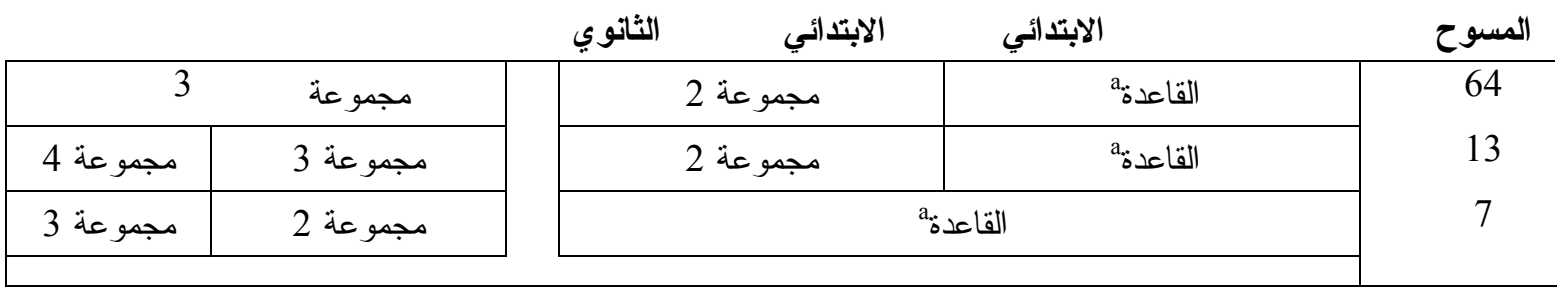

ئتم تعريف المجموعة القاعدية، التي تقوم مقام الفئة المحذوفة في النماذج متعددة المتغير ات على نحو يشمل ما لا يقل عن 8 بالمائة من العينة الحضرية.

و ابتكار نظام منسق لتصنيف التحصيل الدراسي هو أمر صعب اذ تتباين الخبرات التعليمية للنساء وأزواجهن بدرجة كبيرة في كم ضخم من الأقاليم و البلدان التي يغطيها هذا التحليل. فعلى سبيل المثال، أتمت أكثر من 80 بالمائة من النساء تعليمهن الثانوي أو حصلن على قسط أعلى من التعليم في كل من كاز اخستان وأوزبكستان، بينما لم يتسن هذا سوى لــ 8 بالمائة و 1 بالمائة من النساء في مالي وبوركينا فاسو على التو الي. فلا يمكن فرض فلى نظام و واحد للتصنيف على جميع البلدان. 
وقد اخترنا تعريف التحصيل الدراسي للنساء وأزو اجهن تبعاً لنوزيع التحصيل داخل كل بلد. وينتج عن هذا المنتج

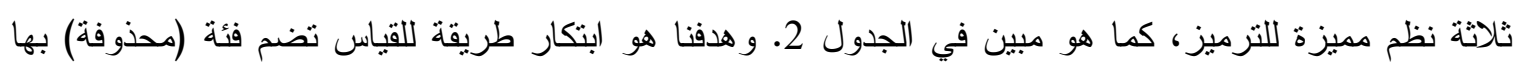

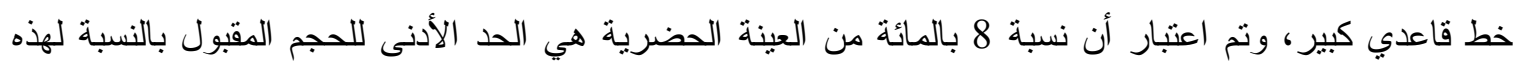

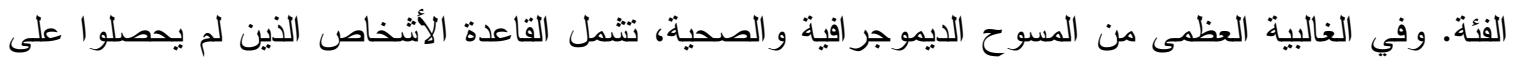

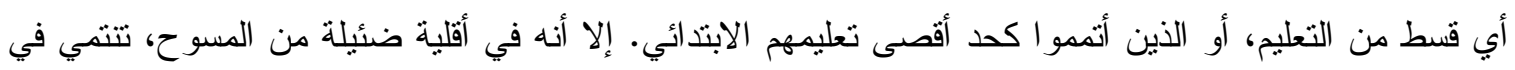

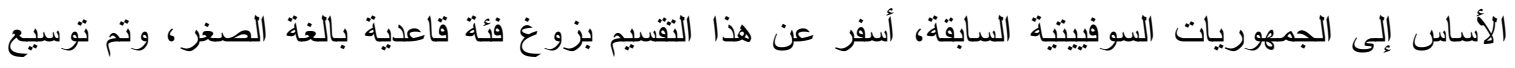
نطاق القاعدة لتشمل الأثخاص الذين أكلوا التعليم الابتدائي، أو درسو ا في المرحلة الثانوية و إن كانو الم يكملوها.

\section{مؤشر ات مستويات المعيشة}

تشمل مجموعة مؤشر ات مستويات المعيشة

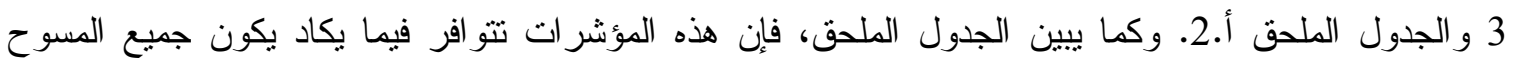

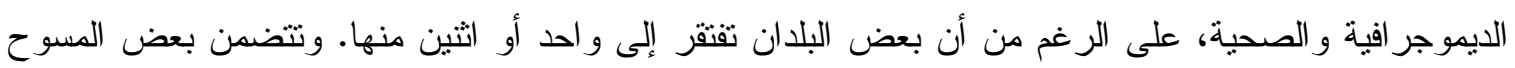

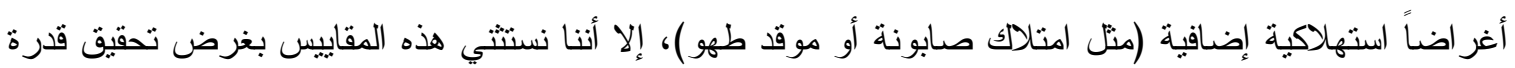
معقولة على المقارنة عبر البلدان.

\section{مستويات معيشة الأسر المعيشية ومناطق الجوار}

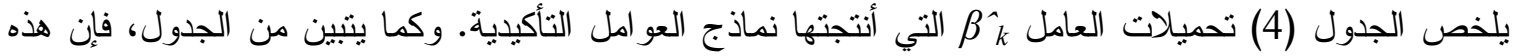

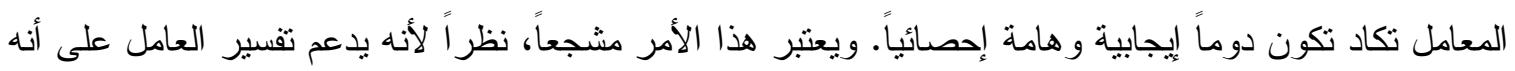

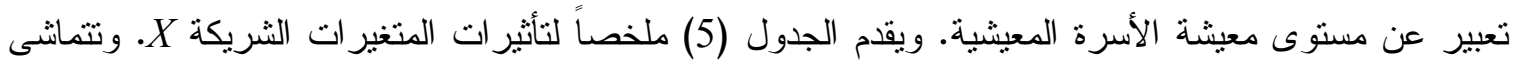
هذه الثأثير ات كنلك و إلى حد بعيد مع التوقعات.

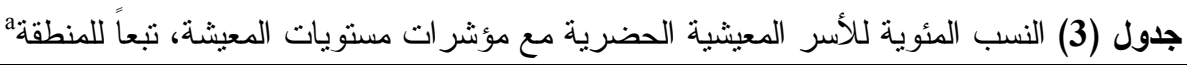

\begin{tabular}{lcccccc}
\hline جنال \\
\end{tabular}


a متوسطات غير موزونة، تقوم على أسر معيثية بها نساء تتطبق عليهن شروط المشاركة في تحليل الحاجات غير الملباة،

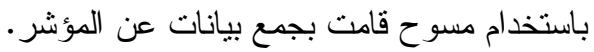

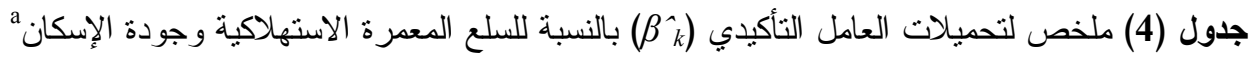
سلبي وهام إيجابي وهام

المقّر

71

76

83

79

57

75

1

6

7

78
54

65

77

75

82

75

(0)

2
0

3

9

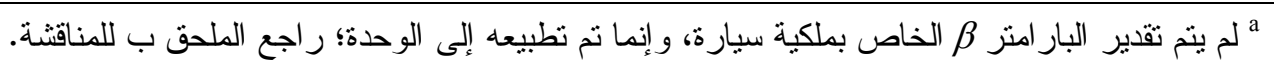

جدول (5) ملخص لــ ^ر ، تأثنير ات المحددات X على عامل مستويات المعيشة

\begin{tabular}{|c|c|c|c|}
\hline سلبي وهام & إيجابي وهام & المقدّر & 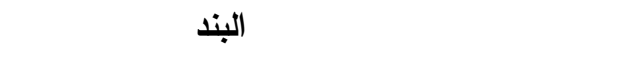 \\
\hline & & & متغير ات ديموجر افية بالنسبة لرب الأسرة المعيشية \\
\hline 11 & 74 & 85 & ذكر \\
\hline 0 & 85 & 85 & 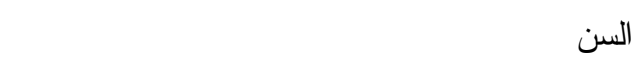 \\
\hline 85 & 0 & 85 & a السن بعد التزبيع a \\
\hline & & & تعليم رب الأسرة المعيشية b \\
\hline 0 & 76 & 76 & أتمّ التعليم الابتدائي أو لم يتم التعليم الثانوي \\
\hline 0 & 60 & 60 & أتمّ التعليم الثانوي أو ما بعده \\
\hline 0 & 19 & 19 & أنتّمّ التعليم الثانوي \\
\hline 0 & 20 & 20 & 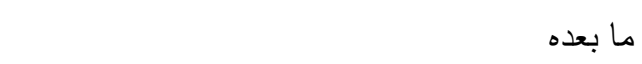 \\
\hline 0 & 12 & 12 & غير معروف \\
\hline & & & غير ذلك \\
\hline 0 & 61 & 61 & بالأسرة المعيشية كهرباء \\
\hline 11 & 60 & 71 & السكن في مدينة صغيرة \\
\hline 7 & 74 & 82 & السكن في إحدى العو اصم \\
\hline
\end{tabular}


يتم aقدير عامل مستويات المعيشة بحيث يرتفع مع ارتفاع سن رب الأسرة المعيشية حنى سن 59.7 سنة، وهو منوسط "نقطة التحول" في جميع النماذج المقدّرة.

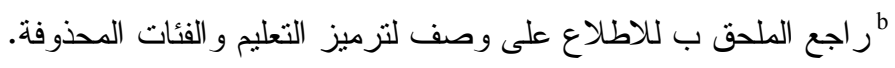

ويرنبط نوفير الكهرباء بشكل إيجابي بمستويات المعيشة، كما يمكن أن يتوقع بالنظر إلى دورها كمدخل حيوي.

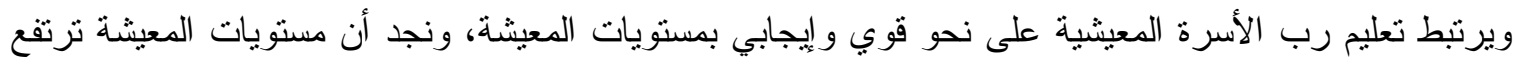

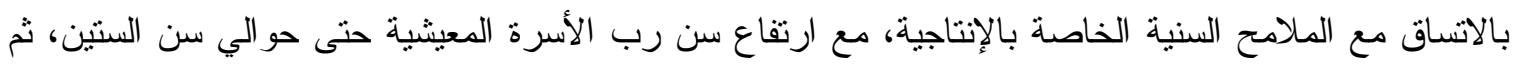
يأخذ بعدها في التز اجع. وتنين المتغيرات الخاصة بحجم المدن تأثثرات أضعف بشكل عام، غير أن التقديرات تشير إلى أن مستويات المعيشة بشكل عام تكون أعلى في المدن الصغيرة و الكبيرة بالنسبة للمسنويات الموجودة

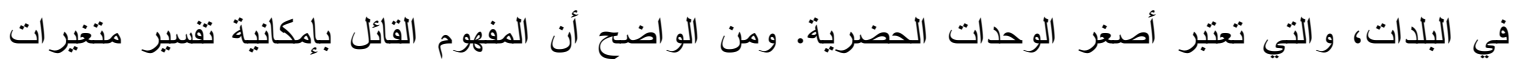
الوكالة التي نم جمعها في المسوح الديموجر افية والصحية كمؤشرات لمستوى معيشة الأسرة المعيشية الذي يكون لئن في غير ذللك من الأحوال غير قابل للملاحظة هو مفهوم يحظى بكثير من الدعم الإحصائي.

ونقوم حالياً بفحص العلاقة بين المؤشرات الخاصة بمستويات المعيشة المقدرة على مستوى الأسرة المعيشية

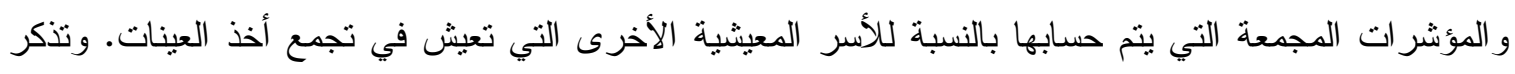

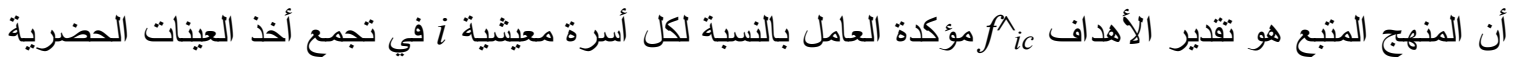
c داخل أية مجموعة بيانات تخص المسح الديموجر افي و الصحي. ويتم حساب متوسطات تجمعات أخذ العينات عن طريق فصل الرقم الذي نم نسجيله عن كل أسرة معيثية i وحساب رقم وسيط عن الأسر المعيشية الأخرى في التجمع. كما نقوم بفحص نسبة الأسر المعيشية التي تقع في الثريحة الأعلى، وينم هذا في هذه المرة أيضاً

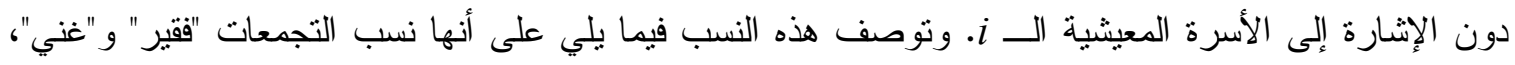
مع تعريف الفقر و الغنى بصورة نسبية. 


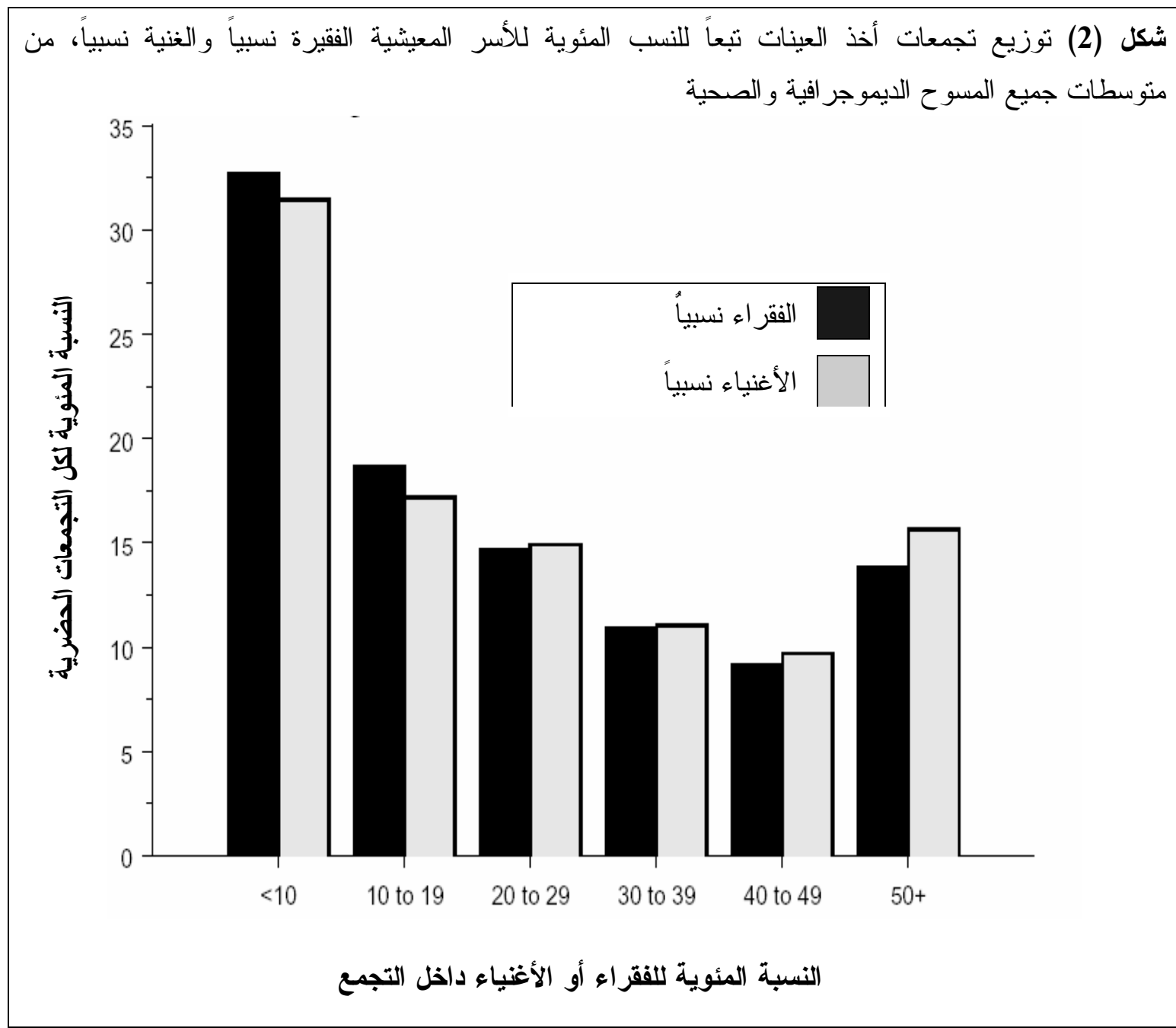

وبالنظر إلى تجمعات أخذ العينات في المسوح الديموجر افية و الصحية، ربما نسأل أولاً ما إذا كانت هناك أدلة على

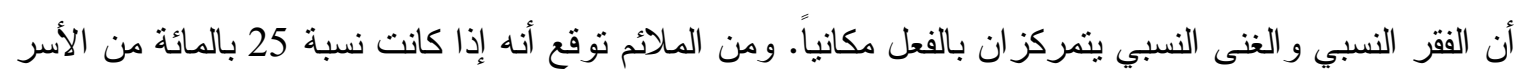

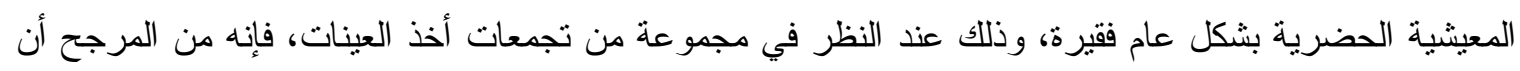
نجد بعض التجمعات ذات التركزات بالغة الارتقاع للفقر وتجمعات أخرى تكون فيها الأسر المعيشية الفقيرة فليلة

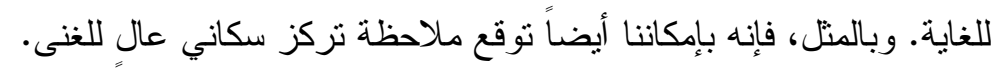

و على الرغم من كون هذه التوقعات معقولة، فإن النتائج التي أسفرت عنها المسوح الديموجر افية و الصحية لا تقدم لها ما يكفي من الدعم. فنرى قدراً أكبر من التتافر في نركيب التجمعات مما كان منوقعاً. ونقوم بتوثيق هذا التنافر

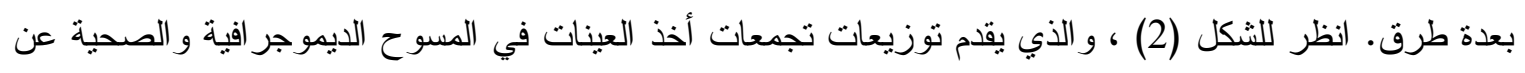
طريق نسبة التجمع الخاصة بالفقر النسبي و الغنى النسبي (تتابه النتائج الخاصة بكل إقليم، وغير المبينة، إلى حد كبير المتوسطات المبينة هنا). ونجد أنه في حوالي ثلث التجمعات الحضرية، تكون أقل من 10 بالمائة من الأسر

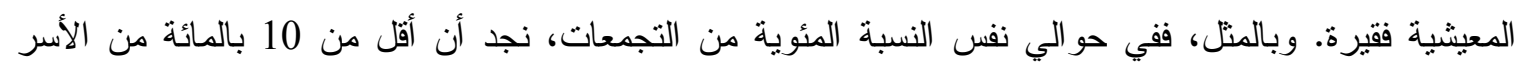


المعيشية تتمتع بثر اء نسبي (بمعنى أنها تنتمي للثريحة الأعلى لجميع الأسر المعيشية الحضرية). ويدل العمودان

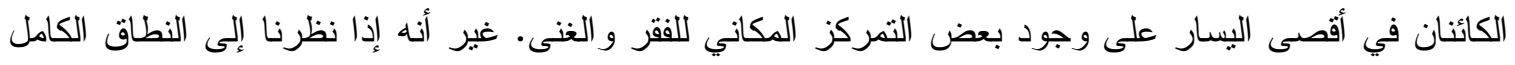

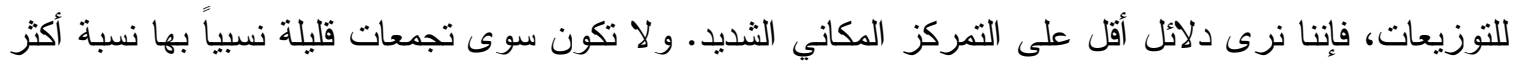

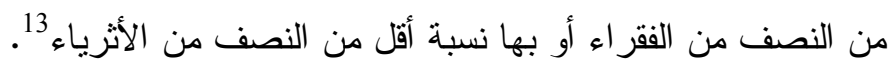

ويمكن للثكلين (3 و4) ، اللذين يشيران إلى جميع المسوح في تحليلنا، أن يوضحا الأمور بصورة أفضل. ففي أول هذين الثكلين، نقوم بتثخيص جيران الأسر المعيشية الفقبرة. فإذا كانت الأسر المعيثية الفقيرة محاطة فعلاً

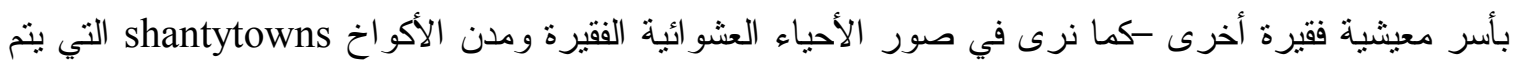

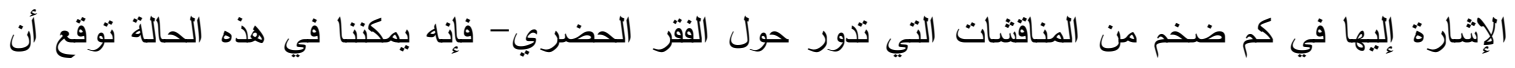

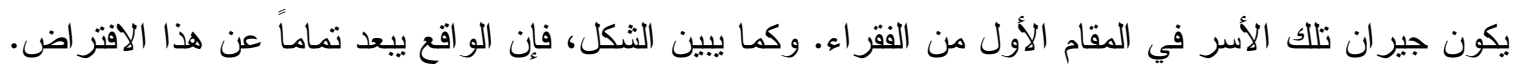

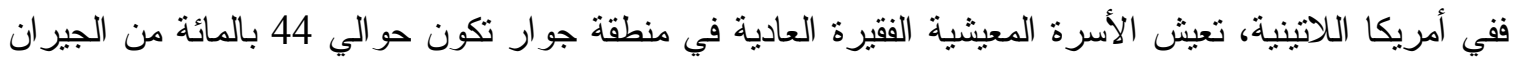

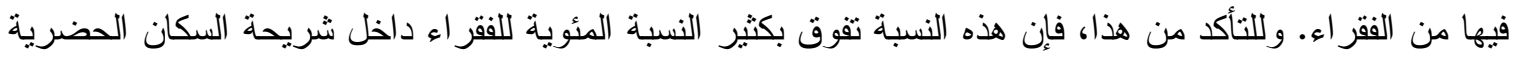
بأكملها (25 بالمائة وفقاً لتعريفنا للفقر)، بيد أنها تترك مساحة ضخمة للجير التهان الذان الذين يحتلون مر اكز النسب المئوية

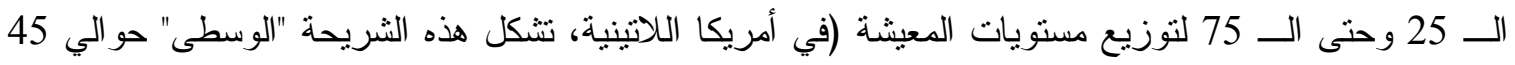

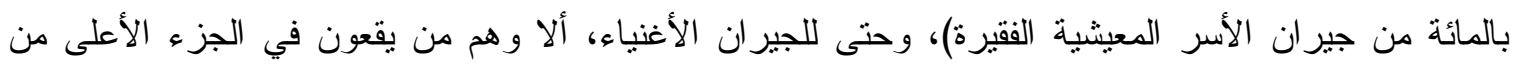

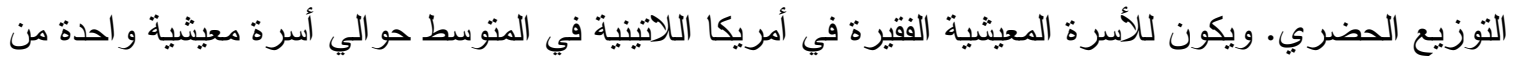
كل عشر أسر تجاور ها من الأغنياء.

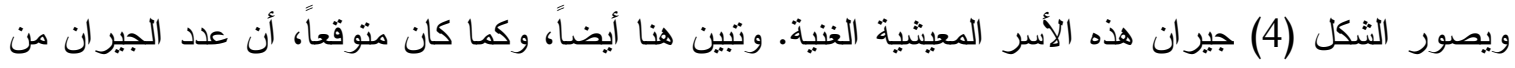

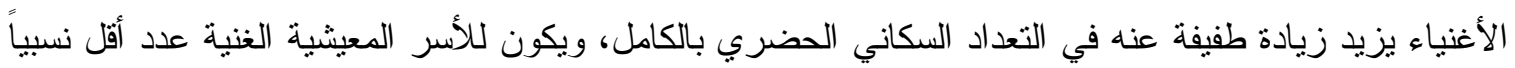

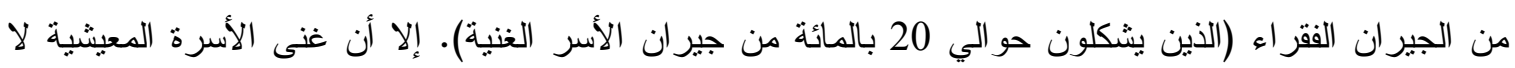
ينم بشكل قاطع عن تركيبة منطقة الجوار التي تعيش فيها- إذ تبتعد بنسبة طفيفة عن حدود الثنريحة الــ الــ 25

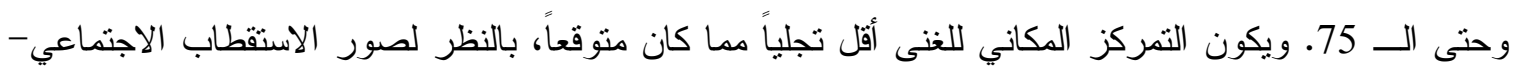
المكاني الصار خ الذي يظهر بثكل متكرر في المر اجع.

ويرسم جدول (6) صورة للاتجاهات المحورية وأوجه التتافر الرئيسية من حيث العلاقات المتبادلة بين رقم عامل مستويات المعيشة بالنسبة للأسرة المعيشية من ناحية، ومجموعة من المقاييس على مستوى التجمعات بالنسبة

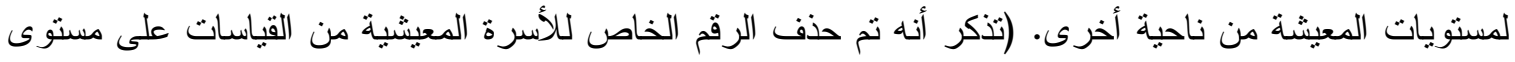

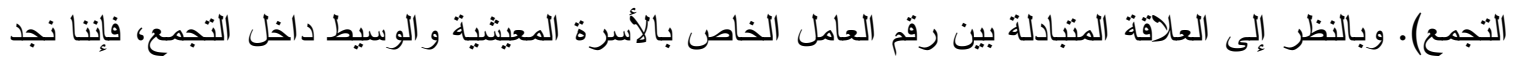

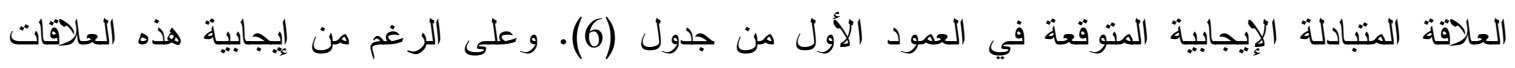

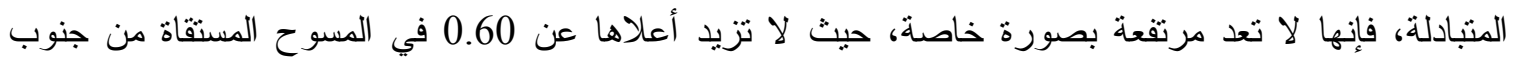

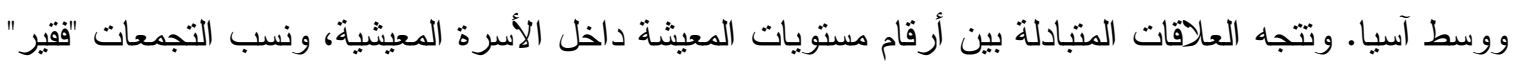


و"أفضل حالاً" (كما هو مبين في آخر عمودين من الجدول) بالمنل في الاتجاهات المتوقعة وإن كانت نتقى منو اضعة حجماً.

وبايجاز، ونظراً لأننا اعتبرنا أن رقم العامل المقدر هو مقياس لمستوى المعيشة، ونظر اً لأننا بحثنا في التركيب الداخلي للتجمعات في هذا البعد، فإننا نجد بعض الدعم للافتر اض الخاص بالتمركز المكاني للفقر و الغنى، ولكن

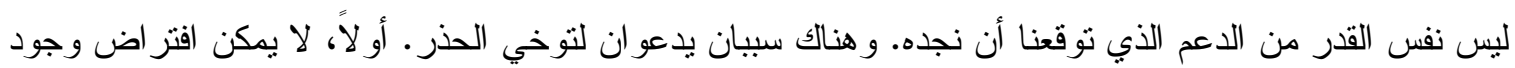
تفاعل بين الأسر المعيشية التي تقطن نفس المساحة المحلية، أو أنه يمكن حتى اعتبارها نقاط مقارنة ذات صلئة. ويشار إلى أن مر اجع أمريكا اللاتينية تكون مفيدة بشكل خاص فيما يتعلق بالأشكال غير المكانية للإقصاء و الفصل الفيل

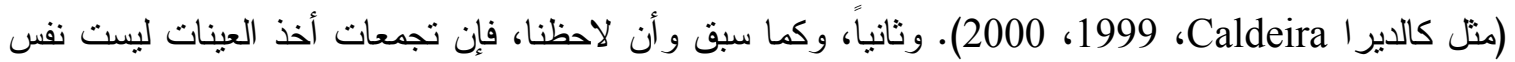
الثيء كمناطق الجو ار، و لا يعرَّ شيء تقريباً عن مدى الاختلاط بينها وبين تصميمات أخذ العينات في المسوح الديموجر افية و الصحية.14

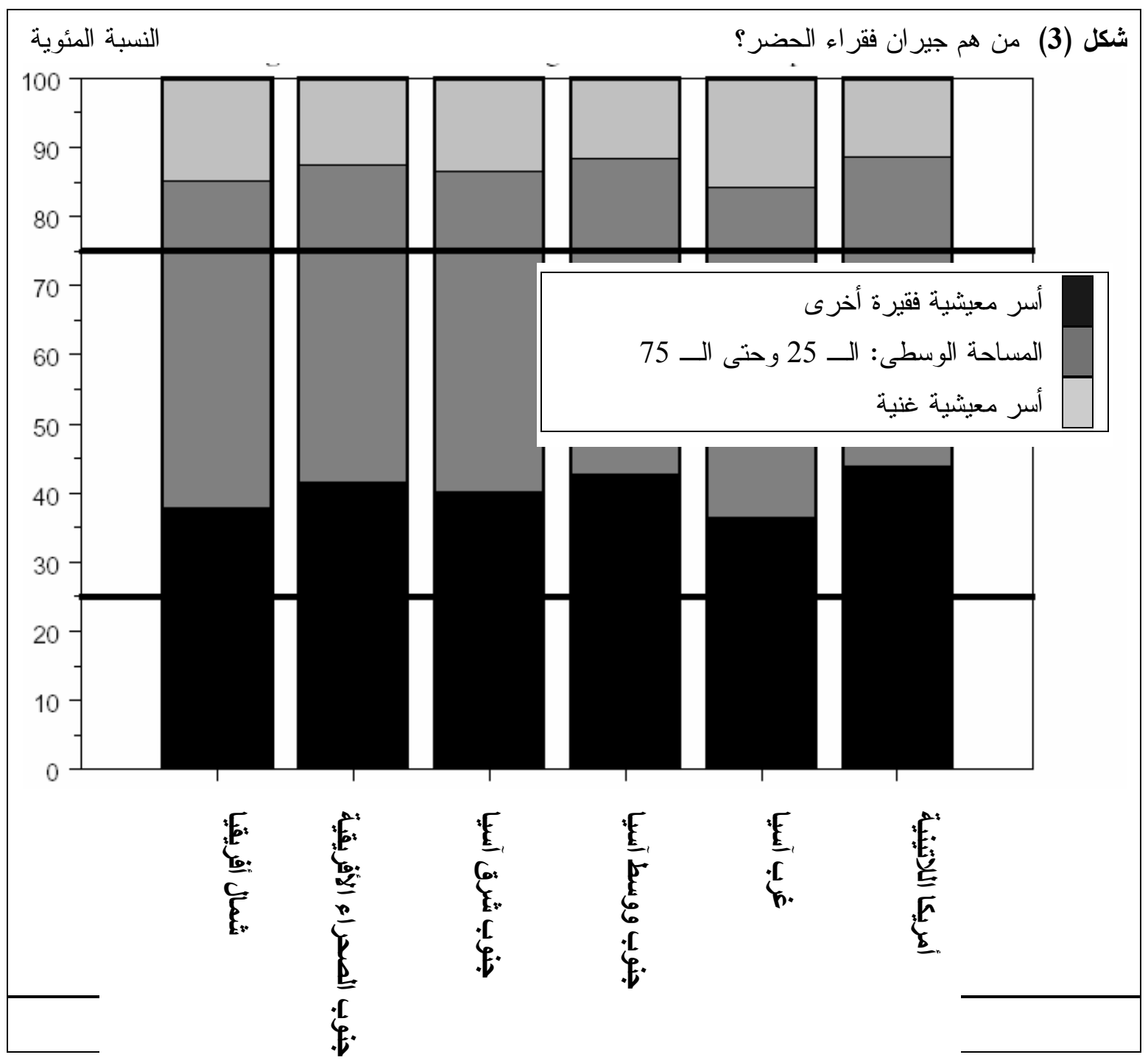




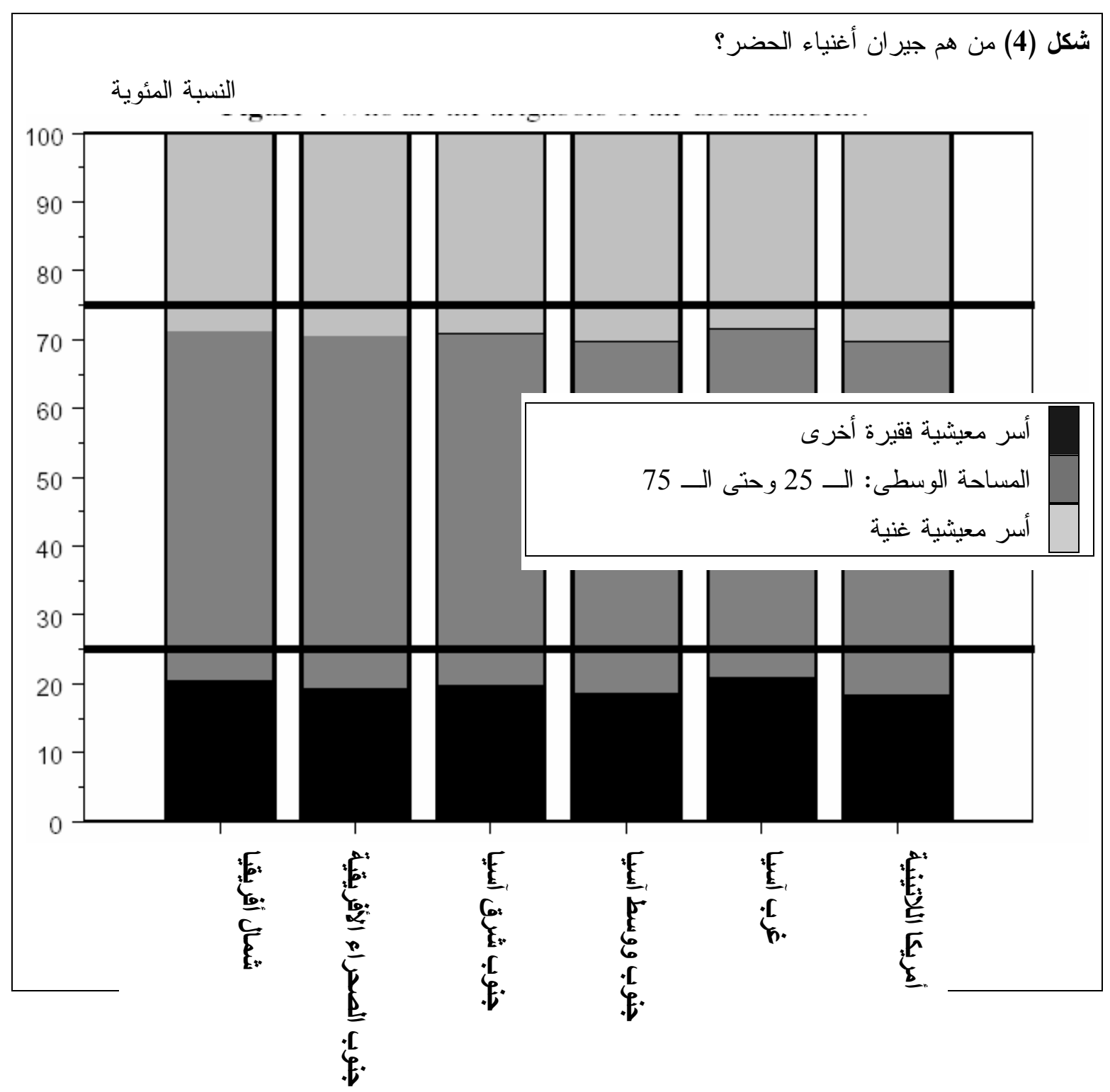

جدول (6) العلاقات المنبادلة بين الارقام الخاصة بالاسر المعيشية وتلك الخاصة بعو امل التجمعات، تبعا للمنطقة

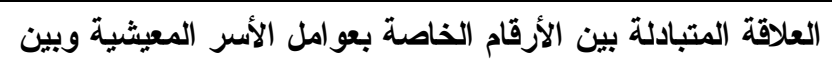

\begin{tabular}{|c|c|c|c|c|}
\hline نسبة أغنياء التجمعات & نسبة فقراء التجمعات & a a وسيط أرقام التجمعات & & المنطقة \\
\hline 0.43 & -0.45 & 0.50 & & شمال إفريقيا \\
\hline \multirow[t]{2}{*}{0.51} & -0.48 & 0.56 & الصحر اء & منطقة جنوب \\
\hline & & & & الإفريقية \\
\hline 0.46 & -0.49 & 0.53 & & جنوب شرق آسيا \\
\hline 0.54 & -0.53 & 0.60 & & جنوب ووسط آسيا \\
\hline 0.41 & -0.41 & 0.47 & & غرب آسيا \\
\hline 0.50 & -0.53 & 0.58 & & أمريكا اللاتينية \\
\hline
\end{tabular}


الحاجة غير الملباة، والتواجد خلا الولادات، والطول بالنسبة للسن

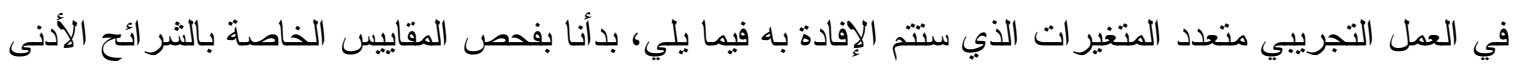

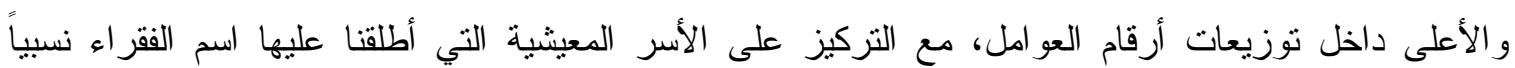

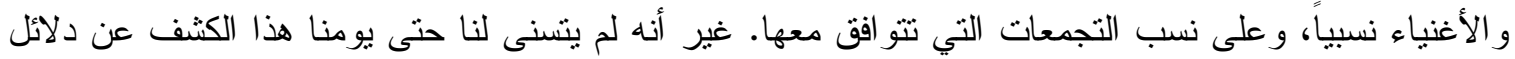

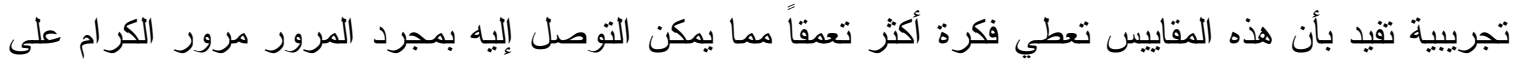

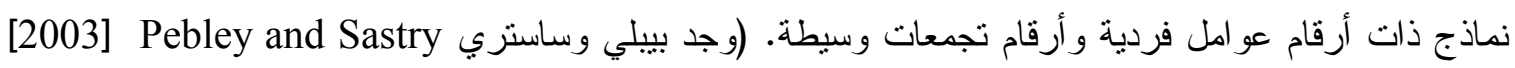

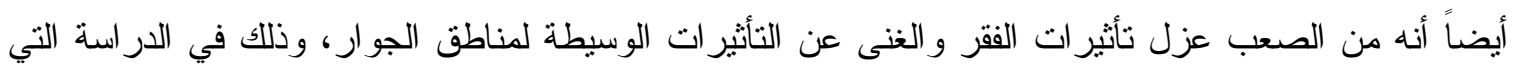
أجرياها حول مناطق الجوار في لوس أنجلوس. وعلى الرغم من وجود حاجة للقيام بمزيد من العمل حول التهل التخصيصات التي تتضمن الفقر و الغنى النسبيين، فإنه يتم بيان النماذج التي نلجأ إليها الآن بطريقة أبسط.

وتستتد النماذج الخاصة بالحاجة غير الملباة و التو اجد خلال الولادات على ارتدادات بروبيت probit عن الأسرة

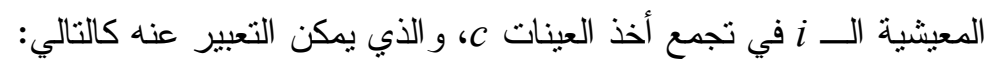

$$
\operatorname{Pr}\left(Y_{\mathrm{ic}}=1 \mid \mathrm{W}_{\mathrm{ic}} \cdot f^{\wedge}{ }_{i c^{\prime}}, f^{\wedge c}{ }_{i}\right)=\Phi\left(W^{\prime}{ }_{\mathrm{ic}} \theta+f^{\wedge}{ }_{i c} \delta+f^{\wedge c}{ }_{i} \delta_{c}\right)
$$

حيث تكون $\Phi$ هي العامل القائم بالتوزيع التزاكمي الطبيعي القياسي، بينما تعبرWic عن مجموعة المتغيرات

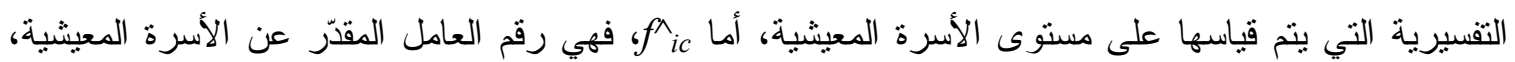
و

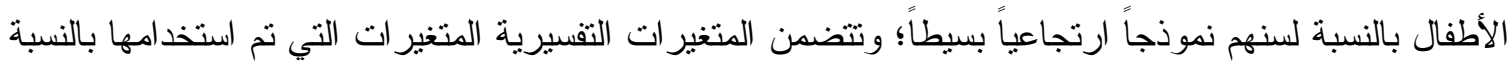

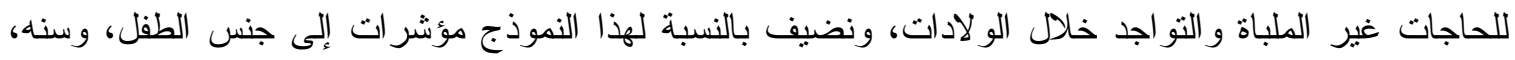

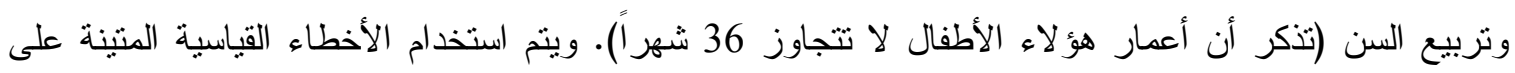

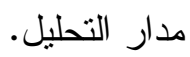

وفي سبيل تتقية عدد أكبر من تقدير ات المعامل لتصبح كميات يسهل تفسير ها، فإننا نوجز ها بالطريقة التالية. فنقوم

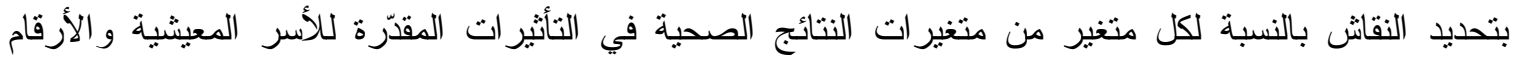

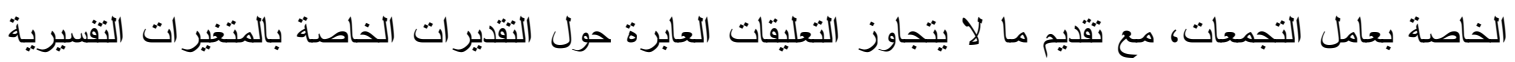
الأخرى. ونقوم بوصف مدى النكر ار الذي تحصل به معاملات أرقام العامل على أهمية إحصائية ومدى تكرار أهيتها، فضلاً عن العلامة المنوقعة.

ثم نقوم برسم حجم نأثير مستويات المعيثة بطريقتين. انظر إلى تحليل الحاجات غير الملباة. ولتلخيص نأثيرات مستويات المعيشة، فإننا نقوم بحساب الاحتمال المتوقع لوجود حاجة غير ملباة للمر أة، هي iأ، بالنظر إلى متغير اتها

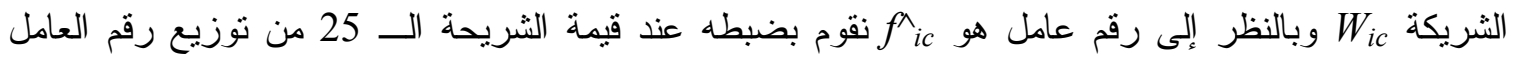




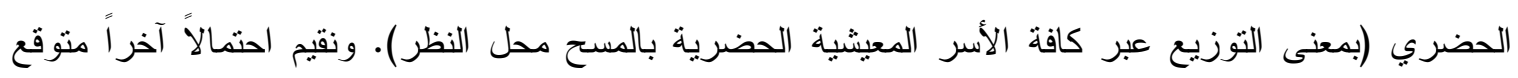

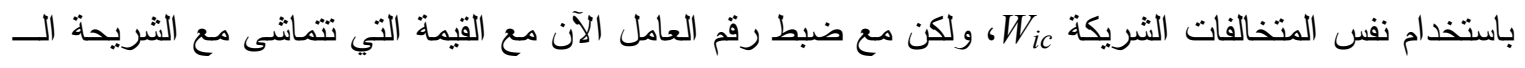

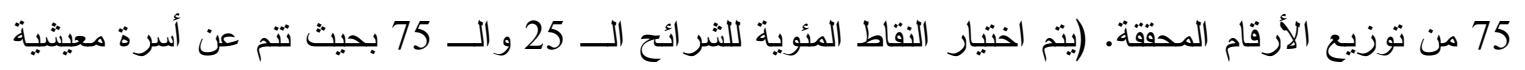
فقيرة نسبياً وأخرى غنية نسبياً). ونقوم بتحديد منوسطات النوقام النقات

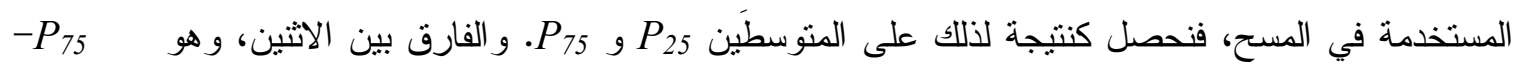

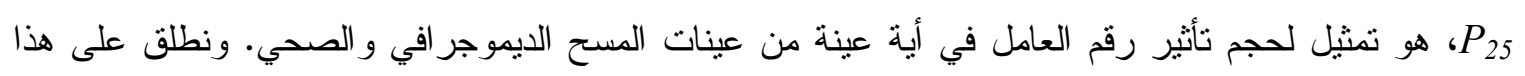

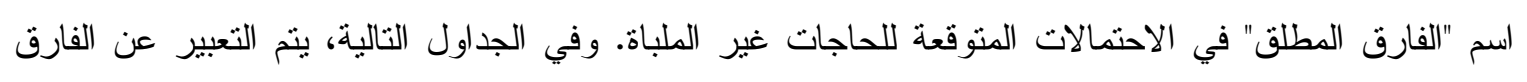

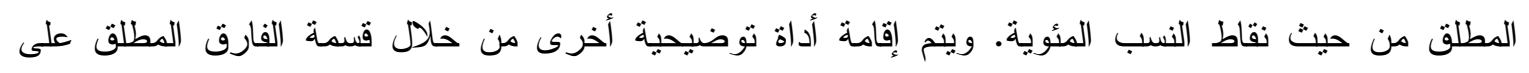
المستوى المتوسط للحاجة غير الملباة في العينة الحضرية من المسح، فنكون النتيجة

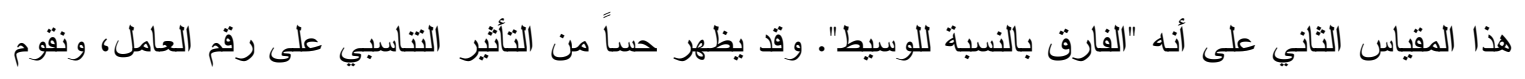
بالإفادة بهذه الفروق النسبية من حيث النسب النب المئوية.

ويتم إتباع منحي مشابه في وصف نأثير ات رقم العامل على المستوى الوسيط للتجمع، على الرغم من أنه تؤخذ

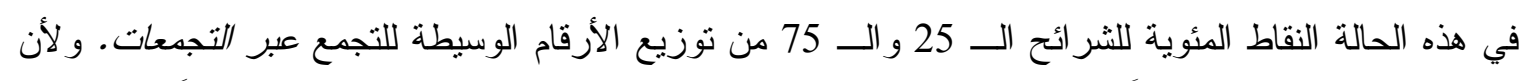

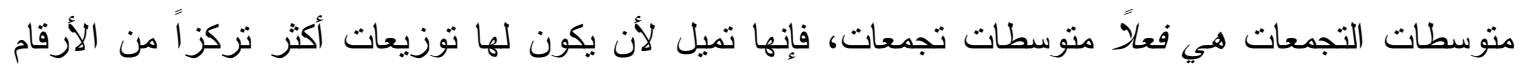

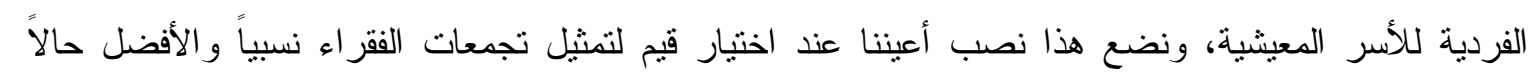

\section{نماذج بعوامل الأسر المعيشية وحدها}

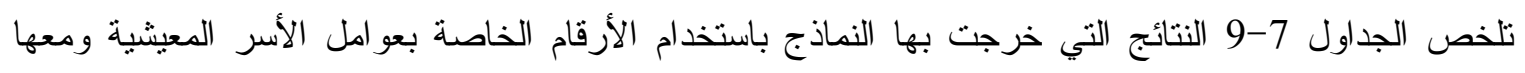

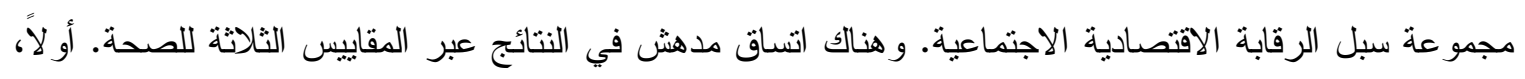

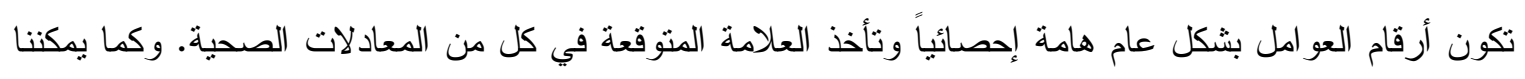

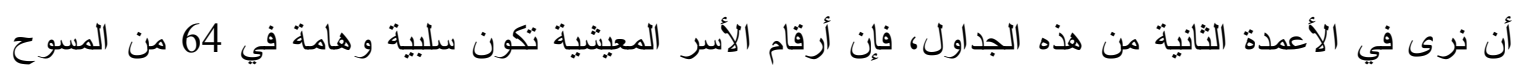

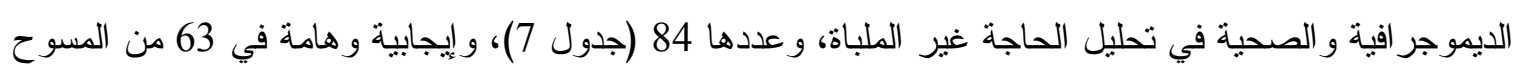

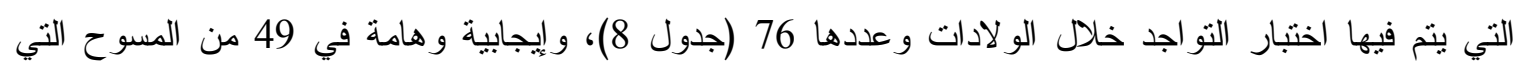

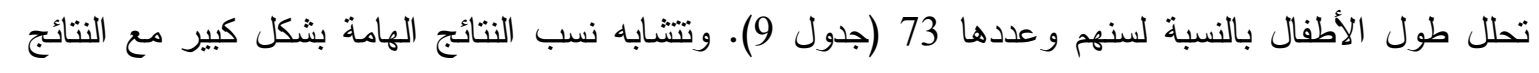
الخاصة بتعليم الأمهات، كما ينبين من الملاحظات الملحقة بالجداول.

ويتم إيجاز التداعيات الجو هرية للأرقام الخاصة بالأسر المعيشية في الأعدة المتنقية من هذه الجداول. فنركز أولاًا

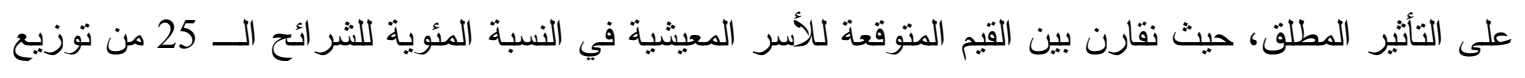

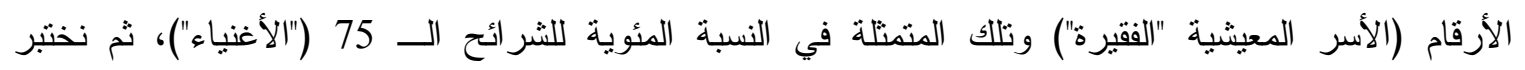

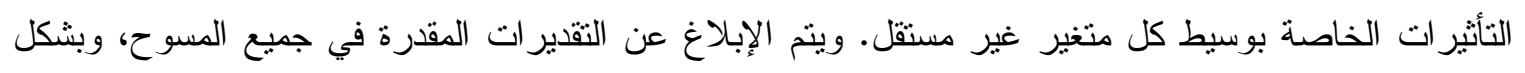


منفصل في المسوح الني وجد فيها معامل هام إحصائياً. وبالنسبة لتحليل الحاجة غير الملباة (جدول 7)، نجد أن

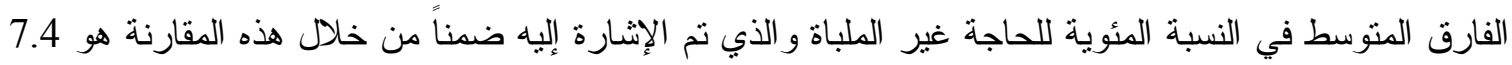
نقطة مئوية في العينة الكاملة (راجع سطر "الإجمالي") و 8.7 نقطة مئوية في العينة ذات النتائج الهامة.

\begin{tabular}{|c|c|c|c|c|c|}
\hline \multicolumn{4}{|c|}{ تأثير رقم العامل الخاص بالأسرة المعيشية } & \multirow{3}{*}{ رقم العامل سلبي } & \multirow[t]{3}{*}{ 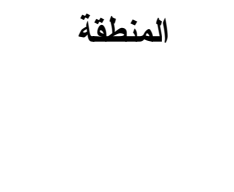 } \\
\hline \multicolumn{2}{|c|}{ الفارق بالنسبة للوسيطع } & \multicolumn{2}{|c|}{ الفارق المطلق b } & & \\
\hline 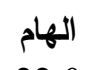 & 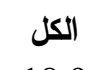 & الهام & 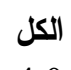 & & \\
\hline 22.0 & 18.9 & 4.9 & 4.0 & 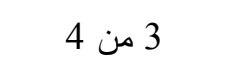 & شمال إفريقيا \\
\hline \multirow[t]{3}{*}{28.1} & 22.9 & 11.5 & 9.5 & 31 من 42 & منطقة جنوب \\
\hline & & & & & الصحر اء \\
\hline & & & & & 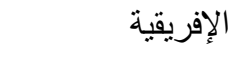 \\
\hline 24.8 & 17.3 & 5.7 & 4.5 & 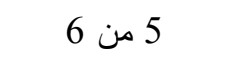 & جنوب شرق آسيا \\
\hline 26.6 & 22.7 & 7.1 & 5.2 & 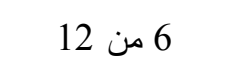 & و وسط \\
\hline 28.0 & 22.5 & 4.8 & 3.9 & 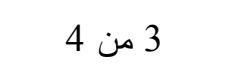 & غرب آسيا \\
\hline 31.1 & 31.1 & 6.3 & 6.3 & ا & أمريكا اللاتينية \\
\hline 28.1 & 23.8 & 8.7 & 7.4 & 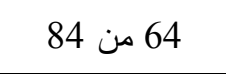 & الإجمالي \\
\hline
\end{tabular}

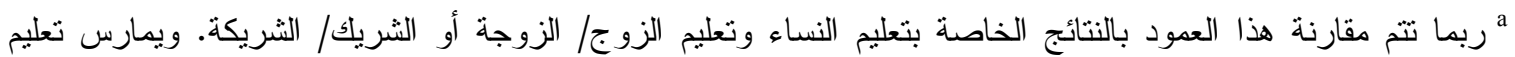

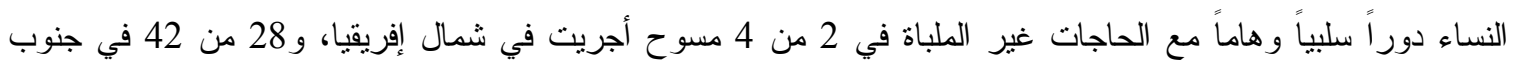

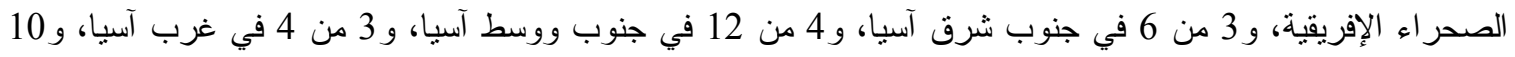

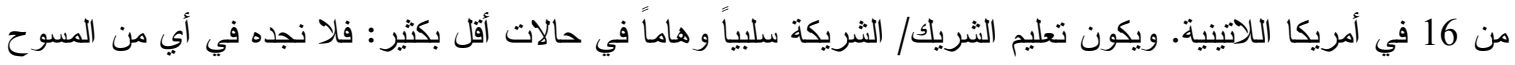

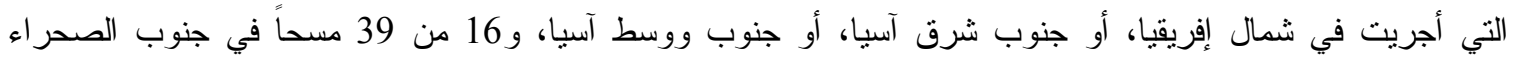

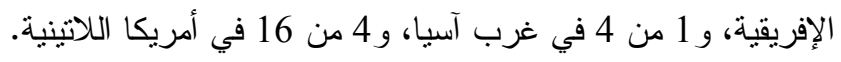

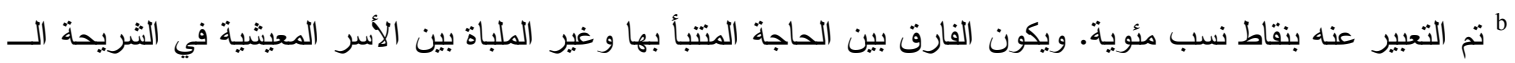

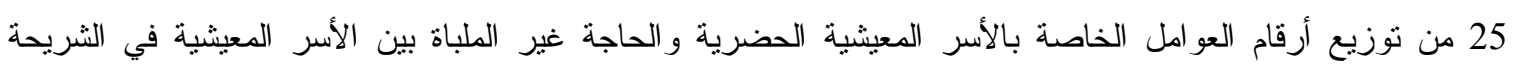

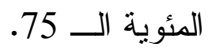
" تم التعبير عنها بالنسبة المئوية للحاجة الوسيطة غير اللمباة في العينات الحضرية. 
جدول (8) ملخص للتقدير ات الخاصة بتو اجد طبيب، أو ممرضة، أو قابلة مدربة خلال الو لادات، باستخدام الأرقام الخاصة

\begin{tabular}{|c|c|c|c|c|c|}
\hline \multicolumn{4}{|c|}{ تأثير رقم العامل الخاص بالأسرة المعيثية } & 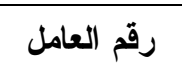 & المنطقة \\
\hline \multicolumn{2}{|c|}{ الفارق بالنسبة للوسيطc } & \multicolumn{2}{|c|}{ bارق المطلق القارق } & إيجابي وهامª & \\
\hline الهام & الكل & الهام & الكل & & \\
\hline 11.6 & 11.6 & 7.1 & 7.1 & 4 من 4 & 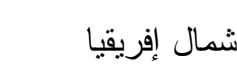 \\
\hline \multirow[t]{2}{*}{20.2} & 18.7 & 12.9 & 10.7 & 31 من 39 & منطقة $\quad$ الصحر اء \\
\hline & & & & & الإفريقية \\
\hline 19.5 & 14.9 & 14.3 & 10.8 & 4 من 5 & جنوب شرق آسيا \\
\hline 47.6 & 47.6 & 18.8 & 18.8 & 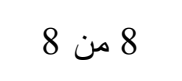 & 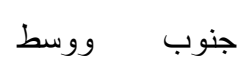 \\
\hline 9.4 & 7.6 & 5.3 & 4.4 & 3 من 4 & غرب آسيا \\
\hline 16.4 & 13.8 & 9.4 & 7.9 & 13 من 16 & 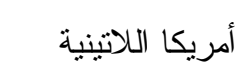 \\
\hline 21.8 & 19.5 & 12.3 & 10.4 & 63 من 76 & 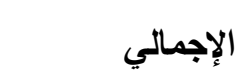 \\
\hline
\end{tabular}

ملاحظة: لم تقم المسوح التي أجريت في كل من إثيوبيا 1999، و النيجر 1998، والفلبين 1998 بجمع بيانات حول التواجد

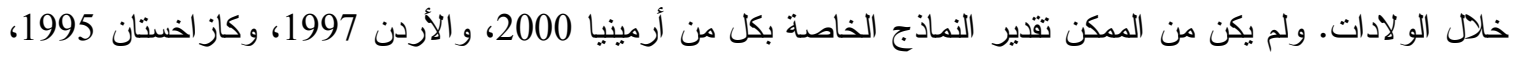

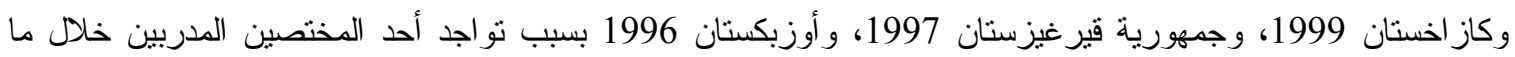
يكاد يكون جميع الو لادات.

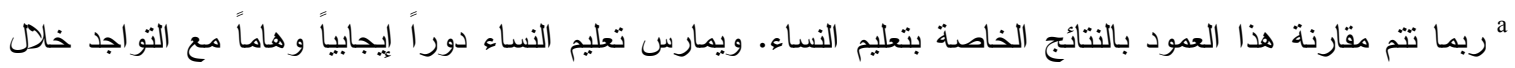

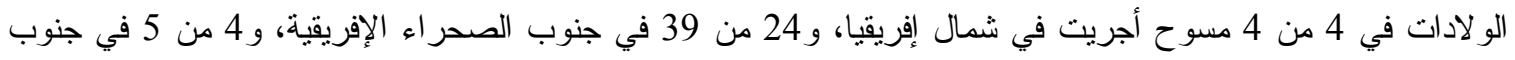

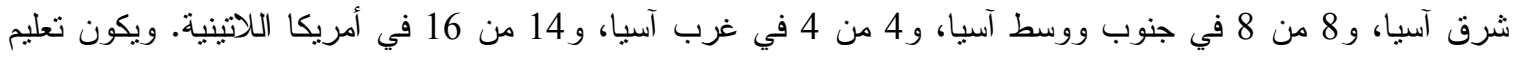

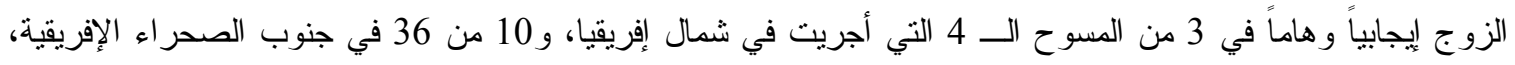
و3 من 5 في جنوب شرق آسيا، و3 من 8 في جنوب ووسط آسيا، و2 من 4 في غرب آسيا، و6 من 16 في أمريكا اللاتينية.

b تم التعبير عنه بنقاط نسب مئوية. ويكون الفارق بين التواجد المتتبأ به خلال الولادات بين الأسر المعيشية في الثريحة الـــ

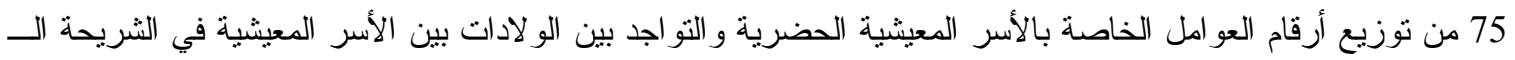




\begin{tabular}{|c|c|c|c|c|c|}
\hline \multicolumn{4}{|c|}{ تأثير رقم العامل الخاص بالأسرة المعيشية } & \multirow{3}{*}{ 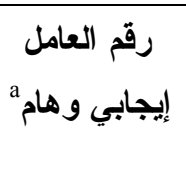 } & \multirow[t]{3}{*}{ المنطقة } \\
\hline \multicolumn{2}{|c|}{ الفارق بالنسبة للوسيطc } & \multicolumn{2}{|c|}{ bارق المطلق الفارق } & & \\
\hline الهام & الكل & الهام & الكل & & \\
\hline 45.2 & 19.7 & 0.252 & 0.123 & 1 & شمال إفريقيا \\
\hline \multirow[t]{2}{*}{36.1} & 29.7 & 0.398 & 0.322 & 25 من 39 & الصحرة اء $\quad$ جنوب \\
\hline & & & & & الإفريقية \\
\hline 20.9 & 23.2 & 0.322 & 0.212 & 5 من 11 & 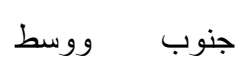 \\
\hline 49.5 & 42.7 & 0.224 & 0.211 & 3 من 5 & غرب آسيا \\
\hline 42.6 & 42.6 & 0.328 & 0.328 & 15 من 15 & 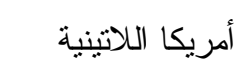 \\
\hline 37.6 & 31.8 & 0.355 & 0.291 & 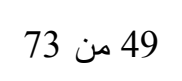 & 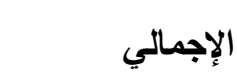 \\
\hline
\end{tabular}

a ربما تتم مقارنة هذا العمود بالنتائج الخاصة بتعليم النساء. ويمارس تعليم النساء دوراً إيجابياً وهاماً مع طول الأطفال

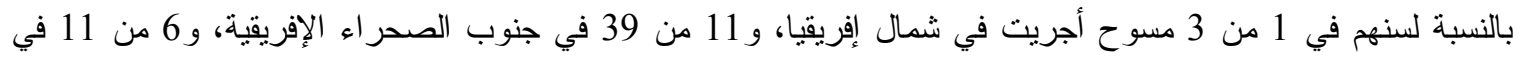

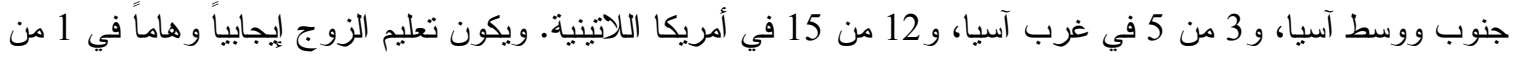

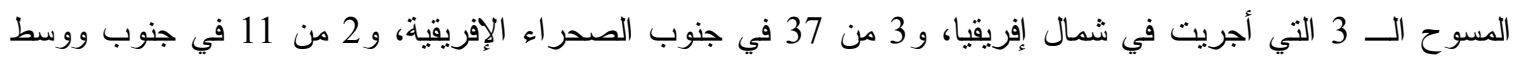
آسيا، و2 من 5 مسوح في غرب آسيا، و 5 من 15 في أمريكا اللاتينية. نم التعبير عنه عن طريق الانحر افات المعيارية، في الوحدات التي ينم فيها بيان الطول بالنسبة للسن. ويكون الفارق بين

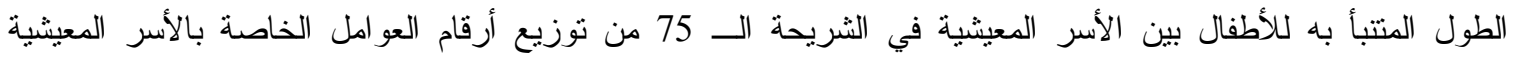

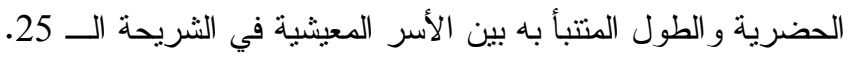
c c التعبير عنها بالنسبة المئوية للطول الوسيط بالنسبة للسن في العين العينات الحضرية. 
و على مستوى المناطق، نجد أن أكبر التأثثرات المطلقة نوجد في منطقة جنوب الصحراء الإفريقية و أمريكا اللاتينية. وعندما تتم ترجمة هذه التأثيرات المطلقة إلى قيم نسبية (آخر عمودين من الجدول)، نجد أن الفارق

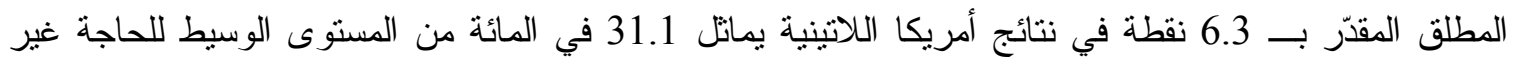
الملباة. وتككن التأثيرات النسبية لعامل الأسر المعيشية بالنسبة للأقاليم الأخرى بشكل عام أصغر من ذلك، وإن فئن

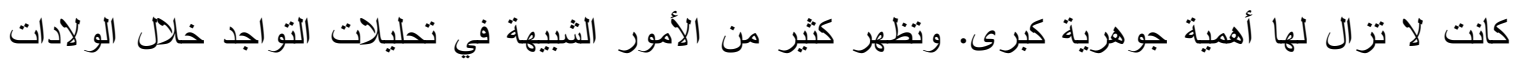
وطول الأطفال بالنسبة لسنهم، والتي يتم اختصارها في الجدولين 8 و99. ويكون التأثير المقدر لعامل مستويات

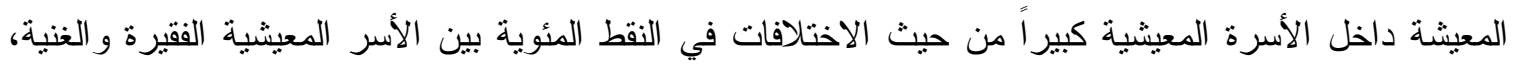

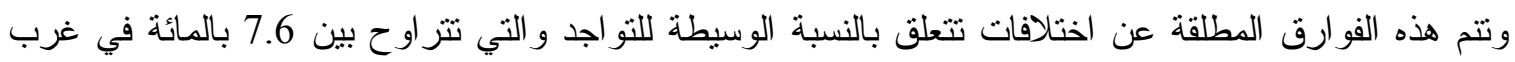
آسيا و47.6 بالمائة بالنسبة للحالات الهامة في جنوب ووسط آسيا. أما بالنسبة لنماذج الطول بالنسبة للسن (جدول 9)، حيث ينم التعبير عن التأنثر ات المطلقة من حيث الانحر افات المعيارية من الوسيط المرجعي، يكون الاختلاف

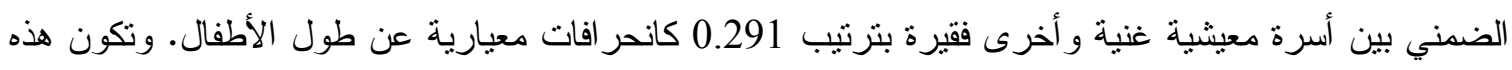
الاختلافات كبيرة إلى حد ما من حيث القيمة النسبية، لاسيما في أمريكا اللاتينية. ويتضح، حتى داخل دئل القطاعات الحضرية التي تكون عموماً مزودة بشكل أفضل بخيار ات المواصلات و الخدمات الصحية، فإن مستوى المعيشة

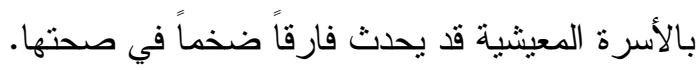

\section{نماذج تضم أرقاماً تخص الأسر المعيشية وعامل التجمعات}

في سبيل وزن الأدلة الخاصة بـ "تأثثرات منطقة الجوار"، فإننا نضيف الآن وسيط التجمعات الخاصة بأرقام عو امل الأسر المعيشية إلى النماذج، مع الاحتفاظ بجميع المتغيرات الثريكة ورقم العامل الخاص بالأسرة

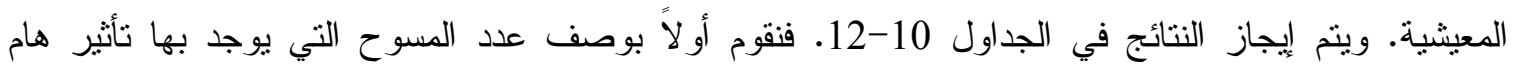
بالنسبة لمتغير التجمع، ونتحقق كذلك من أهمية أرقام الأسر المعيثية لتحديد ما إذا كان يمكن حقاً تمييز تأثير ات الأسر المعيشية المنفصلة وثأثثرات التجمعات. ثم نقوم بوصف تأثنير أرقام التجمعات، مقارنين القيم المتوقعة بالثريحة الـــ 25 من توزيع رقم التجمع (التجمعات "الفقيرة") بالقيم الو اقعة في النسبة المئوية الـــ 75 (التجمعات

وبشكل عام، لا تكون العو امل على مستوى التجمعات هامة إحصائياً بنفس قدر العوامل الفردية للأسر المعيشية، ولا تتأثر أهمية عو امل الأسر المعيشية في الواقع سوى قليلاً بتضمين مقاييس التجمعات. (يضم كل جدول عموداً

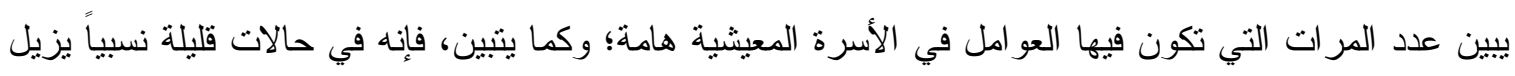

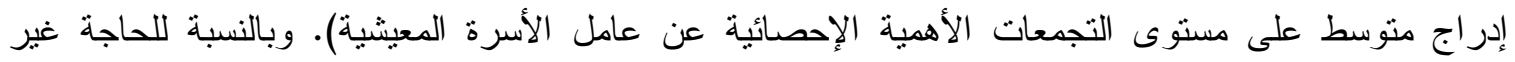
الملباة، يكون الرقم الوسيط للتجمع سلبياً وهاماً في 16 من المسوح الـــ 84 التي نم اختبارها (جدول 10)؛ ويكون الإنه إيجابياً وهاماً في 53 من الحالات الخاصة بالتو اجد خلال الولادات و عددها 76 حالة (جدول 11)؛ ويكون إيجابياً

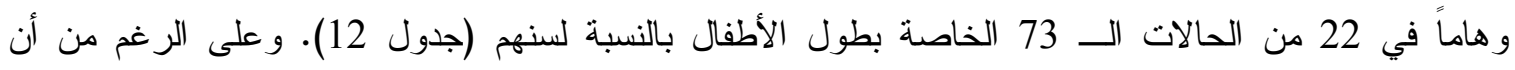

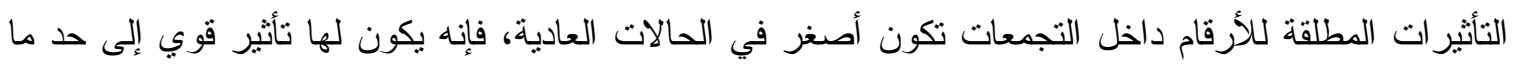


على المقاييس الثلاثة الخاصة بالصحة، وحيث تكون الثأثيرات في أبرز حالاتها في حالة التو اجد خلال الولادات. فإذا ما تمت ترجمة الثأثثرات المطلقة إلى شروط نسبية، فإنه يمكن اعتبار أن لها أهمية جوهرية.

جدول (10) ملخص للنقيرات الخاصة بالحاجات غير الملباة لنع الحمل الحديث، باستخدام الأرقام الخاصة بمتوسط العامل

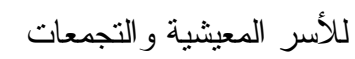

\begin{tabular}{|c|c|c|c|c|c|c|}
\hline \multicolumn{4}{|c|}{ تأثير رقم العامل التجمع الوسيط } & رقم الأسرة & رقم التجمع & المنطقة \\
\hline \multicolumn{2}{|c|}{ الفارق بالنسبة للوسيطb } & \multicolumn{2}{|c|}{ a الفارق المطلق a } & المعيشية & سلبي وهام & \\
\hline 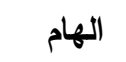 & الكل & الهام & 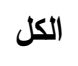 & سلبي وهام & & \\
\hline 13.2 & 10.1 & 2.9 & 2.1 & 3 من 4 & 2 & شمال إفريقيا \\
\hline 23.9 & 4.3 & 8.1 & 2.0 & 24 من 42 & 5 من 42 & الصنطرة جنوب \\
\hline - & 4.0 & - & 0.3 & 5 من 6 & 0 من 6 & جنوب شرق \\
\hline 18.6 & 6.1 & 3.0 & 1.5 & 7 من 12 & 2 من 12 & جنوب وسط \\
\hline 28.1 & 19.4 & 4.9 & 3.4 & 3 من 4 & 3 من 14 & غرب آسيا \\
\hline 22.3 & 7.8 & 5.8 & 1.8 & 14 من 16 & 4 من 16 & أمريكا اللاتينية \\
\hline 22.3 & 5.6 & 5.6 & 1.8 & 56 من 84 & 16 من 84 & الإجمالي \\
\hline
\end{tabular}


جدول (11) ملخص للتقديرات الخاصة بتو اجد طبيب أو ممرضة أو قابلة مدربة خلال عمليات الولادة، باستخدام الأرقام

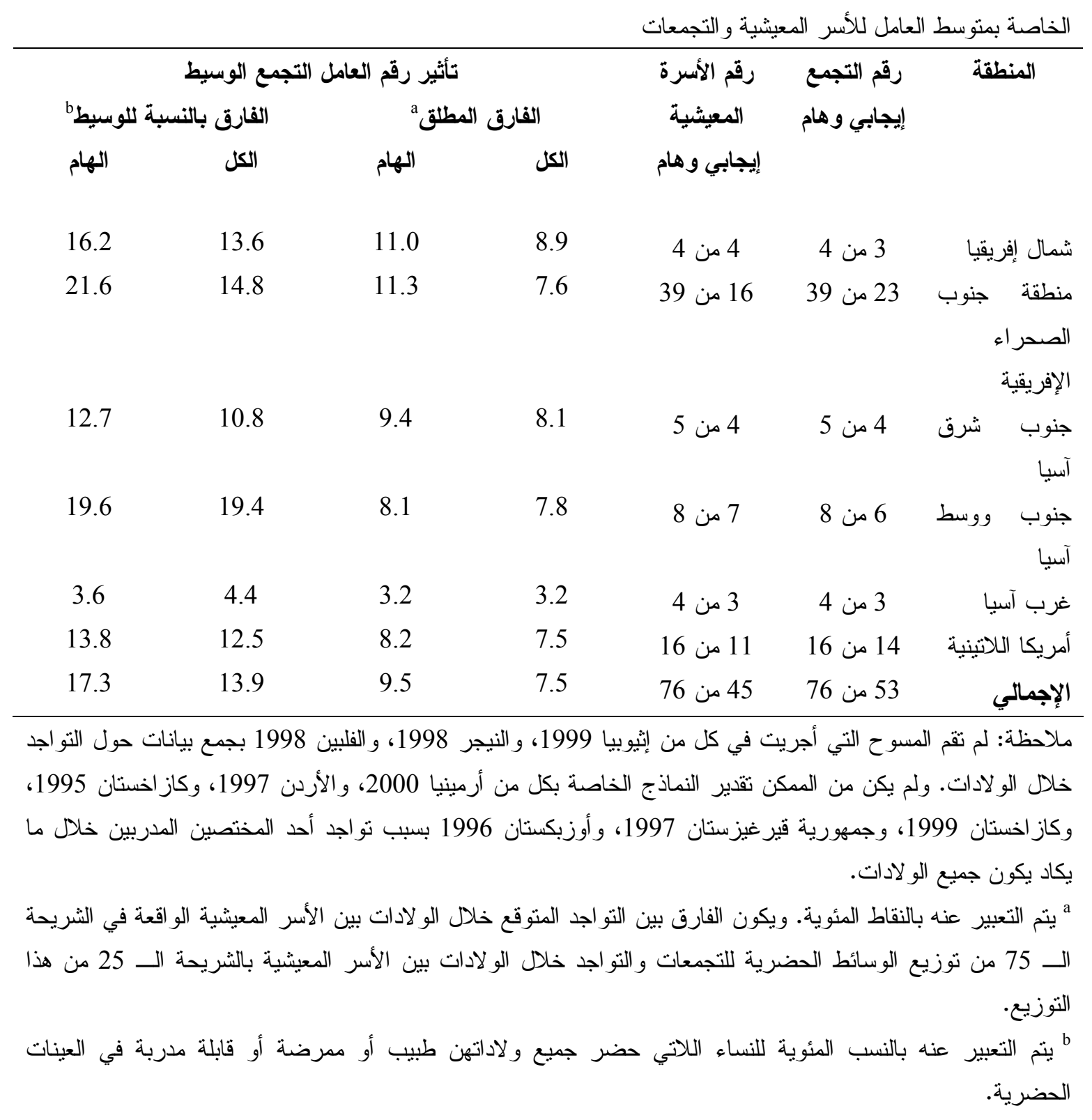


جدول (12) ملخص للتقديرات الخاصة بالطول بالنسبة للسن باستخدام الأرقام الخاصة بمنوسط العامل للأسر المعيشية

\begin{tabular}{|c|c|c|c|c|c|c|}
\hline \multicolumn{4}{|c|}{ تأثثر رقم العامل التجمع الوسيط } & \multirow{3}{*}{ رقايجمابي الأسرة } & \multirow{3}{*}{ رقم التجمع } & \multirow[t]{3}{*}{ المنطقة } \\
\hline \multicolumn{2}{|c|}{ الفارق بالنسبة للوسيطb } & \multicolumn{2}{|c|}{ a الفارق المطلق } & & & \\
\hline الهام & الكل & الهام & الكل & & & \\
\hline 25.4 & 25.4 & 0.174 & 0.174 & | l 1 من 3 & 3 من 3 & شمال إفريقيا \\
\hline 25.8 & 11.3 & 0.253 & 0.107 & 22 من 39 & 5 من 39 & منطقة جنوب \\
\hline & & & & & & الإقريقية \\
\hline 9.1 & 17.0 & 0.145 & 0.151 & 5 من 11 & 2 من 11 & جنوب ووسط \\
\hline 39.7 & 21.7 & 0.181 & 0.104 & 3 من 5 & 2 من 5 & غرب آسيا \\
\hline 35.0 & 24.9 & 0.244 & 0.182 & 14 من 15 & 10 من 15 & أمريكا اللاتينية \\
\hline 29.7 & 16.3 & 0.222 & 0.132 & 45 من 73 & 22 من 73 & الإجمالي \\
\hline
\end{tabular}

ينم التعبير عنه بالنقاط المئوية. ويكون الفارق بين الطول المتوقع بالنسبة للسن بين الأسر المعيشية الواقعة في شريحة الــ

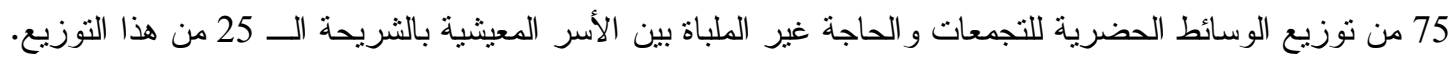
ينم التعبير عنه بالنسب المئوية للطول الوسيط بالنسبة للسن في العينات الحضرية.

كيف يتفق النمط العام للنتائج مع النظريات الخاصة بتأثنرات مناطق الجو ار التي تم إعطاء فكرة عامة عنها سابقاً تشمل المسار ات الرئيسية الثناثة للتأثنر الني نم بيانها العوامل الصحية الخارجية المرتبطة بالأمر اض المعدية؛ و العو امل الخارجية الاجتماعية التي تتبع من الأنماط المحلية للتفاعل، وتدفق المعلومات، وما شابه؛ وتأثيرات توفير الخدمات المحلية.

وقد توقعنا العثور على أوضح تعبير عن نأثثرات مناطق الجوار في التحليلات التي أجريت حول طول الأطفال، لأنه يعتقَ أن نكون العو امل الخارجية الخاصة بالصحة و المخاطر المرتبطة بانتقال العدوى في مناطق الجوار

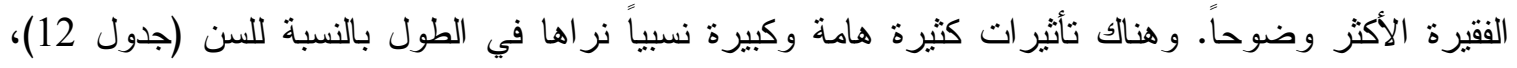

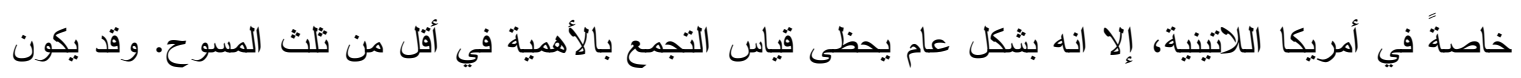
السبب هو أن وسائط التجمعات الخاصة بأرقام مستويات المعيثة تكون ببساطة أبعد بخطوات كثيرة للغاية عن

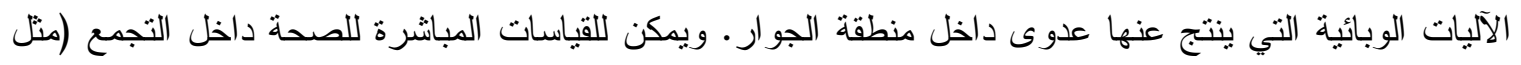
النسب المئوية للأطفال الذين ارتفعت حرارتهم مؤخراً أو أصيبو ا بالإسهال) أن تعزل بشكل أفضل هذا المسار

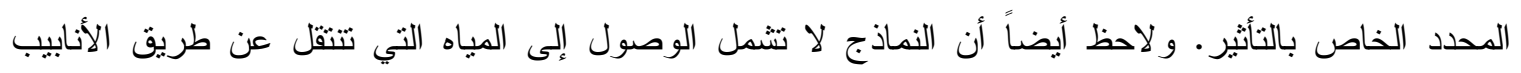
و الصرف الصحي المحسّن، و لابد من فحص هذه القياسات الخاصة بالخدمات قبل الخلوص إلى أية نتائج قاطعة. 
ومن وجهة نظرنا، تكون النتائج التي نربط بين مستويات المعيثة داخل مناطق الجوار بالتو اجد خلال الو لادات

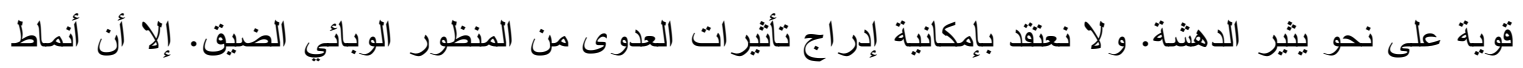

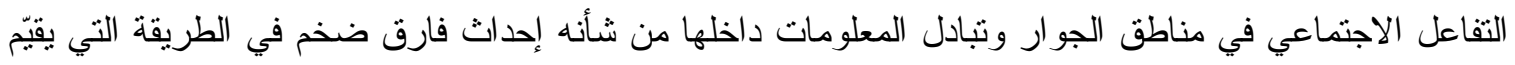

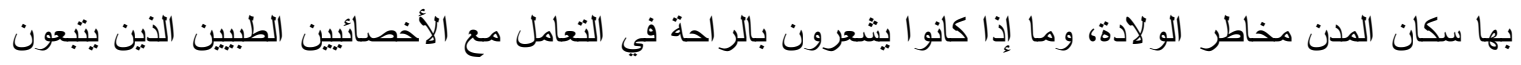

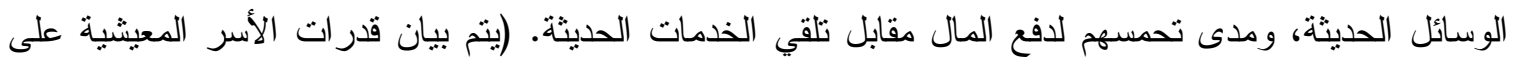
دفع المال في التأثنير القوي للأرقام الخاصة بالعوامل على مستوى الأسرة المعيشية). وتعد هذه أمتلة تمس علم لألم

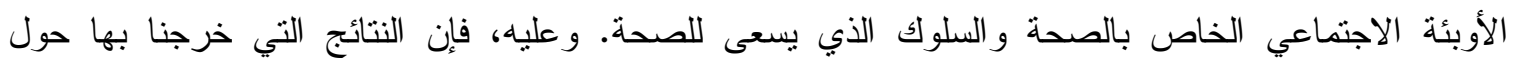
المجتمعات الحضرية قد توازي ما وجده بييلي Pebley و آخرون (1996) بالنسبة للقرى الريفية في جو اتيمالا:

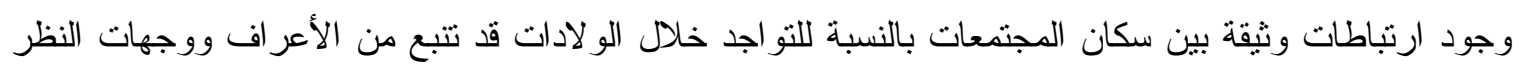
المشتركة حول الرعاية الملائمة خلال الو لادة.

وربما تكون هنالك تفسيرات أخرى للأنماط التي وجدناها. فكما لاحظنا سابقاً، فربما لا تكون مناطق الجوار الحضرية الفقيرة نسبياً مزودة جيداً بالخدمات الصحية التي يقدمها القطاع الخاص، وربما تكون حتى العيادات و المستشفيات الحكومية كائنة في مكان آخر إذا لم تقم الحكومة بما يكفي من الجهد لتقديم خدمات تستهدف الفقر اء.

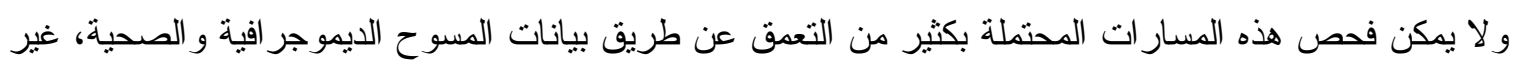
أننا لم نقم بعد باستغلال كافة المقاييس المتاحة و التي توفرها تللك المسوح. فعلى سبيل المثال، وضعت كثير من

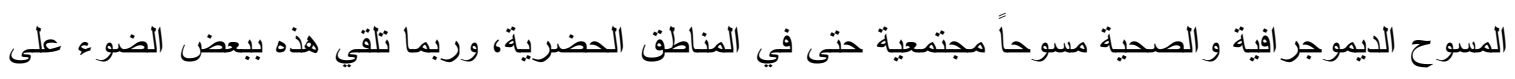
تو افر الخدمات الصحية محلياً.

\section{الخلاصة}

يمكن قر اءة هذه الورقة على أنها ثقرير حالة تحت التنفيذ حول جدول أعمال بحثي لم يكتمل ولم يقترب من الاكتمال. فقد وجدنا أدلة قوية على أن مستويات معيثة الأسر المعيشية، كما يتم قياسها من خلال أرقام للعامل

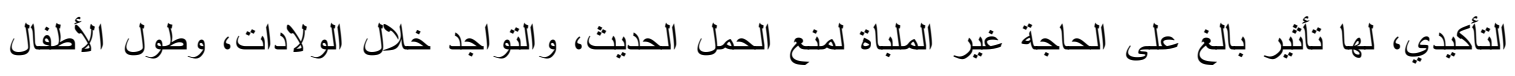

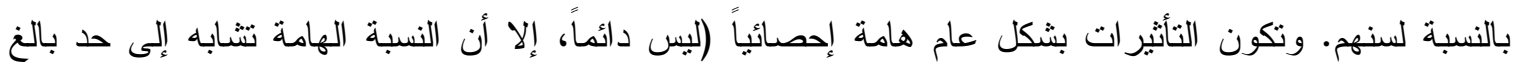

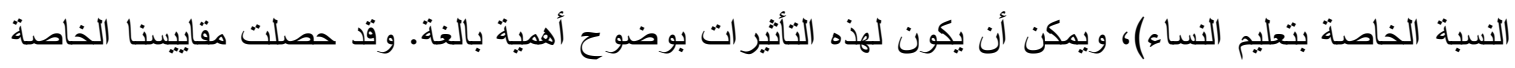
بمسنويات المعيشة على مستوى التجمعات على أهية إحصائية في حالات أقل، إلا أنها عندما كانت هامة، كان

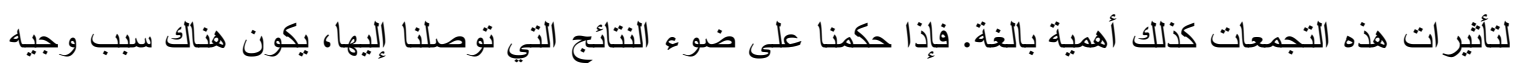
للاعتقاد بأن كلا بعديّ مستويات المعيشة يؤثران على الصحة الحضرية في البلدان النامية. ويبدو أن صحة الأسر المعيثية الفقيرة يمكنها الاعتماد ليس على مستويات معيشة هذه الأسر فحسب، و إنما أيضاً على التركيب الاقتصادي لمناطق الجوار التي تعيش فيها. 
وبينما نفكر في معنى هذه النتائج التجريبية، فإنه يجدر تذكر مدى عدم الدقة التي تتسم بها بعض المقاييس الرئيسية. ويتم قياس مفهوم مستوى المعيشة بطريقة غير منالية عن طريق بعض المؤشرات البسيطة

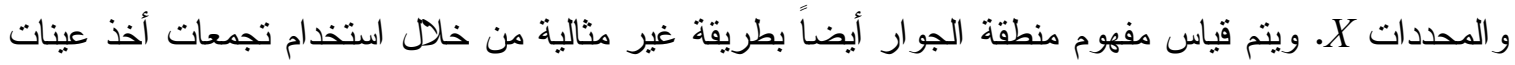
المسوح الديموجر افية والصحية. ونأمل ألا تكون هذه المضاهات غير الملائمة بين مناطق الجوار (تركيبة اجتماعية) وتجمعات أخذ العينات (أداة إحصائية) من الضخامة بحيث أنها تهدد بزعزعة النتائج التي توصل إليها هذا البحث -غير أننا لا نعرف بأية أدلة مباشرة حول هذه النقطة. وينم قياس مفهوم مستويات المعيشة على مستوى مناطق الجوار من خلال متوسطات بسيطة للعو امل على مستوى الأسر المعيشية، ويمكن، كما لاحظنا، القيام بالمزيد لتقوية هذا الجانب من النماذج الإيكونومترية.

و الأسلوب الذي تعرضنا فيه لمفهوم تركيب الأسر المعيشية هو أسلوب مبسط- وكان من الممكن منح مزيد من الانتباه للتركيبة الاجتماعية لمنطقة الجوار، كما تتعكس في النسب المئوية للسكان المحليين المتعلمين على سبيل المثال (كولمان، 1988؛ وكاوفمان Kaufman وآخرون، 2002؛ وكر ادفال Kradval، 2003). ونتير النظريات الخاصة بالتفاعل الاجتماعي و البيئي الحضري و العو امل الخارجية ذات الصلة بها (فريق ديناميكيات سكان الحضر ، 2003) إلى وجود حاجة لجمع بيانات حول الثبكات الاجتماعية وبيانات مكانية تقع خارج نطاق برنامج المسوح الديموجر افية و الصحية تماماً، و التي سنتطلب القيام بأنو اع جديدة من المسوح في مدن البلدان

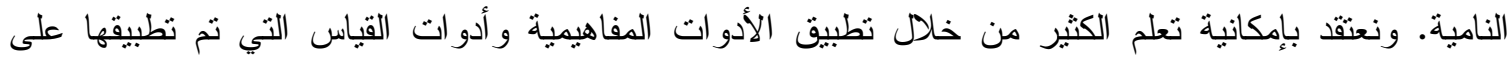
المجتمعات الحضرية الفقيرة في الولايات المتحدة على هذه المدن. ويروق لنا الاعتقاد بأنه عند ظهور نتائج قوية

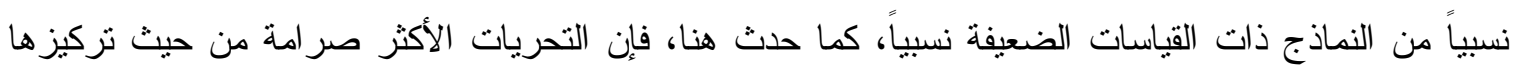
من شأنها أن تعطينا نتائج أكثر قوة.

وكما بينت تحليلاتتا الوصفية، فإن مناطق جوار الأسر المعيشية الحضرية الفقبرة عادة ما تحنتوي على نسب مئوية ملحوظة من الأسر المعيثية غير الفقيرة، بل وحتى نسب لا بستهان بها من الأسر المعيشية الغنية، وينتمي حوالي و احد من بين كل عشرة جيران لأسر معيشية فقيرة في المعتاد إلى الثريحة العليا من التوزيع الحضري. ولم بتهن التعليق على هذا التنافر كثيراً في مستويات المعيشة داخل مناطق الجوار في التحليلات الديموجر افية لمدن البلدان النامية. ويمكن لها أن تفيد بوجود فرصة أكبر للتنخلات القائمة على مستوى مناطق الجوار عما يمكن للبعض أن فئن يعنقد، وذلك للمدى الذي يجلب به هذا التتافر مو ارد اجتماعية و اقتصادية وسياسية في منتاول الفقر اء.

ومن أجل فهم هذه الفرصة وتقديرها، عليك بالنظر في إحدى الأنشطة الصحية التي تهدف إلى تحسين حياة فقر اء

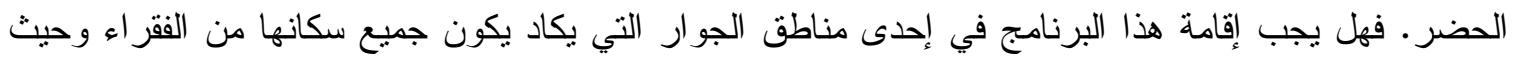
تكون الحاجات الصحية ماسة أكثر منها في أي منطقة أخرى؟ أو هل هنالك سبب للنظر في مواقع الاخل أيضاً؟

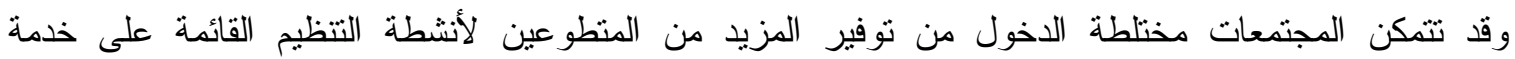
المجتمع، ويمكنها أيضاً أن تمنلك قاعدة أقوى من الجمعيات المحلية. ويمكن للسكان من منوسطي ومرتفعي الدخل 
في هذه المجتمعات أن يكونو ابمثابة "جسور" إلى رجال السياسة، و الوكالات الحكومية، ومصادر للتمويل الخارجي

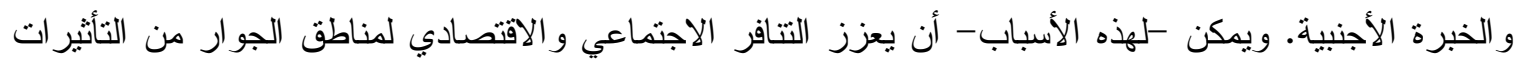

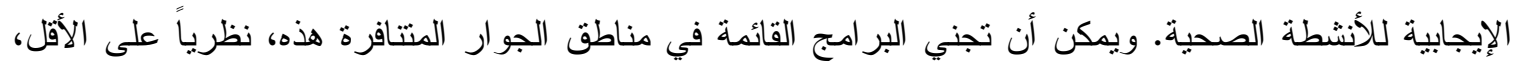

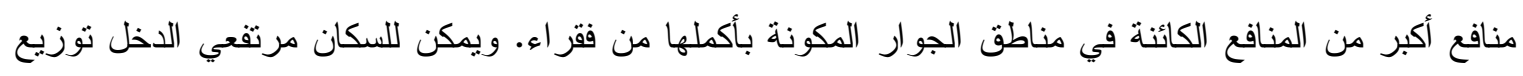

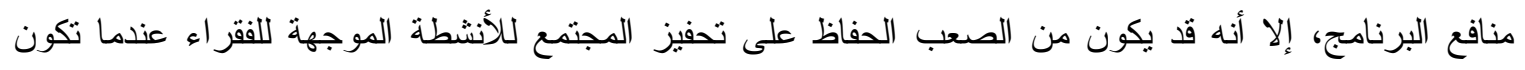

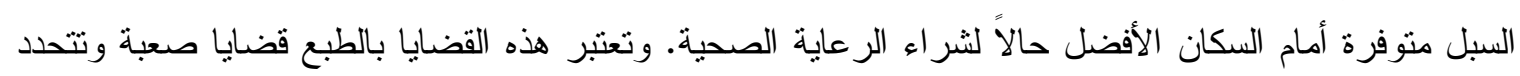

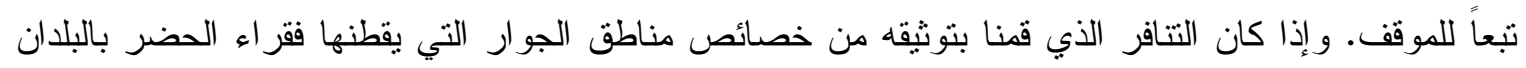
النامية، فإنه سيقدم تحديات وفرص على حد سو اء بالنسبة للبر امج و السياسات الصحية. 


\section{ملحق أ. مزيد من الوصف للمسوح و البيانات الديموجر افية والصحية}

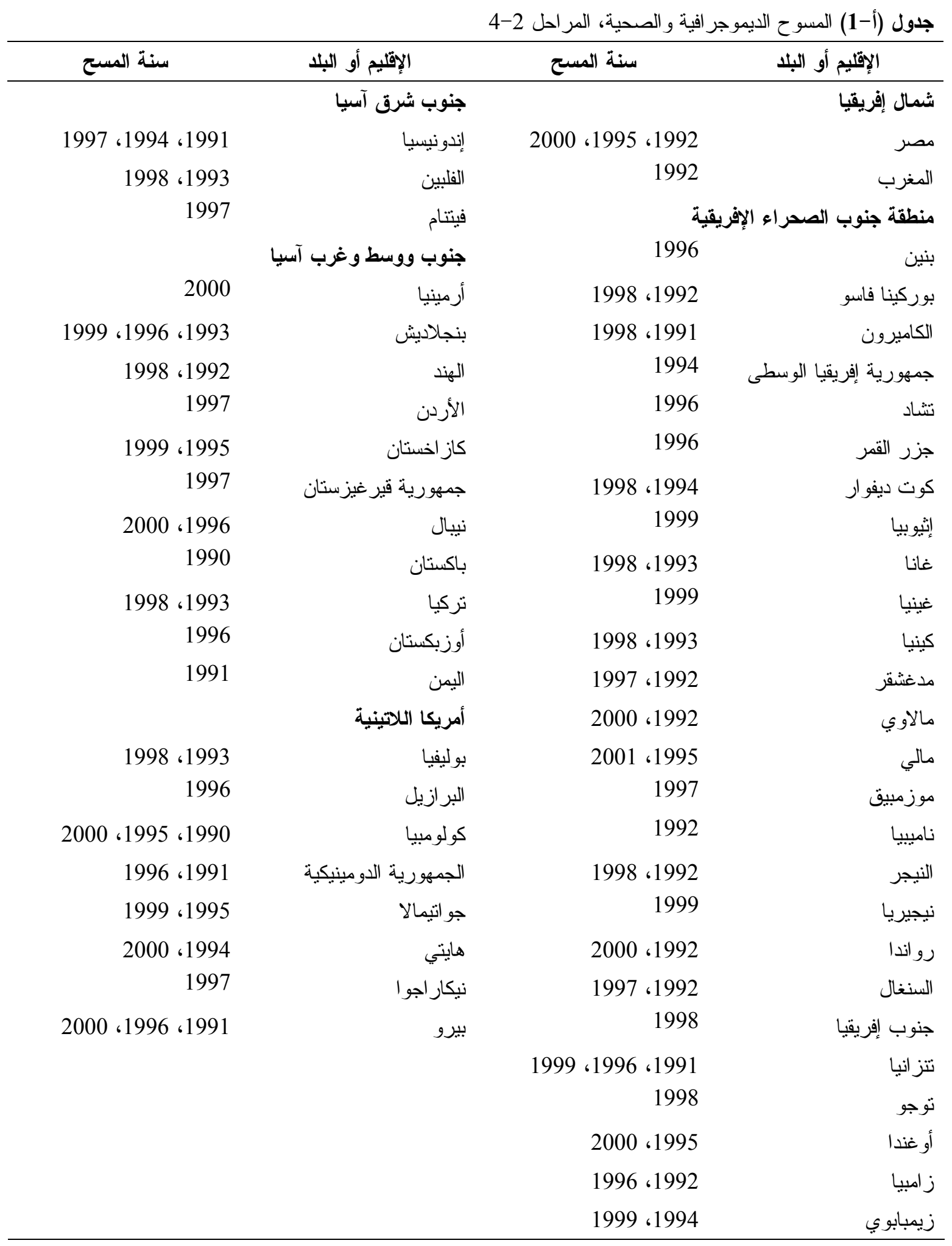




\begin{tabular}{|c|c|c|c|c|c|c|}
\hline أمريكا & 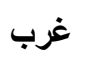 & جنوب & جنوب شرق & جنوب الصحراء & 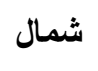 & \\
\hline الكلاتينية & آسيا & ووسط آسيا & آسيا & الإفريقية & إفريقيا & \\
\hline & & & & & & مسوح تضم سلعاً معمرة استهلاكية \\
\hline 16 & 4 & 7 & 5 & 39 & 4 & 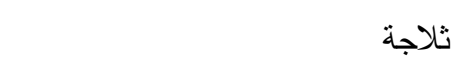 \\
\hline 16 & 4 & 12 & 6 & 40 & 4 & جهاز تليفزيون \\
\hline 16 & 3 & 12 & 5 & 42 & 4 & جهاز ر اديو \\
\hline 12 & 2 & 12 & 6 & 42 & 4 & 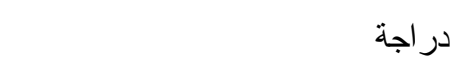 \\
\hline 12 & 2 & 8 & 5 & 41 & 2 & در اجة بخارية (موتوسيكل) \\
\hline 13 & 4 & 6 & 6 & 41 & 2 & 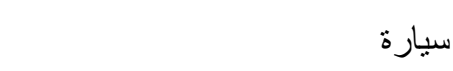 \\
\hline & & & & & & مسوح تضم قياسات لجودة السكن \\
\hline 15 & 3 & 6 & 3 & 36 & 3 & عدد غرف النوم \\
\hline 16 & 4 & 9 & 6 & 42 & 4 & الأر اضي الجاهزة \\
\hline 16 & 4 & 12 & 6 & 42 & 4 & عدد المسوح الديموجر افية و الصحية \\
\hline
\end{tabular}

جدول (أ.3) إحصائيات وصفية حول وضع السكان (بالنسبة المئوية)

\begin{tabular}{|c|c|c|}
\hline مدينة صغيرة & العاصمة أو المدينة الكبرى & 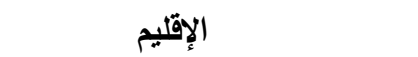 \\
\hline 40.7 & 35.6 & شمال إفريقيا \\
\hline 30.8 & 43.6 & منطقة جنوب الصحر اء الإفريقية \\
\hline 35.2 & 30.2 & جنوب شرق آسيا \\
\hline 30.0 & 34.3 & جنوب ووسط آسيا \\
\hline 30.0 & 40.6 & غرب آسيا \\
\hline 31.8 & 40.4 & أمريكا اللاتنينية \\
\hline
\end{tabular}




\begin{tabular}{|c|c|c|c|c|c|c|c|c|}
\hline \multicolumn{9}{|c|}{ جدول (أ.4) إحصائيات وصفية حول سن النساء } \\
\hline \multicolumn{7}{|c|}{ سن النساء (بالنسب المئوية) } & \multirow{2}{*}{\multicolumn{2}{|c|}{ الإقليم }} \\
\hline 49-45 & $44-40$ & 39-35 & 34-30 & 29-25 & 24-20 & 19-15 & & \\
\hline 11.7 & 16.8 & 22.2 & 21.4 & 17.3 & 9.1 & 1.5 & \multicolumn{2}{|r|}{ 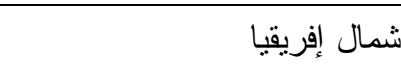 } \\
\hline \multirow[t]{2}{*}{6.3} & 11.1 & 16.8 & 19.1 & 21.8 & 18.5 & 6.4 & الصحر اء & جنوب \\
\hline & & & & & & & & 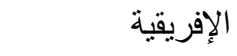 \\
\hline 9.5 & 15.6 & 20.9 & 21.9 & 20.0 & 10.8 & 1.3 & & جنوب شرق آسيا \\
\hline 7.8 & 13.8 & 18.0 & 20.6 & 20.6 & 14.7 & 4.5 & & جنوب ووسط آسيا \\
\hline 9.4 & 15.5 & 20.1 & 20.7 & 20.0 & 12.2 & 2.1 & & غرب آسيا \\
\hline 7.9 & 13.4 & 18.2 & 20.9 & 19.9 & 15.0 & 4.8 & & أمريكا اللاتينية \\
\hline 7.5 & 12.7 & 18.0 & 20.1 & 20.8 & 16.0 & 5.0 & & الإجمالي \\
\hline
\end{tabular}


جدول (أ.5) إحصائيات وصفية حول التحصيل الدراسي للنساء (بالنسبة المئوية)

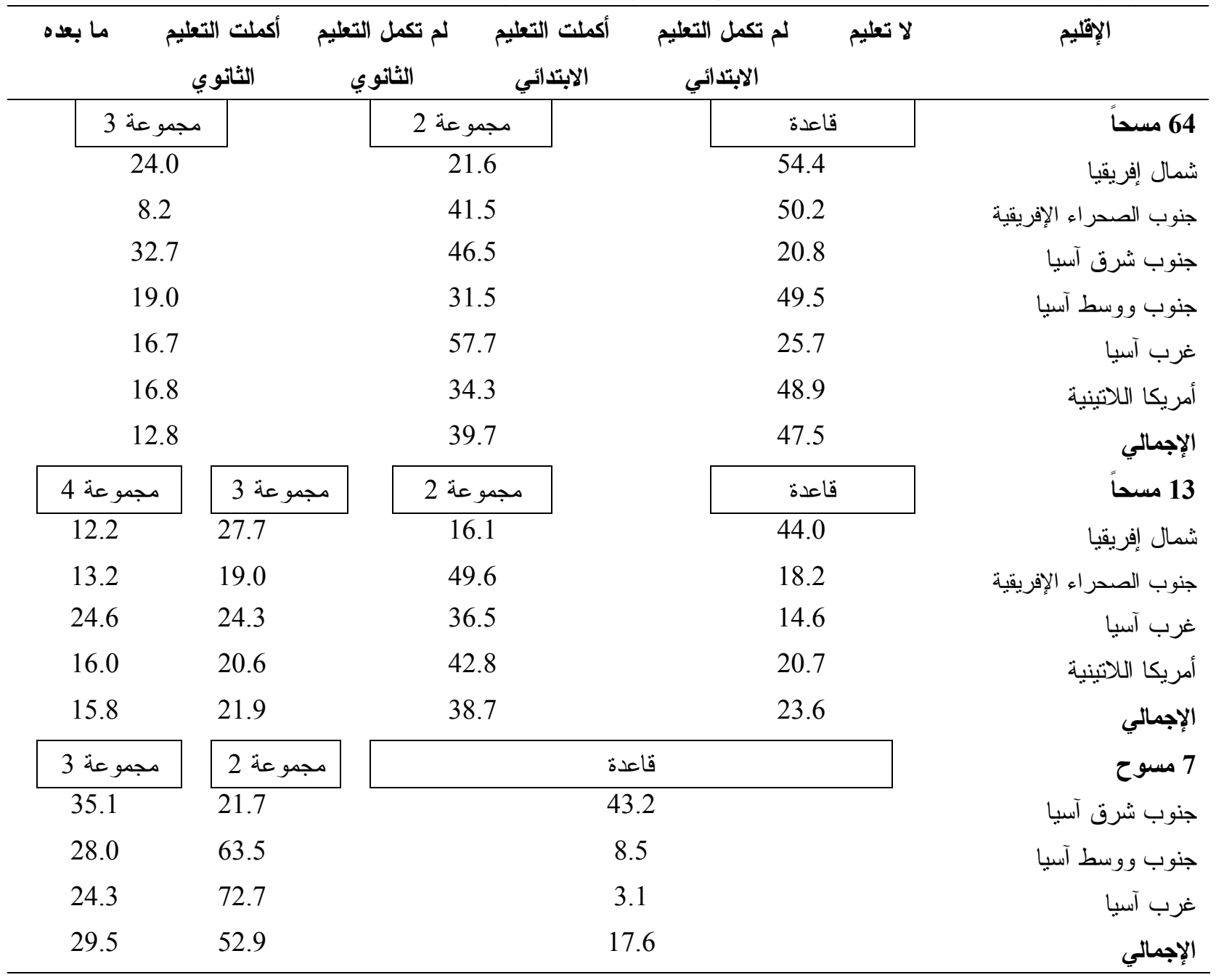


جدول (أ.6) إحصائيات وصفية حول التحصيل الدراسي للزوج (بالنسبة المئوية)

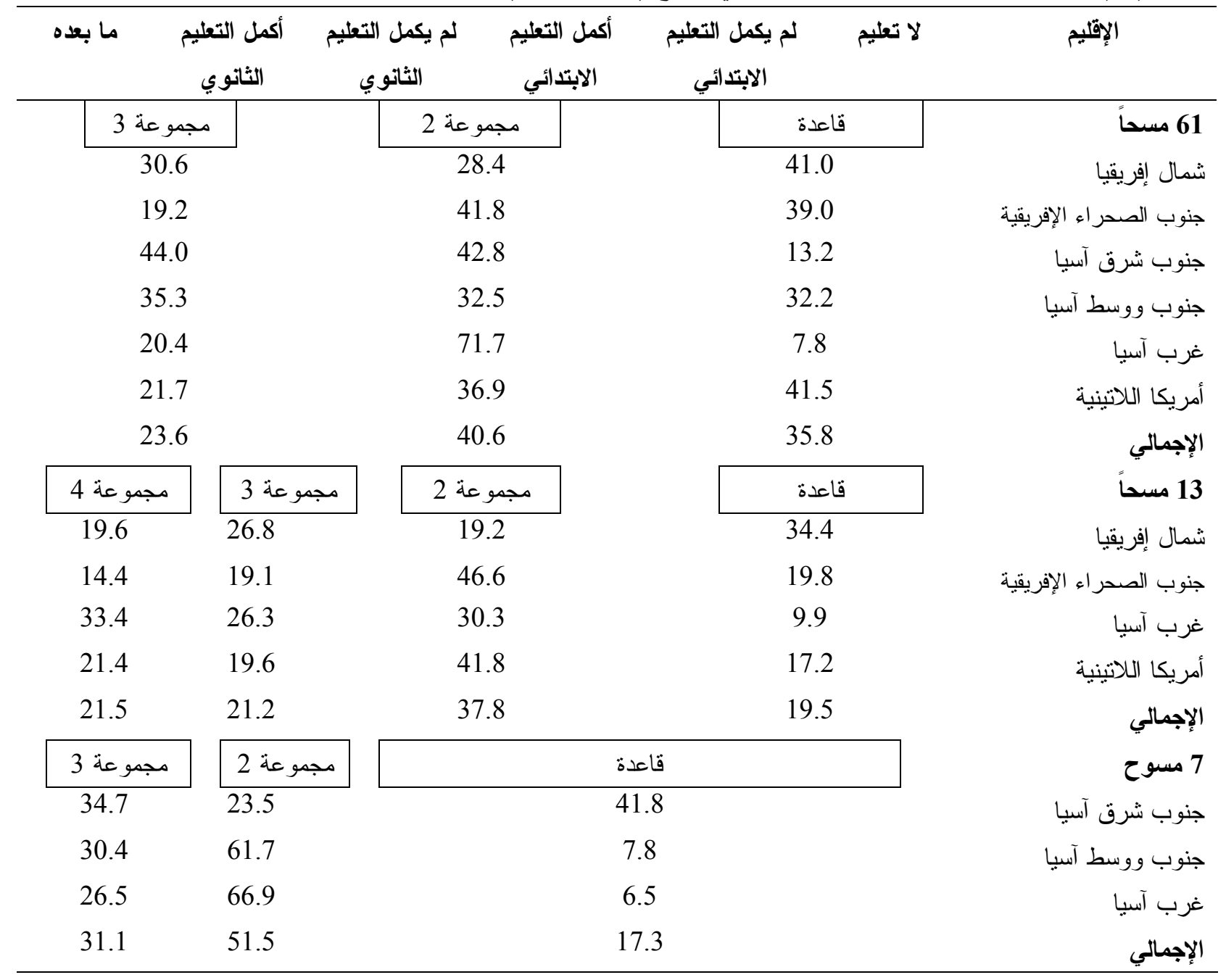




\section{ملحق ب. تقدير النماذج ذات العامل الواحد بالمؤشرات الثنائية المتعددة}

يتضمن التطبيق الذي كتبَ هذا الملحق من أجله مجموعة من القياسات الثنائية الخاصة بالسلع المعرة الاستهلاكية- و التي يطلق عليها هنا وفي النص مصطلح "المؤشرات" indicators- لإلقاء الضوء على التزكيبة التي لا تتم في غير ذلك من الأحو ال ملاحظتها، ألا وهي "مستوى معيشة" الأسرة المعيشية. ونتبادر الكثير من ون

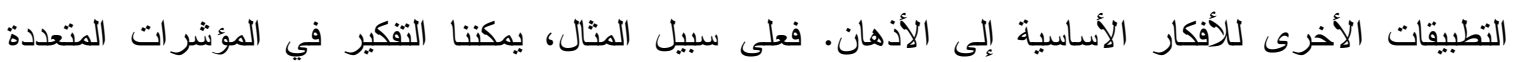
للصحة، و التي يعكس كل منها "صحة" فردية كامنة.

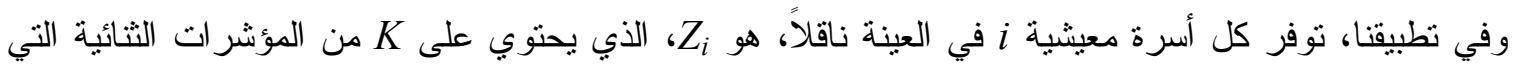
تمت ملاحظتها، ويرمز إلى كل منها بـ المؤشر ات معبرة عن عامل لم تتم ملاحظته هو

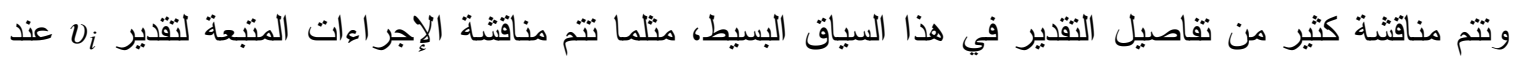
تو افر القيم التي تتم ملاحظتها و الخاصة بالمؤشر ات. ويرسم القسم الأخير من الملحق نموذجاً موسعاً تكون فيه

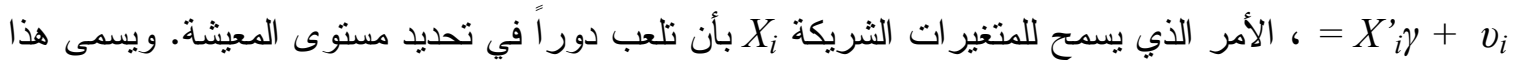

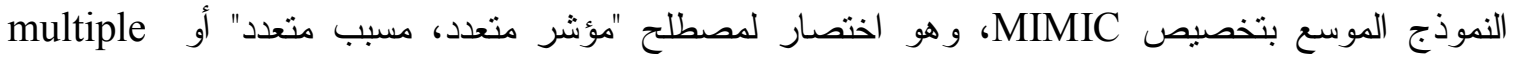
ن.indicator, multiple cause. و على مدار هذه المناقتنة، يفترض أن تكون المؤشر ات متفر عة إلى قسمين بدلاًا

من نقييمها على نحو مستمر - من

نموذج المؤشر المتعدد

في هذا التخصيص، يفترَض أن يعنمد كل عنصر في الناقل $Z_{i}$ على العامل

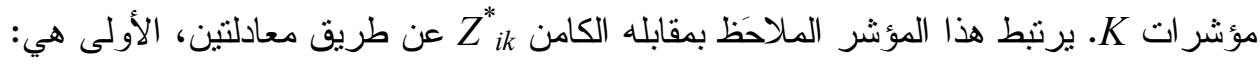

$$
\begin{aligned}
Z_{i k}^{*} & =\alpha_{K}+\beta_{K} f_{i}+v_{i k} \\
& =\alpha_{K}+\beta_{K} v_{i}+v_{i k}
\end{aligned}
$$

$(1-ب)$

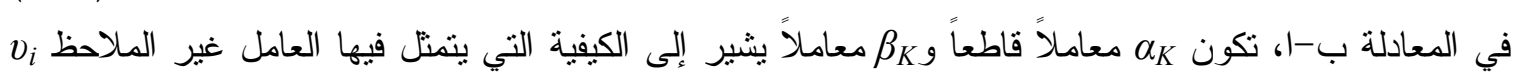

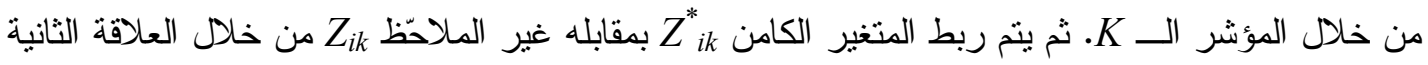

$$
\begin{aligned}
Z_{i k}= & \left\{1 \text { if } Z_{i k}^{*}>0,\right. \\
& \left\{-1 \text { if } Z_{i k}^{*} \leq 0 .\right.
\end{aligned}
$$

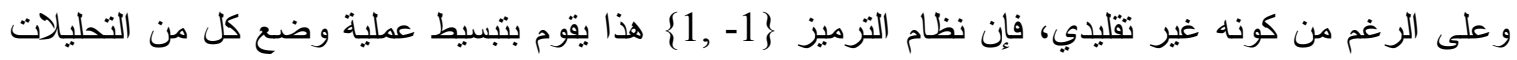
و البر امج. 
وفيما يلي، سنقوم بيان اعتماد الناقل الاحتمال المشترك المرتبط بـ Z Z، ومشروطاً بالقيمة (غير المعلومة) لـ

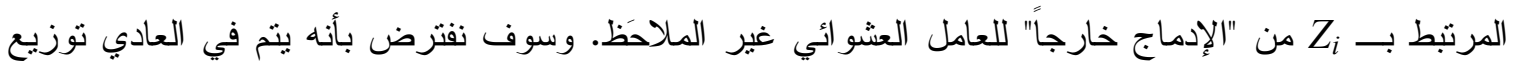
العامل iv بالوسيط صفر و المنباينp. فإذا ما قبلنا هذا، فإنه يتم النعبير عن الاحتمال غير المشروط عن طريق المتكاملة

$$
\int_{-\infty}^{\infty}(2 \pi)^{-1 / 2} p^{-1 / 2} e-1_{/ 2 p}{ }^{u 2}{ }_{i} P_{i}\left(v_{i}\right) d v_{i}
$$

$(2-\varphi)$

ولسوء الحظ، لا تتو افر المنكاملة في صورة مغلقة، وتتمثل الحاجة لأساليب نقريب رقمية لنقييمها.

\section{فكرة خلفية عن التربيع}

كثيراً ما يتم تطبيق طريقة التربيع الجاوسي Gaussian quadrature عندما ير غب شخص ما في القيام بنقريب

$$
\int_{-\infty}^{\infty} e^{-\varepsilon^{2}} P(\varepsilon) d \varepsilon
$$

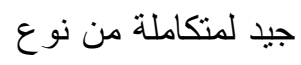

حيث تكون الوظيفة 0 > P(ع) و لا يمكن تمثيل المتكاملة محل النظر في صورة مغلقة. (لاحظ أنه تم في هذه

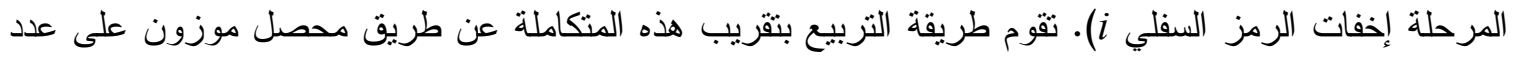

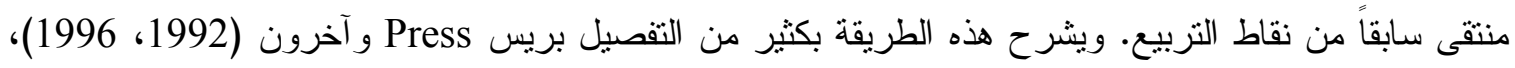

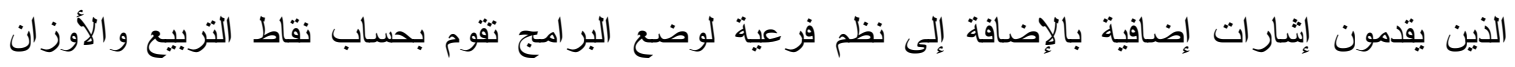
المرتبطة بها.

ولوضع المعادلة (ب-2) في هذا الثنكل، لا نحتاج سوى لتغيير المتغيرات

$$
\begin{aligned}
& =\frac{v}{\sqrt{2 p^{1 / 2}}} \\
& \text { حيث تكون } p^{1 / 2} \\
& \\
d v & \\
d \varepsilon & \sqrt{ } 2 p^{1 / 2}
\end{aligned}
$$$$
\text { و عند قيامنا بتغيير المتغيرات، نحصل على: }
$$ 


$$
\pi^{-1 / 2} \int e^{-\varepsilon^{2}} P\left(\sqrt{ } 2 p^{1 / 2} \varepsilon\right) d \varepsilon
$$

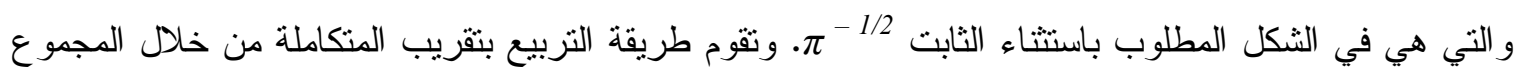
الإجمالي

$$
\sum_{j=1}^{n} \quad w_{j} P\left(\sqrt{ } 2 p^{1 / 2} e_{j}\right)
$$

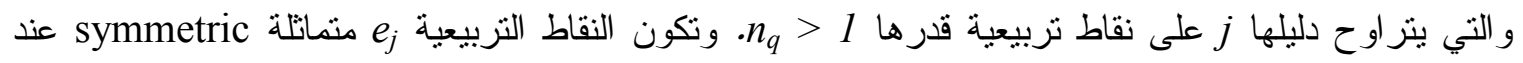

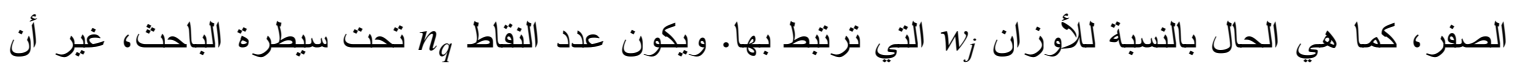
جودة الثقريب تتحسن في المعتاد بينما يرتقع عدد النقاط.

تقير الأرجحية القصوى Maximum likelihood estimation: منحى عام

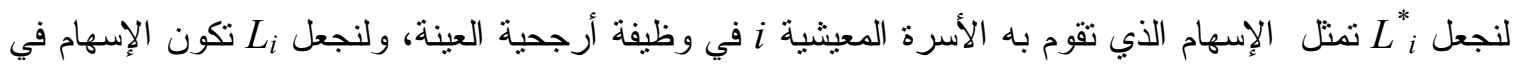

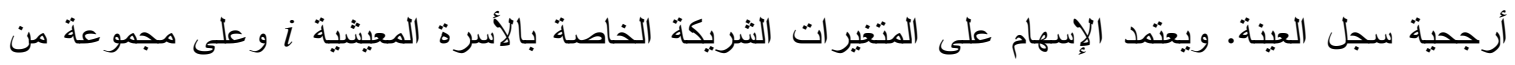

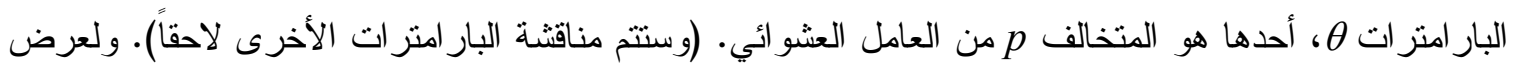

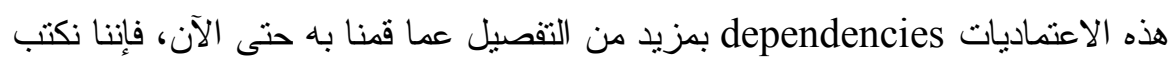

$$
L^{*}{ }_{i}=\pi^{-1 / 2} \quad \sum_{J=1}^{n} w_{j} P_{i}\left(\theta_{0}, \sqrt{ } 2 p^{1 / 2} e_{j}\right)
$$

في هذا التذوين، تحتوي $\theta_{0}$ على كل المعامل غير المعروفة باستثاء p، وسنقوم بتدوين المجموعة الكاملة من

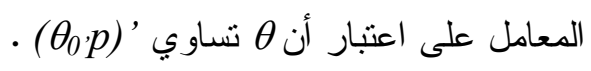

ويجري تقدير المعامل $\theta$ من خلال تعظيم وظيفة أرجية سجل العينة بالكامل، وهي

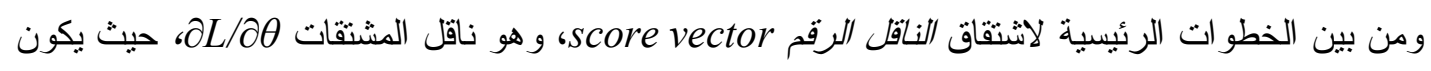

$$
\frac{\partial L}{\partial \theta}=\boldsymbol{\Sigma}_{i} \frac{\partial L_{i}}{\partial \theta_{i}}
$$

لاحظ أن إسهام الأسرة المعيشية i في الرقم هو 


$$
\frac{\partial L_{i}}{\partial \theta_{i}}=\boldsymbol{\Sigma}_{j w_{j}} \frac{\partial P_{i j}}{\partial \theta}
$$

وسيكون من المفيد إعادة التعبير عن هذا المشتق على هيئة

$$
\frac{\partial L_{i}}{\partial \theta_{i}}=\frac{\boldsymbol{\Sigma}_{j} w_{j} P_{i j}}{\frac{\partial \ln P_{i j}}{\partial \theta}}
$$

وذلك لأن مشتقات In $P_{i j}$ بالنسبة لـ $\theta$ نكون في العموم مشابهة لمقابلاتها في النماذج التي لا نكون لديها عو امل عشو ائية.

تقبير النموذج نكرر، تحقيقاً للر احة، معادلة المتغير الكامن (ب-1-1)

$$
Z_{i k}^{*}=\alpha_{K}+\underline{\beta}_{\underline{K}} v_{i}+v_{i k}
$$

$(1-4)$

و عند قيامنا بوضع تعبيرات احتمالية للمؤشرات الملاحَظة Zik، فإنتا نفترض أن مصطلح التثويش

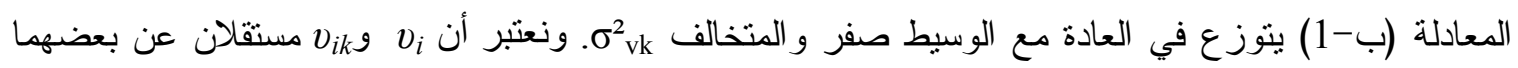

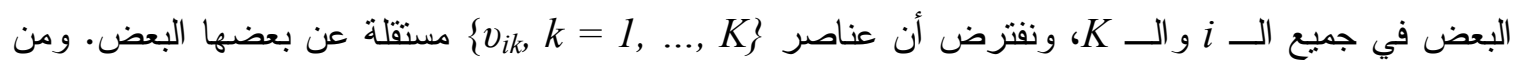

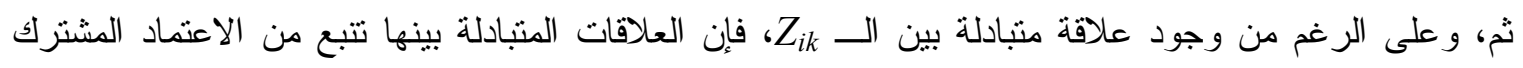

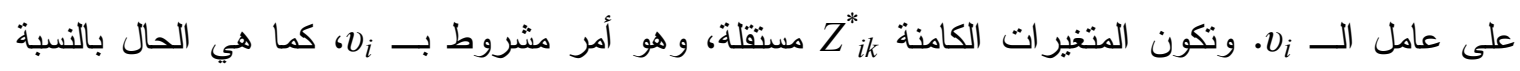

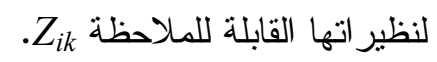

وفي هياكل بروبيت Probit structures من هذا النوع، لا يتم تحديد أحجام متغير ات التثويش، و لابد من فرض

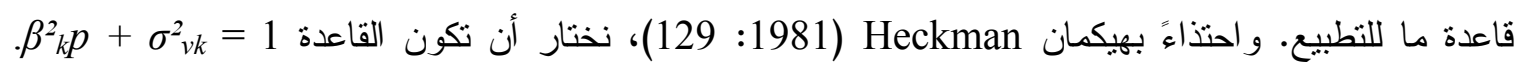

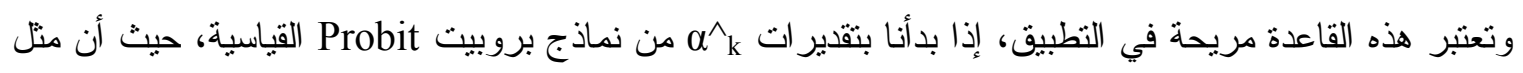

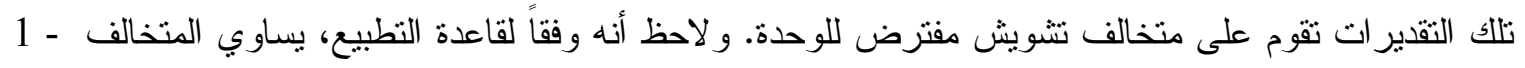

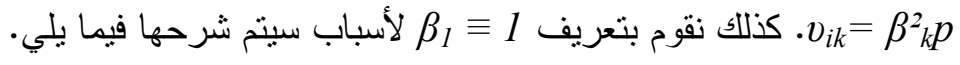




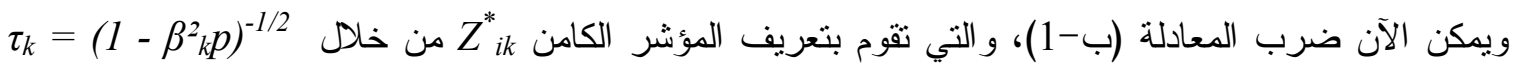

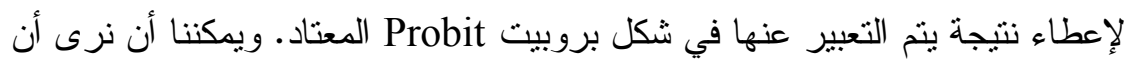

$$
\begin{aligned}
& \left.\tau_{k} Z_{i k}^{*}=\tau_{k}\left(\alpha_{\mathrm{k}}+\beta_{k} v_{i}\right)+\tau_{k} v_{i k}\right)
\end{aligned}
$$

تكون في الثكل المرغوب فيه، حيث أن

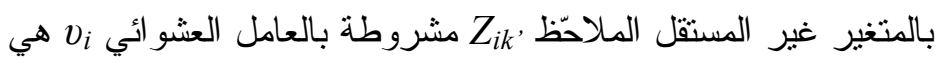

$$
\operatorname{Pr}\left(Z_{i k}=z_{i k} \mid v_{i}\right)=\Phi\left(z_{i k} \tau_{k} \cdot\left(\alpha_{\mathrm{k}}+\beta_{k} v_{i}\right)\right)
$$

حيث تكون $\Phi$ هي وظيفة التوزيع التراكي الطبيعية القياسية، وقد استفدنا من نظامنا غير التقليدي في التزميز، و هو نظام \}1, -1, بالنسبة لــ المؤشر ات الخاصة بالأسرة المعيشية $i$ هو

$$
P(v i)=\prod_{k=1}^{k} \Phi\left(z_{i k} \tau_{k} \cdot\left(\alpha_{k}+\beta_{k} v_{i}\right)\right)
$$

وتذكر أنه من أجل الإدماج الخارجي للتأثثر العشو ائي غير الملاحّظ v، فإننا نحتاج للتقريب التربيعي لمتكاملة تكون هيئتها العامة

$$
\int_{-\infty}^{\infty}(2 \pi)^{-1 / 2} p^{-1 / 2} e-1 / 2 p{ }^{u 2} P(v) d v
$$

$$
L_{i}=\pi^{-1 / 2} \sum_{j=1}^{n} \quad w_{j} P_{i}\left(\theta_{0}, \sqrt{ } 2 p^{1 / 2} e_{j}\right)=\pi^{-1 / 2} \sum_{j=1}^{n} \quad w_{j} P_{i j}
$$

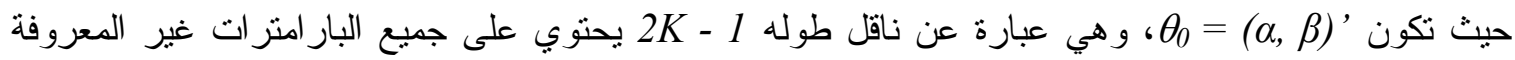

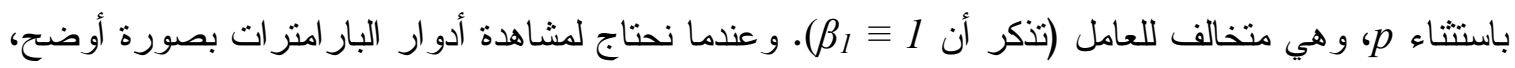
فإننا نكتب التعبير الخاص بــ

$$
P_{i j}=P_{i}\left(0, \sqrt{ } 2 p^{1 / 2} e_{j}\right)=\quad \mathbf{I}^{K} \Phi\left(z_{i k} \tau_{k} \cdot\left(\alpha_{k}+\beta_{k} \sqrt{ } 2 p^{1 / 2} e_{j}\right)\right)
$$

$k=1$

وفيما يلي سنشير إلى هذا التعبير على أنه (t) ويحتوي على جميع البار امتز ات غير المعروفة للنموذج. 


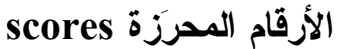

تذكر أن إسهام الأسرة المعيشية i في الناقل الكامل للرقم الدحرّز هو

$$
\frac{\partial L_{i}}{\partial \theta}=\frac{\boldsymbol{\Sigma}_{j} w_{j} P_{i j} \frac{\partial \ln P_{i j}}{\partial \theta}}{\boldsymbol{\Sigma}_{i} w_{j} P_{i j}}
$$

و الآن، فإن In Pي نفسها الإجمالي الخاص بعدد k من سجلات الأرجحيات الخاصة بالمؤشر k:

$$
\ln P_{i j}(\theta)=\sum_{k=1}^{K} \ln \Phi\left(z_{i k} \tau_{k} \cdot\left(\alpha_{k}+\beta_{k} \sqrt{ } 2 p^{1 / 2} e_{j}\right)\right)
$$

(3-)

$$
\begin{aligned}
& \text { وبالتالي، فإننا نأخذ بالنسبة للبار امتر ات ه مثتقات من المعادلة (ب-3) للحصول على } \\
& \frac{\partial \ln P_{i j}}{\partial \alpha_{\mathrm{k}}}=\frac{\Phi_{i k j}}{\Phi_{i k j}} \mathrm{Z}_{i k} \tau_{k}
\end{aligned}
$$

(4-ب)

حيث يكون $W_{k j}=\alpha_{k}+\Phi_{i k j}$ مشنقاً من

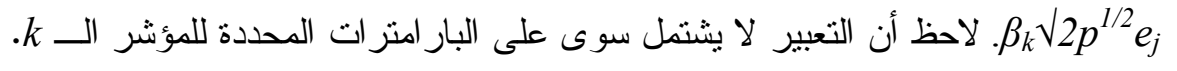

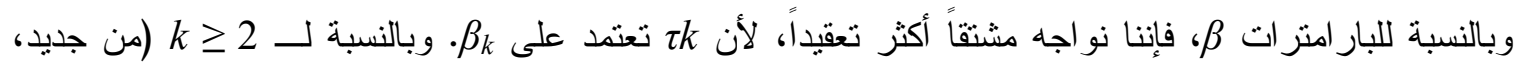

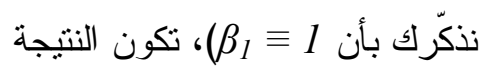

$$
\frac{\partial \ln P_{i j}}{\partial \beta_{\mathrm{k}}}=\frac{\partial \ln P_{i j}}{\partial \alpha_{\mathrm{k}}}\left(W_{k j} \tau_{k}^{2} \beta_{k} p+\sqrt{ } 2 p^{1 / 2} e_{j}\right)
$$

$(5-4)$

أما عن المشتق بالنسبة لــ p، وهو بارامتر يدخل جميع معادلات المؤشرات، فإذا ما تذكرنا أن kع هي أيضاً

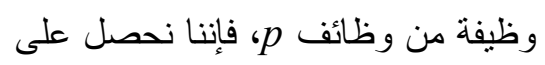

$$
\frac{\partial \ln P_{i j}}{\partial p}=\sum_{k=1}^{K} \frac{\partial \ln P_{i j} \cdot \beta_{\mathrm{k}}}{\partial \alpha_{\mathrm{k}}} \quad\left(W_{k j} \tau^{2}{ }_{k} \beta_{k}+\sqrt{ } 2 p^{-1 / 2} e_{j}\right)
$$

$(6-4)$

$$
\text { تقدم هذه النتائج كافة الدكونات اللازمة لنقدير النموذج. }
$$


ملاحظات عن التحديد

في وضعنا للنموذج متعدد المؤشر ات، فرضنا عدداً من المحددات، وينبغي القبام ببعض التعليق حول سبب الحاجة لوجودها، وكيفية مساعدة هذه المحددات في تحديد المعامل. لاحظ أولاً أن المحدد

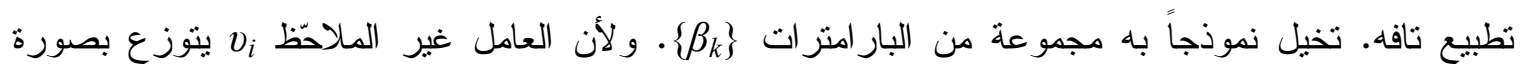

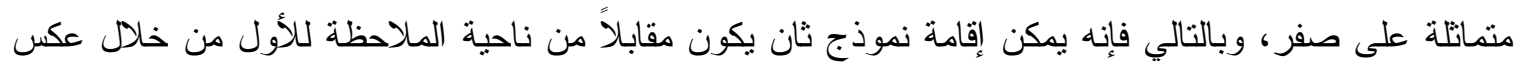

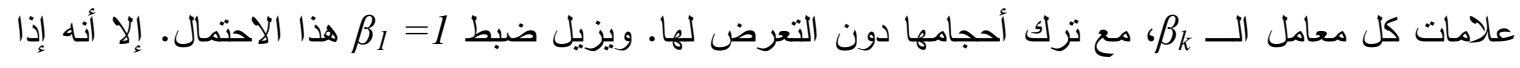

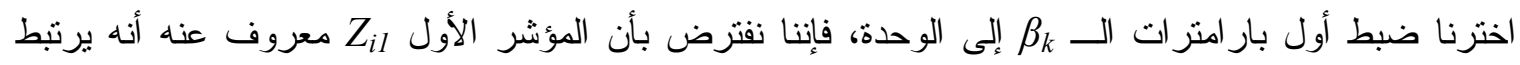

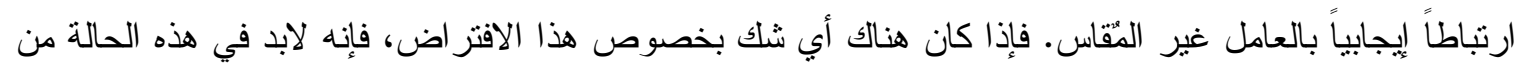
استخدام مؤشر آخر مكانه.

و هنالك نقطة أخرى تجدر ملاحظتها، ألا وهي أنه لا يتت تعريف متغيرات مصطلحات التشويش المركبة سوما نعنيه بــ "المركبة" composite هو و عند ضبط كل من المتغير ات المركبة للوحدة، فإننا نفرض محددات تقر بهذه الحقيقة.

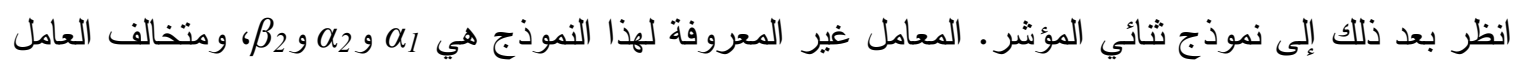

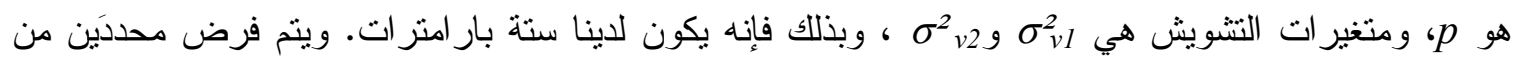
خلال افتر اضات متخالف الوحدة، ويقلل هذا من عدد البار امتزات غير المعروفة إلى أربعة. إلا أن البيانات

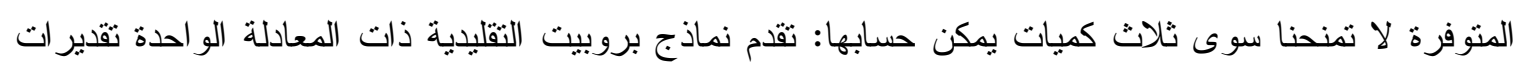

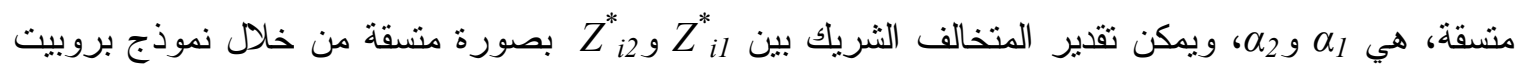
ثنائي التخالف. وما لم ينم طرح افتز اضات أخرى، فإن النموذج ثنائي المؤشر يكون غير معرّف بالقدر الكافي.

just- ويبين جمع البار امنزات و الكميات القابلة للحساب لنموذج ثلاثي المؤشر أن هذا النموذج معرّف بالكاد identified

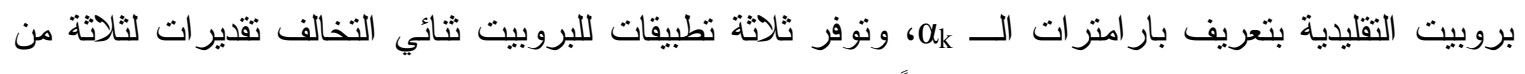

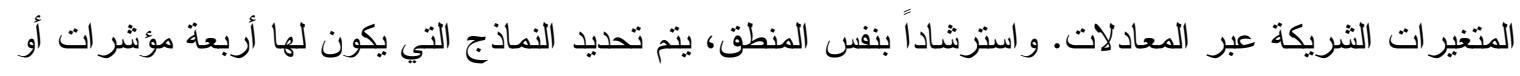

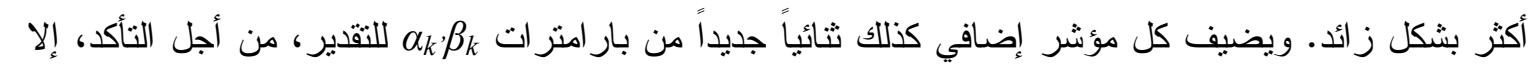

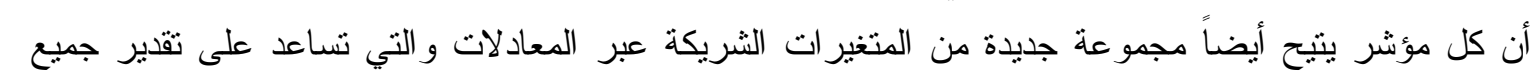

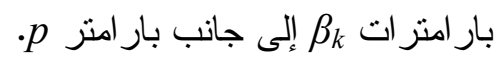

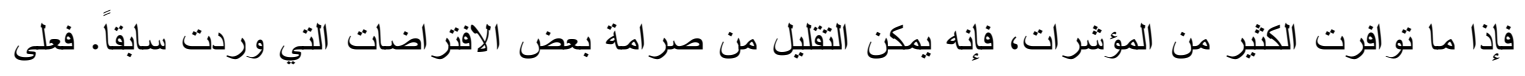

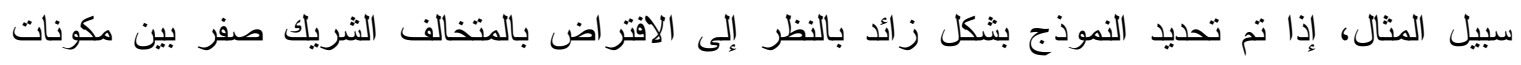


التثويش الصفرية.

\section{قضايا التقريب الرقمي إلى الكمال}

تفيد تجربتا في تقدير هذه النماذج بأنها تثكل في بعض الأحيان بعض الصعوبات الرقمية. فقد واجهنا بثكل

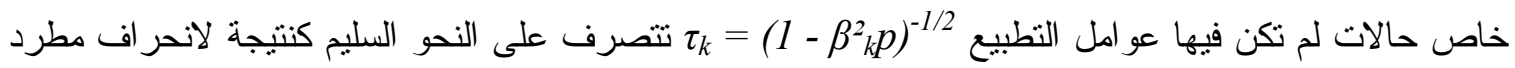

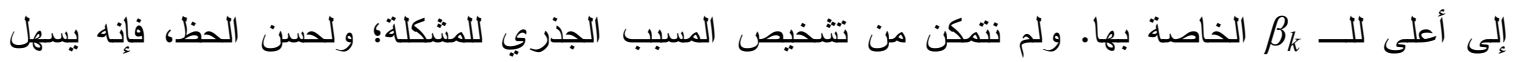

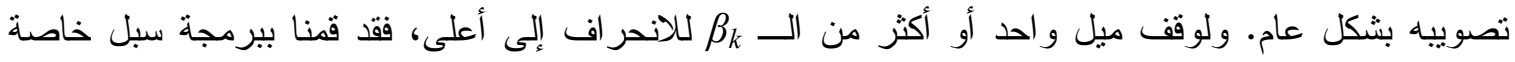

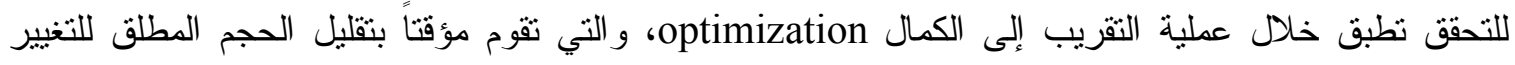

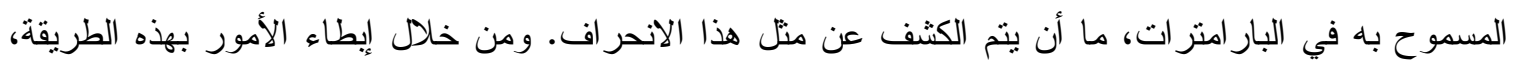

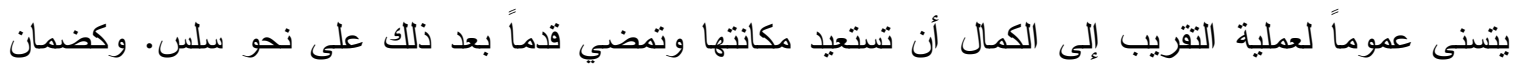

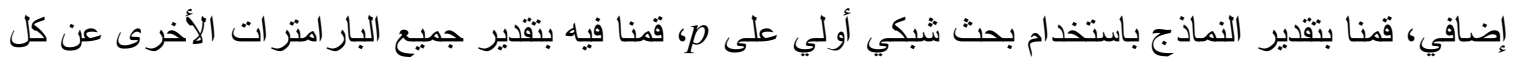

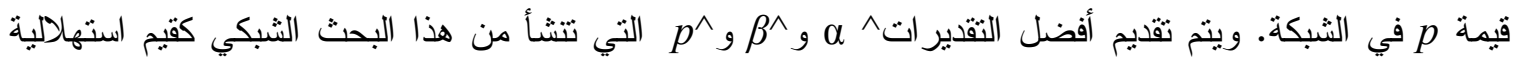
حتى نظام تقدير كامل للأرجحية العظمى.

تقدير العامل غير الملاحّظ

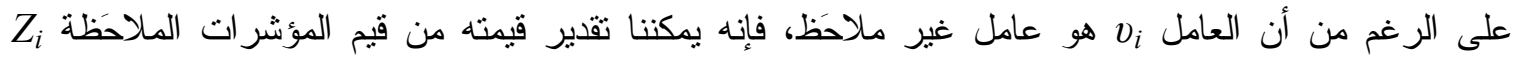

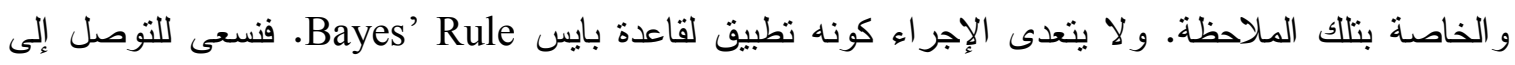

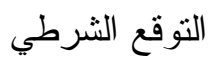

$$
E\left(v_{i} \mid Z_{i}\right)=\int v P\left(v \mid Z_{i}\right) d v
$$

$(7-ب)$

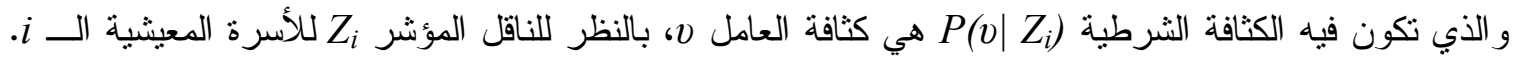
ونبعاً لقاعدة بايس فكرن فيه

$P\left(v \mid Z_{i}\right)=\quad \frac{P\left(v, Z_{i}\right)}{P\left(Z_{i}\right)}=\frac{P\left(Z_{i} \mid v\right) \Phi(v)}{P\left(Z_{i}\right)}$

(ب-)

حيث يكون (v) هو وظيفة الكثافة الطبيعية لعامل وسيطه صفر وتخالفه p. لاحظ أن (P) هي الإنهام الإسام الذي تقوم به الملاحظة i في أرجحية العينة. 
وبالنظر للقيم المتحققة الجانب الأيمن من المعادلة (ب-8) بالثكل الثناليم

$$
\mathbf{I I}_{K=1}^{K} \Phi\left(z_{i k} \tau_{k} \cdot\left(\alpha_{k}+\beta_{k} v\right)\right) . \Phi(v)
$$

$(9-4)$

ومقام denominator المعادلة (ب-8) هو متكاملة (ب-9) على v.

ولحساب التوقع الثرطي لـ v، نبدأ بالنقريب الرباعي لــ dv dv(v)

$$
\pi^{-1 / 2} \sum_{j=1}^{n_{q}} \quad w_{j}\left(, \sqrt{ } 2 p^{1 / 2} e_{j}\right) . \quad \prod_{k=1}^{K} \Phi\left(z_{i k} \tau_{k} \cdot\left(\alpha_{k}+\beta_{k}, \sqrt{ } 2 p^{1 / 2} e_{j}\right)\right)
$$

(ب-

في هذا التعبير، يحل المكون الأول بين القوسين،

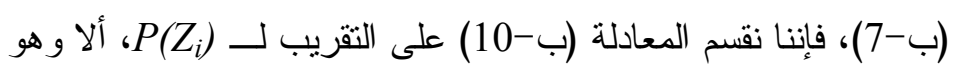

$$
\pi^{-1 / 2} \sum_{j=1}^{n} \quad w_{j} \quad \prod_{k=1}^{K} \Phi\left(z_{i k} \tau_{k} \cdot\left(\alpha_{k}+\beta_{k}, \sqrt{ } 2 p^{1 / 2} e_{j}\right)\right) .
$$

$(11-4)$

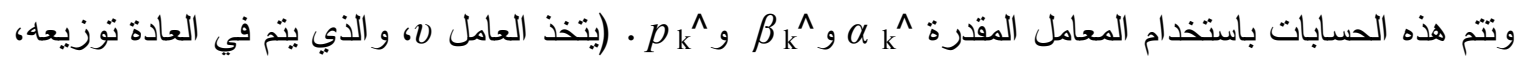

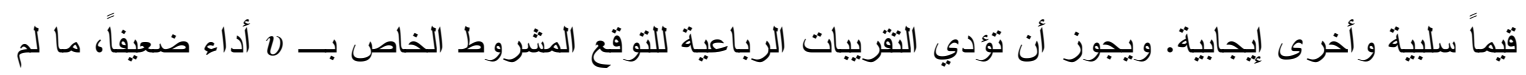
تكن التكاملية إلى الوكيل المنكاملة).

\section{نموذج المؤشر المتعدد، المسبب المتعدد}

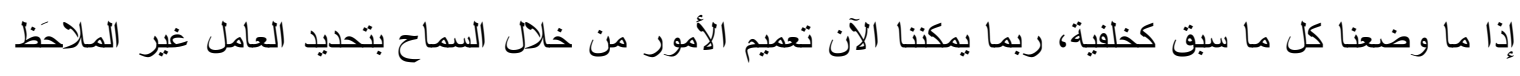

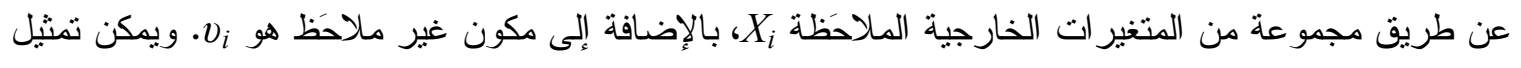


نموذج MIMIC هذا (ومعناها "multiple indicator, multiple cause" أو "المؤشر المتعدد، المسبب المتعدد") من خلال، حيث يكون لهد

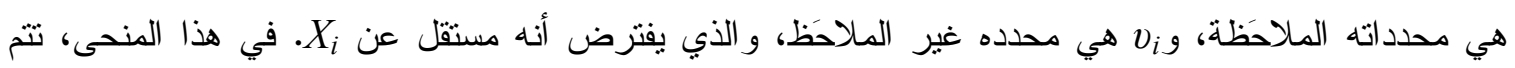
كتابة المؤشر الكامن

$$
\begin{gathered}
Z_{i k}^{*}=\alpha_{K}+\beta_{K} f_{i}+v_{i k} \\
=\alpha_{K}+\beta_{K} X^{\prime}{ }^{\prime}{ }^{\prime}+\beta_{K} v_{i}+v_{i k}
\end{gathered}
$$

$(4-4)$

$$
\begin{aligned}
& \text { ونقوم بنطبيق محددات تخالف الوحدة كما فعلنا سابقاً } \\
& \left.\tau_{k} Z_{i k}^{*}=\tau_{k}\left(\alpha_{\mathrm{k}}+\beta_{K} X_{i}^{\prime} \gamma+\beta_{k} v_{i}\right)+\tau_{k} v_{i k}\right)+\tau_{k} v_{i k,}
\end{aligned}
$$

$(13-4)$

لنحصل على

$$
\ln P_{i j}=\sum_{k=1}^{K} \ln \Phi\left(z_{i k} \tau_{k} .\left(\alpha_{k}+\beta_{k} X_{i}^{\prime}{ }^{\prime}{ }^{\prime}+\beta_{k^{\prime}} \cdot \sqrt{ } 2 p^{1 / 2} e_{j}\right)\right)
$$

$(4-)$

$$
\text { و الني تنبه هي الأخرى كثير اً ما قمنا به سابقا. }
$$

وتبقى أثنكال الأرقام المتحققة في أبعاد م و م في الأساس بلا تغيير • إلا أنه بالنسبة للمعامل الأخرى، لدينا

$$
\frac{\partial \ln P_{i j}}{\partial \gamma}=\sum_{k=1}^{K} \frac{\partial \ln P_{i j}}{\partial \alpha_{\mathrm{k}}} \cdot \beta_{\mathrm{k}} \cdot X_{i},
$$

$(15-4)$

$$
\begin{aligned}
\frac{\partial \ln P_{i j}}{\partial p} & =\sum_{k=1}^{K} \frac{\partial \ln P_{i j}}{\partial \alpha_{k}}\left(W_{k j} \tau^{2}{ }_{k} \beta_{k} p+X_{i}, \gamma+\sqrt{ } 2 p^{1 / 2} e_{j}\right)
\end{aligned}
$$

(ب)

حيث يكون

$$
\text { للمعادلات (ب-4) و (ب-5) }
$$


أما عن تقدير العامل غير الملاحظ، فلا يوجد الكثر الذي يمكن تمييزه في نموذج MIMIC عن النموذج القياسي. وفي هذه الحالة، نهذف لنقدير القير ثم نطبق الإجر اءات المبينة عاليه للتنبؤ بـ المان 
1- راجع الموقع www.un.org/millenniumgoals لمزيد من المعلومات حول إعلان الألفية والأهداف

$$
\text { العامة، و الأهداف الفرعية، وبر امج البحث المرتبطة به. }
$$

2- وجدت أحد أهم أنشطة التنخل المصاغة عثو ائياً تأثنير اً في ناريخ تتظيم الأسرة، ألا وهي تجربة تايكونج Taichung الاجتماعية في هذه المدينة التايو انية (فريدمان Freedman وتاكيشيتا Takeshita، 1969). راجع كاسترلاين (2001) للاطلاع على تلخيص رائع للنتائج ذات الصلة في مجالات عدة من البحث الايموجر افي.

3- ربما تكون هناك علاقة بين رأس المال الاجتماعي المحلي والخدمات الصحية- فيطبق جيلسون Gilson يوفر مفهوم الثقة طريقة لقياس الأبعاد الاجتماعية للوصول للرعاية الطبية الفعالة. 4- وفقاً لفريد أرنولد Fred Arnold (اتصال شخصي)، نتمل مجالات التعديد في البلدان النامية، والتي تستخدم في القيام بالإحصاءات السكانية، والتي عادةً ما توفر إطار أخذ العينات الخاص بالمسوح، في

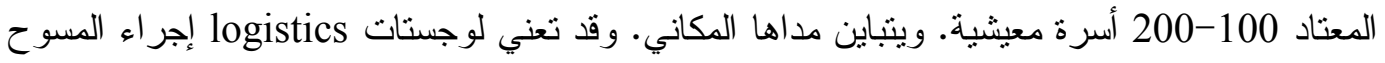

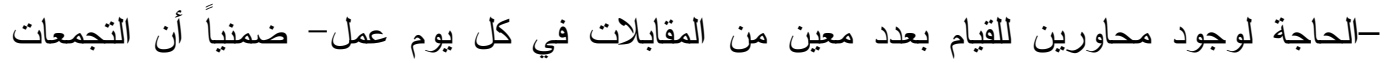
الحضرية ستكون في العموم مضغوطة، خاصة في الأماكن السكنية ذات الكثافة السكانية العالية.

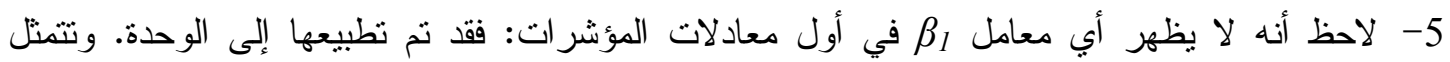
الحاجة كذلك إلى مزيد من عمليات النطبيع، كما ناقثنا في الملحق ب. وفي نماذج المتغير ات الكامنة من هذا النوع، لا يمكن تحديد أحجام المتغير ات مله قاعدة النطبيع 1 قاع

6- كما سيتضح، يكون من الأكثر دقة وصف طريقة التقدير على أنها "الأرجحية شبه القصوى" أو

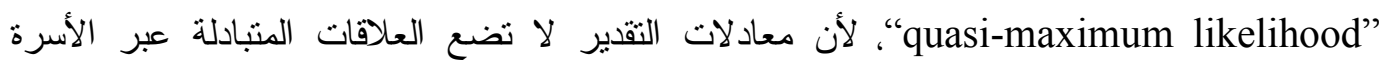
المعيشية أو داخل منطقة الجوار في اعتبار ها. لاحظ أنه يمكن الاطلاع على النظام الكامل، المعادلات (1) و (2)، كنسخة مقننة من نظام بروبيت ضخم منعدد المتغير ات. ولمعرفة الكيفية التي تختلف بها مثل تقنيات التقدير لمنل نماذج المؤشر ات الثنائية هذه عن تقنيات النماذج الخاصة بالمؤشر ات التي يتم تقييمها بصورة مستمرة، قارن بين لولي Lawley وماكسويل Maxwell (1962)، وبولَّين Bollen (1989)، ويوريسكوج Jöreskog (2000، 2002). ونطرح مشكلة التعظيم بعض الصعوبات الرقمية، ويبدو أن وسائل الأرجحية القصوى لم تستخدم بنفس القدر من التكرار في مشكلات من هذا النوع من تقدير الحد الأدنى للمسافات. 


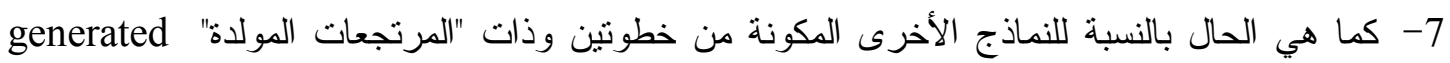

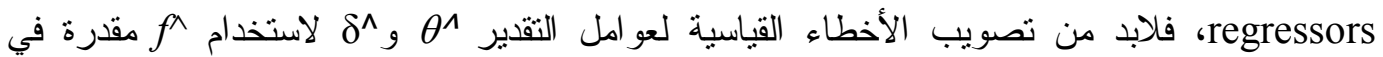
الخطوة الثانية. ونقوم باستخدام أخطاء قياسية منينة، لابد لها من التصدي لذلك بصورة ملائمة ولمصادر أخرى.

8- يفترض هذا الاستقلال بين \}, 9- إلا أنه على مدار السنة الماضية، كانت المسوح الديموجر افية و الصحية تجرب مسائل جديدة حساسة لاحتياجات الحضر ونتعلق بملكية المساكن و الحيازة الآمنة في عدد من المسوح.

10- يوجد في معظم عيناتتا تباين كاف في إدارة هذا الإسترانيجية للخروج بمتغيرات تعليمية مميزة في معادلات المؤشر ات و الصحة.

11- يوفر أحد المسوح، وهو الخاص باليمن، بيانات حول السلع المعرة ومحدداتها، ولكن ليس حول المتغير ات الصحية.

12-على الرغم من أن غالبية المسوح الديموجر افية و الصحية قامت بجمع معلومات عن الأطفال المولودين خلال السنو ات الخمس الأخيرة، فقد حدنا الحد الأعلى الخاص بالسن ليصبح ثلاث سنو ات للاستقادة من جميع المسوح المتو افرة ذات البيانات الخاصة بالطول.

13- تبين أن عدد الأسر المعيشية الحضرية الفقيرة نسبياً في أي مسح لا تتجاوز الربع، كما أن عدد الأغنياء

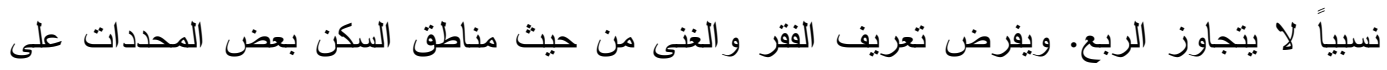
توزيعات منل التي نشاهدها في الثكل. ومن بين العوامل المعقدة هو أن تجمعات أخذ العينات في بعري المسوح الديموجر افية و الصحية تختلف من حيث حجم السكان. ومن شأن تحليل أكثر دقة مما يمكن لنا القيام به هنا أن يضع مثل هذه التعقيدات في الحسبان.

14-اختبر فريد آرنولا وزملاؤه في المسح الديمو غر افي و الصحي حالة مومباي بالهند، حيث يمكن للخر ائط الخاصة بمناطق تعديد المسح من التغطية على خر ائط المجتمعات العثوائية الحضرية التي رسمهاي المخططون و العلماء الاجتماعيون الهنود. فيفيد برؤيته للعديد من التفاوتات بين هذين النوعين من

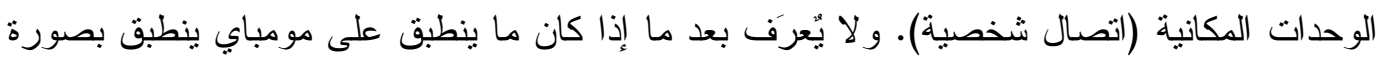
أكثر عموماً. 
Aber, J. L., Gephart, M. A., Brooks-Gunn, J., and Connell, J. P. (1997). Development in context: Implications for studying neighborhood effects. In Brooks-Gunn, J., Duncan, G. J., and Aber, J. L., editors, Neighborhood Poverty, volume I: Context and Consequences for Children, pages 44-61. Russell Sage Foundation, New York.

Aberg Yngwe, M., Fritzell, J., Lundberg, O., Diderichsen, F., and Burstr”om, B. (2003). Exploring relative deprivation: Is social comparison a mechanism in the relation between income and health? Social Science and Medicine, 57(8):1463-1473.

African Population and Health Research Center (2002). Population and Health Dynamics in Nairobi's Informal Settlements: Report of the Nairobi Cross-Sectional Slums Survey (NCSS) 2000. African Population and Health Research Center, Nairobi.

Astone, N., Nathanson, C. A., Schoen, R., and Kim, Y. J. (1999). Family demography, social theory, and investment in social capital. Population and Development Review, 25(1):1-31.

Behrman, J., Kohler, H.-P., and Watkins, S. (2001). Social networks, family planning, and worrying about AIDS. Paper presented at the 2001 Annual Meetings of the Population Association of America, Washington, DC, 29-31 March.

Bollen, K. (1989). Structural Equations with Latent Variables. John Wiley \& Sons, New York.

Caldeira, T. P. R. (1999). Fortified enclaves: The new urban segregation. In Holston, J., editor,

Cities and Citizenship, pages 114-138. Duke University Press, Durham and London.

Caldeira, T. P. R. (2000). City of Walls: Crime, Segregation, and Citizenship in S ao Paulo. University of California Press, Berkeley, CA.

Casterline, J. B., editor (2001). Diffusion Processes and Fertility Transition: Selected Perspectives. National Academies Press, Washington, DC.

Casterline, J. B.,Montgomery, M. R., Agyeman, D. K., Aglobitse, P., and Kiros, G.-E. (2001). Social networks and contraceptive dynamics in southern Ghana. Paper presented at the 2001 Annual Meetings of the Population Association of America, Washington, DC, 29-31 March.

Casterline, J. B. and Sinding, S. W. (2000). Unmet need for family planning in developing countries and implications for population policy. Population and Development Review, 26(4):691-723. 
Coleman, J. S. (1988). Social capital in the creation of human capital. American Journal of Sociology, 94(supplement):S95-S120.

Coulton, C., Korbin, J., Chan, T., and Su, M. (1997). Mapping residents' perceptions of neighborhood boundaries: A methodological note. Working Paper, Center on Urban Poverty and Social Change. Case Western Reserve University, Cleveland, OH.

Drukker, M., Kaplan, C., Feron, F., and van Os, J. (2003). Children's health-related quality of life, neighbourhood socio-economic deprivation and social capital. A contextual analysis. Social Science and Medicine, 57(5):825-841.

Ferguson, B. D., Tandon, A., Gakidou, E., and Murray, C. J. L. (2003). Estimating permanent income using indicator variables. Global Programme on Evidence for Health Policy Discussion Paper no. 42. World Health Organization, Geneva.

Filmer, D. and Pritchett, L. (1999). The effect of household wealth on educational attainment: Evidence from 35 countries. Population and Development Review, 25(1):85120.

Filmer, D. and Pritchett, L. (2001). Estimating wealth effects without expenditure dataor tears: An application to educational enrollments in states of India. Demography, 38(1):115-132.

Freedman, R. and Takeshita, J. Y. (1969). Family Planning in Taiwan: An Experiment in Social Change. Princeton University Press, Princeton, NJ.

Furstenberg, F. F. (1993). How families manage risk and opportunity in dangerous neighborhoods. InWilson,W. J., editor, Sociology and the Public Agenda, pages 231-258. Sage Publications, Newbury Park, CA.

Furstenberg, F. F. and Hughes, M. E. (1997). The influence of neighborhoods on children's development: A theoretical perspective and a research agenda. In BrooksGunn, J.,Duncan, G. J., and Aber, J. L., editors, Neighborhood Poverty, volume II: Policy Implications in Studying Neighborhoods, pages 23-47. Russell Sage Foundation, New York.

Gilson, L. (2003). Trust and the development of health care as a social institution. Social Science and Medicine, 56(7):1453-1468.

Ginther, D., Haveman, R., and Wolfe, B. (2000). Neighborhood attributes as determinants of children's outcomes: How robust are the relationships? Journal of Human Resources, 35(4):603-633.

Harpham, T. and Tanner, M., editors (1995). Urban Health in Developing Countries: Progress and Prospects. St. Martin's Press, New York. 
Heckman, J. J. (1981). Statistical models for discrete panel data. InManski, C. F. andMcFadden, D., editors, Structural Analysis of Discrete Data with Econometric Applications, pages 114-178. MIT Press, Cambridge, MA.

Herr, H. and Karl, G. (2002). Estimating global slum dwellers: Monitoring the Millennium Development Goal 7, Target 11. Monitoring Systems Branch, Global Urban Observatory. UN-HABITAT, Nairobi.

Herr, H. and Mboup, G. (2003). Slum dweller estimation methodology. Unpublished paper (in progress). UN-HABITAT, Nairobi.

J"oreskog, K. G. (2000). Latent variable scores and their uses. Unpublished paper, available at http://www.ssicentral.com/lisrel.column6.pdf.

J"oreskog, K. G. (2002). Structural equation modeling with ordinal variables using LISREL. Unpublished paper, available at http://www.ssicentral.com/lisrel/corner.htm.

Kaufman, C. E., Clark, S., Manzini, N., and May, J. (2002). How community structures of time and opportunity shape adolescent sexual behavior in South Africa. Policy Research Division Working Paper no. 159. Population Council, New York.

Kravdal, Ø. (2003). Community mortality in India: Individual and community effects of women's education and autonomy. East-West Center Working Papers, Population Series, no. 112. East-West Center, Honolulu, HI.

Lawley, D. N. and Maxwell, A. E. (1962). Factor analysis as a statistical method. Statistician, 12(3):209-229.

Massey, D. S. (1990). American apartheid: Segregation and the making of the underclass. American Journal of Sociology, 96(2):329-357.

Massey, D. S. (1996). The age of extremes: Concentrated affluence and poverty in the twenty-first century. Demography, 33(4):395-412.

McCulloch, A. (2003). An examination of social capital and social disorganisation in neighbourhoods in the British household panel study. Social Science and Medicine, 56(7):1425-1438.

McDade, T. W. and Adair, L. S. (2001). Defining the 'urban' in urbanization and health: A factor analysis approach. Social Science and Medicine, 53(1):55-70.

Montgomery, M. R., Gragnolati, M., Burke, K. A., and Paredes, E. (2000). Measuring living standards with proxy variables. Demography, 37(2):155-174.

Montgomery, M. R., Lloyd, C., Hewett, P. C., and Heuveline, P. (1997). The consequences of imperfect fertility control for children's survival, health, and schooling. 
Demographic and Health Surveys Analytical Reports no. 7. Macro International, Inc., Calverton, MD.

Panel on Urban Population Dynamics (2003). Cities Transformed: Demographic Change and Its Implications in the Developing World. National Academies Press, Washington, DC. Montgomery, M. R., Stren, R., Cohen, B., and Reed, H., editors.

Pebley, A. R., Goldman, N., and Rodr'ýguez, G. (1996). Prenatal and delivery care and childhood immunization in Guatemala: Do family and community matter? Demography, 33(2):231-247.

Pebley, A. R. and Sastry, N. (2003). Concentrated poverty vs. concentrated affluence: Effects on neighborhood social environments and children's outcomes. Paper presented at the 2003 Annual Meetings of the Population Association of America, Minneapolis, MN, 1-3 May.

Press, W. H., Teukolsky, S. A., Vetterling, W. T., and Flannery, B. P. (1992). Numerical Recipes in FORTRAN: The Art of Scientific Computing. Cambridge University Press, New York.

Press, W. H., Teukolsky, S. A., Vetterling, W. T., and Flannery, B. P. (1996). Numerical Recipes in Fortran 90: The Art of Parallel Scientific Computing, volume 2. Cambridge University Press, New York.

Sahn, D. E. and Stifel, D. C. (2000). Poverty comparisons over time and across countries in Africa. World Development, 28(12):2123-2155.

Sampson, R. J., Morenoff, J. D., and Gannon-Rowley, T. (2002). Assessing 'neighborhood effects': Social processes and new directions in research. Annual Review of Sociology, 28:443-478.

Sastry, N. (1996). Community characteristics, individual and household attributes, and child survival in Brazil. Demography, 33(2):211-229.

Sastry, N., Pebley, A., and Zonta, M. (2002). Neighborhood definitions and the spatial dimension of daily life in Los Angeles. Paper presented at the 2002 Annual Meetings of the Population Association of America, Atlanta, GA, 9-11 May.

Szwarcwald, C. L., de Andrade, C. L. T., and Bastos, F. I. (2002). Income inequality, residential poverty clustering and infant mortality: A study in Rio de Janeiro, Brazil. Social Science and Medicine, 55(12):2083-2092.

Tandon, A., Gakidou, E., Murray, C. J. L., and Ferguson, B. (2002). Cross-population comparability and PPPs: Using micro-data on indicators of consumer durables. Evidence and Information for Policy Cluster draft paper. World Health Organization, Geneva. 
Timæus, I.M. and Lush, L. (1995). Intra-urban differentials in child health. Health Transition Review, 5(2):163-190.

United Nations (2000). World Urbanization Prospects: The 1999 Revision: Data Tables and Highlights. United Nations, Department of Economic and Social Affairs, Population Division, New York.

Van den Eeden, P. and H"uttner, H. J. M. (1982). Multi-level research. Current Sociology, 30(3):1-182.

Wellman, B. and Leighton, B. (1979). Networks, neighborhoods, and communities: Approaches to the study of the community question. Urban Affairs Quarterly, 14(3):363390.

Wen, M., Browning, C. R., and Cagney, K. A. (2003). Poverty, affluence, and income inequality: Neighborhood economic structure and its implications for health. Social Science and Medicine, 57(5):843-860.

Westoff, C. F. and Bankole, A. (1995). Unmet Need 1990-1994. Demographic and Health Surveys Comparative Studies. Macro International, Inc., Calverton, MD.

Westoff, C. F. and Pebley, A. R. (1981). Alternative measures of unmet need for family planning in developing countries. International Family Planning Perspectives, 7(4):126136.

White, M. J. (2001). Residential concentration/segregation, demographic effects of. In Smelser, N. J. and Baltes, P. B., editors, International Encyclopedia of the Social andBehavioral Sciences, volume 19, pages 13250-13254. Elsevier Science, Oxford.

Wilkinson, R. G. (1996). Unhealthy Societies: The Afflictions of Inequality. Routledge, London.

Wilson, W. J. (1987). The Truly Disadvantaged: The Inner City, the Underclass and Public Policy. University of Chicago Press, Chicago, IL. 


\section{أوراق عمل صدرت عن قسم بحوث السياسات}

تتو افر نسخة واحدة مما يصل إلى ثلاث ورقات عمل من عام 1989 وحتى عام 2003 بالمجان، وذلك بشرط تو افر ها في صورة مطبو عة.

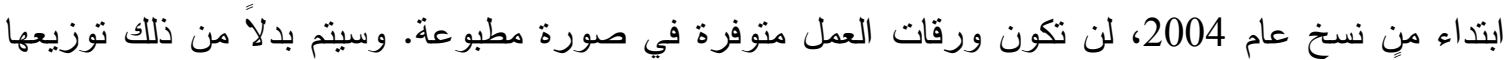

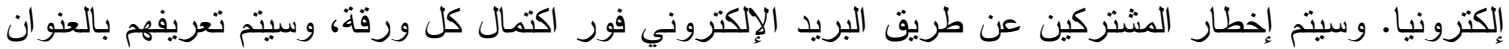

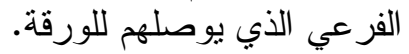

للاثتر الك في قائمة الإخطار الإلكترونية الخاصة بقسم بحوث السياسات، أو للحصول على نسخ قديمة للفترة من prdwp@popcouncil.org. عام 1989 وحتى عام 2003، يرجى إلرسال طلبك إلى لئى

تتو افر إصدارات لأعداد سابقة حديثة المتاحة للتحميل على هيئة ملفات PDF على العنوان الإلكتروني www.popcouncil.org/publications/wp/prd/rdwplist.html

\section{4}

184 Mark R. Montgomery and Paul C. Hewett. "Urban poverty and health in developing countries: Household and neighborhood effects."

\section{3}

183 Agnes R. Quisumbing and Kelly

Hallman. "Marriage in transition: Evidence on age, education, and assets from six developing countries."

182 Paul C. Hewett, Barbara S. Mensch, and Annabel S. Erulkar, "Consistency in the reporting of sexual behavior among adolescent girls in Kenya: A comparison of interviewing methods."

181 Zachary Zimmer, Linda G. Martin, and Hui-Sheng Lin, "Determinants of old-age mortality in Taiwan."

176 Cynthia B. Lloyd and Paul C.
180 Frank K. Nyonator, J. Koku woonorWilliams, James F. Phillips, Tanya C. Jones, and Robert A. Miller, "The Ghana Community-based Health Planning and Services Initiative: Fostering evidencebased organizational change and development in a resourceconstrained setting."

179 John Bongaarts and Griffith Feeney, "Estimating mean lifetime."

178 Elizabeth F. Jackson, Patricia Akweongo, Evelyn Sakeah, Abraham Hodgson, Rofina Asuru, and James F. Phillips, "Women's denial of having experienced female genital cutting in northern Ghana: Explanatory factors and consequences for analysis of survey data."

177 John Bongaarts, "Completing the fertility transition in the developing world: The role of educational differences and fertility preferences."

168 Paul C. Hewett, Annabel S. Erulkar, and Barbara S. Mensch, "The feasibility 


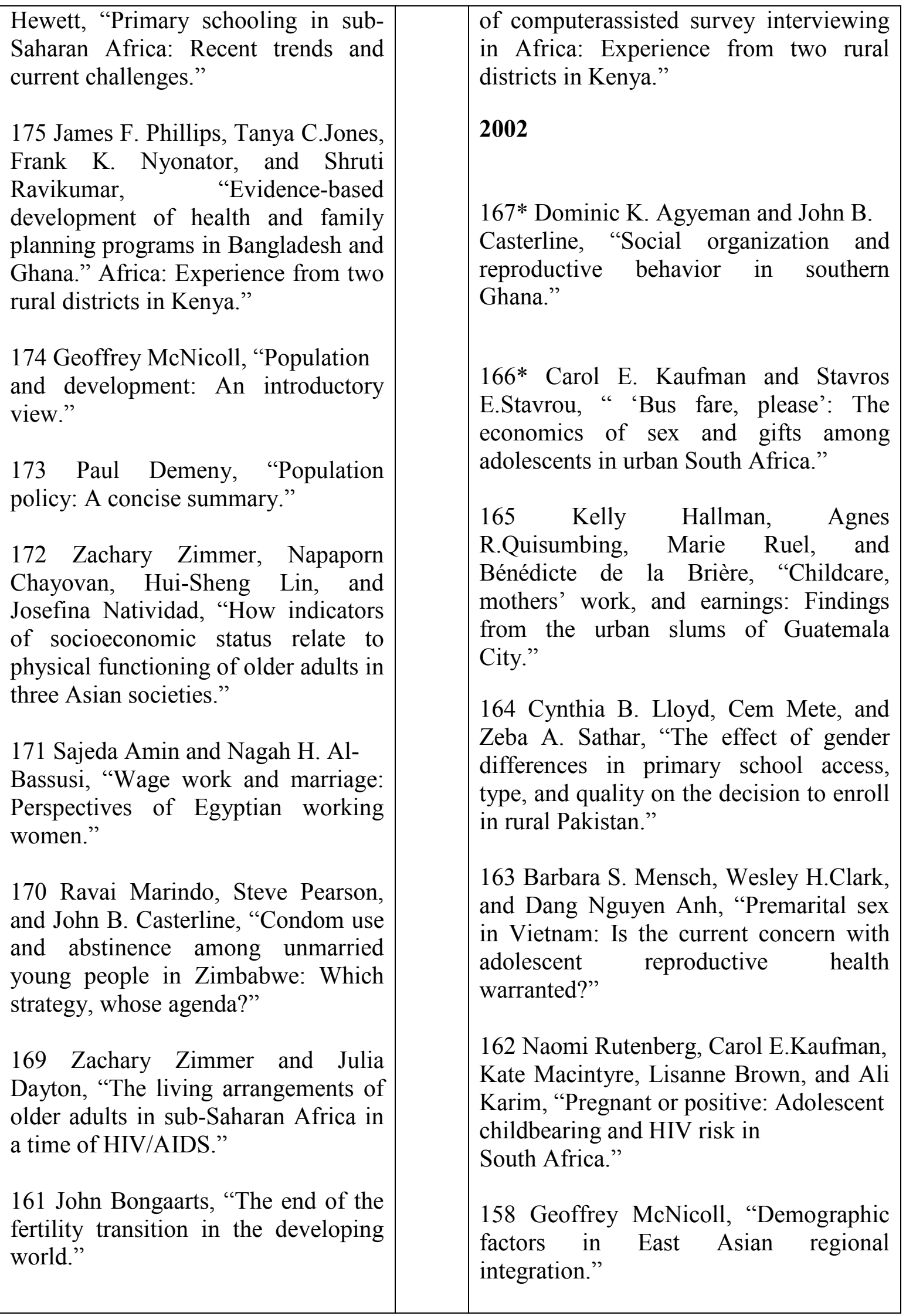




\begin{tabular}{|l|l|l|}
\hline $\begin{array}{l}160^{*} \text { Julia Dayton and Martha } \\
\text { Ainsworth, "The elderly and AIDS: } \\
\text { Coping strategies and health } \\
\text { consequences in rural Tanzania." } \\
\begin{array}{l}\text { 159 Carol E. Kaufman, Shelley Clark, } \\
\text { Ntsiki Manzini, and Julian May, } \\
\text { "How community structures of time } \\
\text { and opportunity shape adolescent } \\
\text { sexual behavior in South Africa." }\end{array}\end{array}$ & $\begin{array}{l}157 \text { Zachary Zimmer and Sovan Kiry } \\
\text { Kim, "Living arrangements and socio- } \\
\text { demographic conditions of older adults in } \\
\text { Cambodia." } \\
\text { 156 John Bongaarts and Griffith Feeney, } \\
\text { "How long do we live?" }\end{array}$ \\
& $\begin{array}{l}155 \text { Zachary Zimmer, Linda G. Martin, } \\
\text { and Ming-Cheng Chang, "Changes in } \\
\text { functional limitations and survival among } \\
\text { the elderly in Taiwan: 1993, 1996, and } \\
1999 . "\end{array}$ \\
\hline
\end{tabular}

